\title{
Insights Gained From Aging Research
}

Manuscript Completed: February 1992

Date Published: March 1992

\section{Prepared by}

D. E. Blahnik, D. A. Casada, J. L. Edson, D. L. Fineman, W. E. Gunther,

H. D. Haynes, K. R. Hoopingarner, M. J. Jacobus, D. B. Jarrell,

R. C. Kryter, H. L. Magelby, G. A. Murphy, M. Subudhi

\section{S. K. Aggarwal, NRC Program Manager}

Brookhaven National Laboratory

Upton, NY 11973

Prepared for

Division of Engineering

Office of Nuclear Regulatory Research

U.S. Nuclear Regulatory Commission

Washington, DC 20555

NRC FIN A3270 


\section{AVAILABILITY NOTICE}

Availability of Reference Materials Cited in NRC Publications

Most documents olted in NRC publications will be avallable from one of the following sources:

1. The NRC Public Document Room, $2120 \mathrm{~L}$ Street, NW., Lower Level, Washington, DC 20555

2. The Superintendent of Documents, U.S. Government Printing Office, P.O. Box 37082, Washington. DC 20013-7082

3. The National Technical Information Service, Springfield, VA 22161

Although the listing that follows represents the majority of documents cited in NRC publications, it is not intended to be exhaustive.

Referenced documents available for inspection and copying for a fee from the NRC Public Document Room include NRC correspondence and internal NRC memoranda; NRC bulletins, circulars, information notices. inspection and investigation notices; licensee event reports; vendor reports and correspondence; Commission papers; and applicant and licensee documents and correspondence.

The following documents in the NUREG series are available for purchase from the GPO Sales Program: formal NRC staff and contractor reports, NRC-sponsored conference proceedings, international agreement reports, grant publications, and NRC booklets and brochures. Also avallable are regulatory guides, NRC regulations in the Code of Federal Regulations, and Nuclear Regulatory Commission Issuances.

Documents avallable from the National Technical Information Service include NUREG-serles reports and technical reports prepared by other Federal agencies and reports prepared by the Atomic Energy Commission, forerunner agency to the Nuclear Regulatory Commission.

Documents avallable from public and special technical libraries include all open literature items, such as books, Journal articles, and transactions. Federal Register notices. Federal and State legislation, and congressional reports can usually be obtained from these libraries.

Documents such as theses, dissertations, foreign reports and translations, and non-NRC conference proceedings are available for purchase from the organization sponsoring the publication cited.

Single coples of NRC draft reports are avaliable free, to the extent of supply, upon written request to the Office of Administration, Distribution and Mail Services Section, U.S. Nuclear Regulatory Commission, Washington, DC 20555.

Copies of industry codes and standards used in a substantive manner in the NRC regulatory process are maintained at the NRC Library, 7920 Norfolk Avenue, Bethesda, Maryland, for use by the publlc. Codes and standards are usually copyrighted and may be purchased from the originating organization or, if they are American National Standards, from the American National Standards Institute, 1430 Broadway, New York. NY 10018.

\section{DISCLAIMER NOTICE}

This report was prepared as an account of work sponsored by an agency of the United States Government. Neither the United States Government nor any agency thereof, or any of their employees, makes any warranty, expressed or implied, or assumes any legal liability of responsibility for any third party's use, or the results of such use, of any information, apparatus, product or process disciosed in this report, or represents that its use by such third party would not infringe privately owned rights. 


\section{DISCLAIMER}

This report was prepared as an account of work sponsored by an agency of the United States Government. Neither the United States Government nor any agency Thereof, nor any of their employees, makes any warranty, express or implied, or assumes any legal liability or responsibility for the accuracy, completeness, or usefulness of any information, apparatus, product, or process disclosed, or represents that its use would not infringe privately owned rights. Reference herein to any specific commercial product, process, or service by trade name, trademark, manufacturer, or otherwise does not necessarily constitute or imply its endorsement, recommendation, or favoring by the United States Government or any agency thereof. The views and opinions of authors expressed herein do not necessarily state or reflect those of the United States Government or any agency thereof. 


\section{DISCLAIMER}

Portions of this document may be illegible in electronic image products. Images are produced from the best available original document. 


\section{Abstruct}

The U.S. NRC Office of Nuclear Regulatory Research has implemented hardware-oriented engineering research programs to identify and resolve technical issues related to the aging of systems, structures, and components (SSCs) in operating nuclear power plants.

This report provides a summary of those research results which have been compiled and published in NUREGS and related technical reports. The systems, components and structures that have been studied are organized by alphabetical order. The research results summary on the SSCs is followed by an assessment guide to emphasize inspection techniques which may be useful for detecting aging degradation in nuclear power plants.

This report will be updated periodically to reflect new research results on these or other SSCs. 


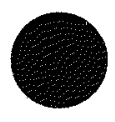

-

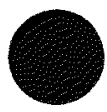




\section{Contents}

\section{COMPONENTS}

1. Auxiliary Feedwater (AFW) Pumps

2. Batteries

3. Battery Chargers

4. Cables

5. Check Valves

6. Emergency Diesel Generators

7. Inverters

8. Motors

9. Motor Control Centers (MCCs)

10. Motor Operated Valves (MOVs)

11. PORVs and Block Valves

12. Snubbers

13. Solenoid Operated Valves (SOVs)

\section{SYSTEMS}

1. Auxiliary Feedwater (AFW) System

2. Component Cooling Water (CCW) System

3. CRD System-Westinghouse

4. IE Power System

5. HPCl and HPCS Systems (BWR)

6. High Pressure Injection System (PWR)

7. Instrument Air System

8. Reactor Protection System (RPS)

9. Residual Heat Removal (RHR) System-BWRs

10. Service Water System 

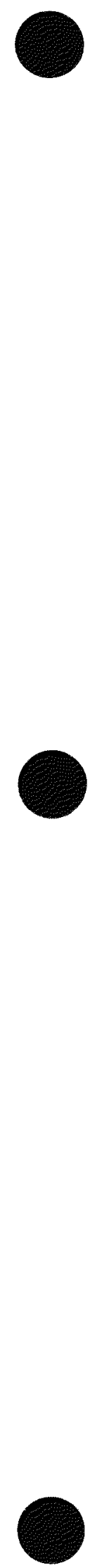


\section{Foreword}

At the end of 1989, the United States had 108 reactors in commercial operation. By the year 2014, forty-eight of these plants will have been operating for forty years. As the population of commercial nuclear power plants has matured, the need to disseminate the results obtained through the U.S. Nuclear Regulatory Commission's (NRC) research programs has increased. This report presents some of the findings from research which could be useful in understanding and managing the effects of aging.

The U.S. NRC's Aging Research programs have produced a large database of operating, maintenance, and testing information for components, systems, and structures. The goals of these integrated research programs are to identify and characterize those plant aging effects that could impair safety; to identify methods of inspection, surveillance, and monitoring of plants that will detect aging effects before the loss of system safety function; and to evaluate the effectiveness of maintenance and component replacement practices for mitigating aging degradation.

Aging, if it is not properly managed, affects the operational safety of reactor components, systems, and structures, and as a result can adversely affect public health and safety. Therefore, understanding the aging processes that occur in a component or system is essential so that they can be effectively managed. One of the NRC's Programs, the Nuclear Plant Aging Research (NPAR) Program has identified those components and systems which have a propensity for age related degradation, and has identified methods for managing aging effects. A similar program on aging that focuses on vessels, piping, steam generators, and nondestructive examination techniques is also being conducted.

This document was developed to consolidate the research results from the assessments of component and system aging sponsored by the NRC for use by industry and by NRC in understanding and managing the aging of systems, structures, and components in nuclear power plants. The input for this document was provided by the NRC contractor who performed the research, as follows: 
Brookhaven National Laboratory

Components: Battery Chargers, Inverters, Motors and Motor Control

Centers

Systems: Component Cooling Water, Control Rod Drive-Westinghouse,

Instrument Air and Residual Heat Removal

Idaho National Engineering Laboratory

Components: Batteries

Systems: 1E Distribution, Reactor Protection, High Pressure Coolant

Injection and Core Spray (BWR) and High Pressure Safety Injection (PWR)

Oak Ridge National Laboratory

Components: Auxiliary Feedwater Pumps, Check Valves, Motor Operated

Valves, Power Operated Relief Valves and Block Valves and Solenoid

Operated Valves

Systems: Auxiliary Feedwater

Paciffe Northwest Laboratory

Components: Emergency Diesel Generators and Snubbers

Systems: Service Water

Sandia National Laboratory

Components: Cables

The "Summary of Research Results" has the following format:

Functional Description/Background - A brief overview of the study addresses the question of whether or not aging is a significant safety concern for the particular component or system.

Source - The research reports upon which the information is based are listed.

Aging Related Issues - This section briefly describes the

subcomponents most susceptible to aging, the stresses which

affect the service life, and the dominant causes of failure of the component or system.

Operating Experience - The failure history of the component or system is discussed. This operating experience is typically based on the LER and NPRDS databases, but could include plant specific data. Significant causes and effects of failure are highlighted.

Research Recommendations - The largest portion of the Summary is devoted to the recommendations presented in the research reports for detecting and mitigating aging effects. Periodic testing, maintenance, continuous monitoring, and routine inspections are some of the techniques described for the specific components and systems.

References - NRC documents and industry standards related to the subject are provided. The NRC documents include AEOD reports, information notices, and regulatory guides, while industry documents could include standards and guides from ASME, IEEE, ISA, NEMA, EPRI, and INPO.

The "Aging Assessment Guide" is a more concise document which provides some general observations of the effects of aging on the component or system. The Guide lists recommendations, associated with the maintenance, operations, design, and testing which the research has shown could be beneficial to understanding and managing the aging of that component or system.

The statements and recommendations made in this document are based on assessments of operating experience, evaluations of materials, testing of naturally aged equipment, and identification of operating and environmental stresses. The perspectives expressed do not reflect regulatory positions or requirements.

This document will be updated periodically to incorporate the results which continue to be obtained through NRC sponsored research into the aging of nuclear power plant components, systems, and structures. 


\section{Acknowledgments}

The following valuable contributions to the preparation of this document are appreciated:

The technical direction from the NRC Program Manager, Mr. Satish K. Aggarwal. The constructive comments provided by NRC reviewers from RES and NRR, particularly Mr. Jit Vora.

The authors and project managers from the NPAR Labs IORNL, INEL, SNL, PNL, and BNL) for their timely editorial and technical comments. Special appreciation is extended to $P$. Yalden of the Photography and Graphic Arts Division, for organizing, designing, and processing the manuscript. 


\section{1.

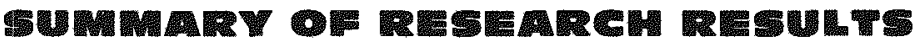

FUNCTIONAL DESCRIPTION/BACKCROUND The AFW pumps in a PWR deliver flow from a safety-related source to the steam generators to support the removal of stored and decay heat from the reactor coolant system by the transfer of heat through the steam generators. The AFW pumps are used in support of startup and shutdown sequences as well as in response to emergency conditions. The AFW pumps in use are multistage pumps driven by motors, turbines, or diesels.

\section{BASED ON MPAR REPORTS:}

1. NUREG/CR-4597, Volume 1, Aging and Service Wear of Auxiliary Feedwater Pumps for PWR Nuclear Power Plants, 7/86.
2. NUREG/CR-4597, Volume 2, Aging and Service Wear of Auxiliary Feedwater Pumps for PWR Nuclear Power Plants, 6/88.

3. NUREG/CR-5404, Auxiliary Feedwater System Aging Study, 3/90.
ACING RELATED ISSUES AFW pumps may be operated at flow rates ranging from as low as $2 \%$ of best efficiency point (BEP) flow during testing to near runout conditions (for example, following certain design basis accident sequences). Wear of pump parts can result from a spectrum of sources, including:

\section{Mechanical Forces}

- Torque transmitted loads (static \& dynamic)

- Assembly (fastener) loads

- Rotor-dynamic loads

- Piping forces

- Seismic loads

- Vibration

\section{Hydratulic Forces}

- Hydraulic loads

- Fluid impingement

- Internal pressure

- Cavitation

\section{Frictional Forces}

- Rubbing between rotating and nonrotating members

- Bearing lubricant breakdown

- Surface fatigue

- Lubricant contamination

- Starts and stops

- Fretting

- Surface oxide abrasive formation

Pump performance is directly tied to the pump driver. Pump drivers are affected by most of the wear sources for the pumps, with the notable exception of most of the hydraulic forces. Pump drivers have, in addition, independent sources of degradation and failure. Examples are corrosion of turbine steam supply valve stems, overheating of motors, and fuel oil line fatigue for diesels. Refer to research results summaries for motors, turbines, and diesels for specific information. 
OPERATING EXPERIENCE AFW pump components and the most significant operational problems are:

- Bearing wear, corrosion, and breakage

- Shaft seal deterioration and breakage

- Binding between the rotating and stationary parts

- Impeller wear and breakage

- Thrust balancer wear, galling, and seizing

- Shaft breakage

Operational failures experienced by pumps which are reflections of system problems, as opposed to pump specific degradation, include vapor binding of pumps due to backleakage of hot main feedwater (or steam) and loss of adequate suction pressure.

Most of the AFW pump operation occurs during testing and plant startup and shutdown sequences. Much of the operating time for AFW pumps occurs under low-flow conditions.
Low-flow operation has been recognized as a significant source of degradation for centrifugal pumps due to the hydraulically unstable conditions associated with low flow. Hydraulically unstable flow conditions can result in radial and axial dynamic loads which can damage bearings, seals, thrust balancing drums or disks, cracking of impeller or diffuser vanes, and shaft failure.

One-half of the historical overall AFW system degradation has come from the combination of AFW pump drivers and pumps. Degradation due to pump driver failures has been the dominant contributor. Instrumentation and control related problems have been responsible for over half of the degradation of each of the types of pump driver (motor, turbine, and diesel). Turbine drive failures have been the most dominant of the three drive types. Diesel drives have also experienced high failure rates; however there are few diesel drives in service.
RESEARCH RECOMMENDATIOMS Surveillance testing and other operation of AFW pumps in minimum flow operation can cause accelerated wear of the pump parts due to hydraulically unstable flow conditions. Furthermore, the results of testing at lowflow conditions provides little useful information about either the hydraulic performance capability of the pump or the capability of the pump driver.

Testing of the AFW pumps is required by the ASME Code (quarterly) and technical specifications (quarterly or monthly). Most plants test at minimum flow conditions. Pump flow, head and vibration are required to be measured (although some plants do not have permanently installed flow instrumentation, and have received relief to Code requirements). For those plants testing under minimum flow conditions, the most important information available from these tests is the vibration data. While the code only requires overall vibration information, the frequency spectrum of vibration should be measured and trended. Periodic testing of the AFW pumps at or near the BEP flow rate should also be conducted. Measurements of pump flow, head, vibration, and for motors, motor power should be made and trended. Pump and driver lube oil, and turbine governor control oil (if separate from the turbine lube oil) analysis should be conducted regularly (for example, quarterly or semiannually). The analysis should consider chemical and physical properties such as:
- Moisture
- Viscosity
- $\mathrm{pH}$
- Color
- Particulates
- Wear metal content.

Periodically (e.g., on a 5 to 10 year frequency), pump disassembly and inspection should be considered. This inspection should include:

- A visual inspection of all rotating and stationary parts

- Penetrant inspection of the shaft, impeller, thrust runner, and diffusers or volutes for surface indications

- Wear surface clearance measurements 
Turbine and diesel speed control systems should be periodically calibrated (e.g., each refueling).

The pumps should be started under system conditions similar to those that would exist

\section{REFERENCES}

1. NRC Bulletin 88-04, Potential SafetyRelated Pump Loss.

2. NRC Bulletin 85-01, Steam Binding of Awxiliary Feedwater Pumps. during emergency demand conditions periodically (e.g., once per fuel cycle) to provide proper pump/system interaction.
3. Information Notice 87-53, Auxiliary Feedwater Pump Trips Resulting from Low Suction Pressure.

4. Information Notice 90-76, Failure of Turbine Overspeed Trip Mechanism Because of Inadequate Spring Tension. 

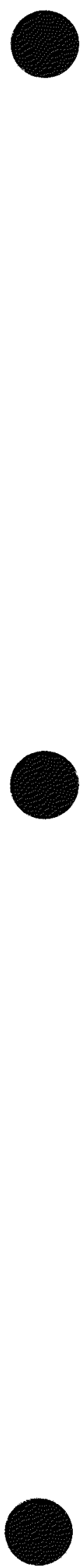


\section{AGING ASSESSMENT GUIDE AUXILIARY FEEDWATER (AFW) PUMPS}

\section{Observations on the aging of Auxiliary Feedwater (AFW) Pumps}

- Pumps and Pump Drivers have been the major sources of $A F W$ system degradation

- Current testing practices have not been totally effective in detecting AFW pump degradation and failures

- Low flow operation is a source of degradation

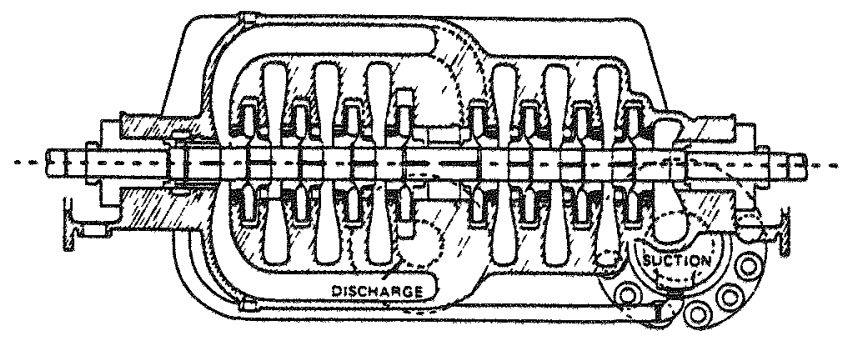

TYPICAL AFW PUMP

\section{RECOMMENDATIONS FOR INSPECTION}

1. In the standby mode, the pump casings and the pump discharge piping should be periodically or continuously monitored for backleakage.

2. The pump packing or mechanical seal should be monitored for excessive external leakage.
3. During system testing and operation, pump and system vibration and noise should be observed. Pump motor current and turbine/diesel speed should be monitored.

\section{MAINTENANCE RECOMMENDATIONS}

\section{AFW Pumps}

1. Measure and trend pump hydraulic performance at or near best efficiency point (BEP) flow rates (not just at minimum flow) at least once per fuel cycle

2. Monitor and trend pump bearing vibration in the frequency domain (track vibration level vs. vibration frequency). This should be done for both normal inservice testing and for the above recommended full flow tests

3. As a supplement to vibration monitoring, periodically perform acoustic highfrequency or stress-wave emission monitoring

4. Perform lube oil analyses

\section{AFW Pumap Drivers}

1. Measure and trend pump motor power during full flow (pump at or near its BEP) testing

2. Perform motor lube oil analyses

3. Periodically (once per fuel cycle) calibrate the turbine/diesel governor speed control system

4. Perform periodic verification of turbine over-speed trip operability (monthly to quarterly)

5. Perform diesel turbine lube oil/governor control oil analyses

6. Monitor and trend turbine/motor/diesel bearing vibration in the frequency domain

7. Observe turbine/diesel governor's ability to maintain the turbine at control speed without hunting (each time the unit is run) 

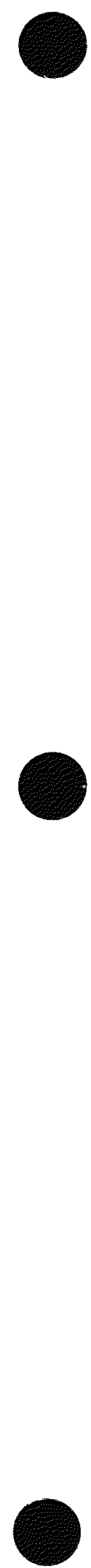

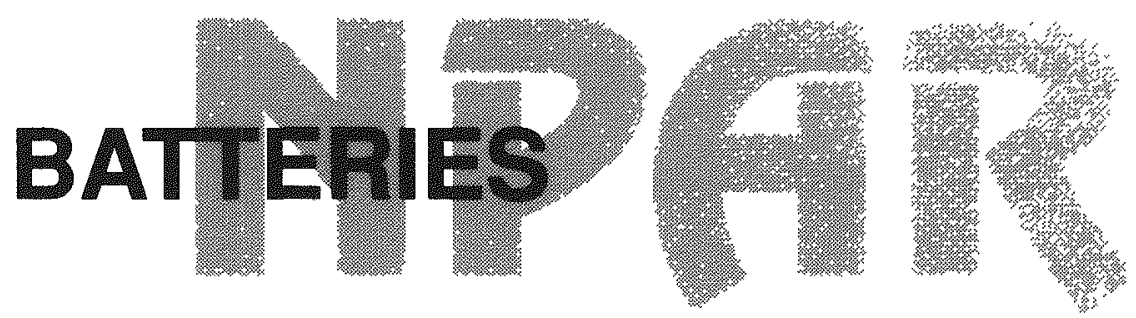

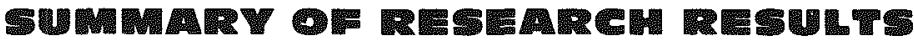

FUNCTONAL DESCRIPTION/BACKGROUND Battery degradation due to aging decreases electrical capacity, decreases reliability, and increases the potential for failure. Because batteries are installed at nuclear facilities to provide power to critical functions in the event of loss of all ac power, failures have a sig- nificant impact on plant safety. The evaluation of battery aging mechanisms and laboratory testing of aged batteries has identified critical elements of a battery maintenance program that include comprehensive inspections and periodic testing.

\section{BASED ON MPAR REPORTS:}

1. NUREG/CR-4457, Aging of Class $1 E$ Batteries in Safety Systems of Nuclear Power Plants, 7/87.
2. NUREG/CR-5448, Aging Evaluation of Class 1E Batteries: Seismic Testing, 8/90.
AGING RELATED ISSUES Evaluation of operating experience combined with testing of naturally aged batteries shows that cracking of the containers and oxidation of the lead are major factors contributing to battery failures. Improper handling, excessive temperature, overcharging, and contaminants in the electrolyte or on the batteries are the primary causes of failures.

1. CONTAINERS: Containers are degraded primarily by improper handling during installation or by the application of cleaning solvents that chemically attack the container material. Breaking or cracking of the containers result in leakage and loss of the electrolyte.

2. PLATES AND INTERNAL BUSSES: Plates and internal busses (straps and terminals) are fabricated from a lead-calcium alloy that may oxidize, corrode, and become brittle when subjected to excessive temperature and charging, or when contaminants are introduced into the battery. Positive plates naturally grow with age and if allowed to continue can press against the container and result in cracking of the container or separation of the container and cover.

3. ELECTROLYTE: Electrolyte can become contaminated as a result of adding impure water or inadvertently allowing contaminants to enter the battery during maintenance and testing activities.

4. TEMPERATURE: Temperature effects are typically caused by inadequate battery room cooling resulting in excessive temperatures from the climate or from heat produced within the facility. Overcharging also results in increased internal heating of the battery.

5. CONTAMINATION: Contamination of the electrolyte causes impurities that chemically reacts with the active material on the plates and results in decreased electrical capacity and self discharging of the battery. Dirt, moisture, and spilled electrolyte on the outside of the battery causes leakage paths between terminals and to ground that may result in short circuits and failure of the battery. 
6. OVERCHARGING: Overcharging can originate from improper attention to charging times or from improper adjust- ment of float voltages. Float voltages must be adjusted when individual cells are removed from the battery bank.
OPERATING EXPERIENCE Battery failures reported in LERs beginning January 1976 and ending August 1986 were reviewed. The accompanying table shows that low specific gravity, maintenance/testing/procedures, insufficient charge, improper electrolyte level, and defective/weak cell are the most commonly reported problems. Defective cells were commonly the result of cracked containers. The human element is a strong contributor to the remainder of the commonly reported problems.

\begin{tabular}{lcc}
\multicolumn{3}{c}{ BATTERY FAILURE EVENTS REPORTED IN LERS } \\
FAILURE CAUSE & NUMBER & PERCENTAGE \\
\hline Low specific gravity & 67 & 27 \\
Maintenance/testing/procedures & 63 & 25 \\
Insufficient charge & 27 & 11 \\
Improper electrolyte lavel & 22 & 9 \\
Defective/weak cells & 22 & 9 \\
Faulty connections & 13 & 5 \\
Charger malfunetiton & 9 & 4 \\
Design/construction & 8 & 3 \\
Unknown & 5 & 2 \\
Corrosion & 4 & 2 \\
Shart circuit & 4 & 2 \\
Normal wear/end of life & 3 & 1 \\
Extreme Environmeni & 1 & $\leq 1$ \\
& 248 & 100 \\
\hline
\end{tabular}

RESEARCH RECOMMENDATIONS A preventive maintenance program should exist for batteries. The PM program should include periodic testing, continuous monitoring, and inspection techniques.

Periodic Testing Periodic tests are in situ tests performed in plant on the equipment at scheduled intervals to detect degradation and verify operability. The following tests are recommended by IEEE Std. 450 and Regulatory Guide 1.129 to verify battery operability:

1. Service tests to verify the ability of the batteries to satisfy the design requirements of the dc system should be performed with intervals not to exceed 18 months, or if the dc system design is changed so that previous tests are no longer a valid test to verify the capability. The service test discharges the battery at a rate and for a period of time for which the system is designed.

2. Performance tests to verify that the battery meets its specification or manufacturer's rating should be performed within the first 2 years of service and at 5 year intervals thereafter until the battery shows signs of degradation, or has reached $85 \%$ of the service life expected for the application. Degradation is indicated when the battery capacity drops more than $10 \%$ of rated capacity from its capacity on the previous performance test, or is below $90 \%$ of the manufacturer's rating. Thereafter the battery should be tested annually. Recommended practice is to replace the battery if its capacity is determined to be below $80 \%$ of the manufacturer's rating.

Continuous Monitoring Readings should be taken on a regular basis to detect conditions that are detrimental to battery life or to provide indications of reduced battery capacity. The following should be monitored at least once per month:

Float voltage

Charger output current and voltage

Electrolyte levels

Ambient temperature

Pilot cell voltage, specific gravity, and electrolyte temperature

The following should be monitored at least quarterly:

Specific gravity of each cell

- Voltage of each cell and total battery terminal voltage

Electrolyte temperature in representative cells 


\begin{tabular}{|c|c|}
\hline MPRR & RIES \\
\hline $\begin{array}{l}\text { The following should be monitored at least } \\
\text { yearly: } \\
\text { Cell-to-cell and terminal connection } \\
\text { resistance } \\
\text { Inspection Visual inspections of the bat- } \\
\text { tery should be performed to detect evidences } \\
\text { of degradation. Inspections for the following } \\
\text { should be performed at least monthly: } \\
\text { General appearance and cleanliness of } \\
\text { battery, battery rack, and area }\end{array}$ & $\begin{array}{l}\text { Cracks in cells or leakage of electrolyte } \\
\text { Evidence of corrosion at terminals, } \\
\text { connectors, or racks } \\
\text { Condition of ventilation equipment } \\
\text { Inspections for the following should be } \\
\text { performed at least yearly: } \\
\text { Individual cell condition } \\
\text { Tightness of bolted connections } \\
\text { Integrity of the battery rack }\end{array}$ \\
\hline $\begin{array}{l}\text { REFEREMCES There is a large amount of } \\
\text { reference material available for batteries. } \\
\text { However the following reflect those which } \\
\text { may be readily accessible to the inspector. } \\
\text { 1. IEEE Std. } 450 \text {, IEEE Recommended } \\
\text { Practice for Maintenance, Testing, and } \\
\text { Replacement of Large Lead Storage } \\
\text { Batteries for Generating Stations and } \\
\text { Substations. } \\
\text { 2. Regulatory Guide 1.129, Maintenance, } \\
\text { Testing, and Replacement of Large Lead }\end{array}$ & $\begin{array}{l}\text { Storage Batteries For Nuclear Power } \\
\text { Plants. } \\
\text { 3. Information Notice } 83-11 \text {, Possible Seis- } \\
\text { mic Vulnerability of Old Lead Storage } \\
\text { Batteries. } \\
\text { 4. Information Notice } 84-83 \text {, Various Bat- } \\
\text { tery Problems. } \\
\text { 5. Information Notice } 85-74, \text { Station Bat- } \\
\text { tery Problems. } \\
\text { 6. Information Notice 86-37, Degradation } \\
\text { of Station Batteries. }\end{array}$ \\
\hline
\end{tabular}



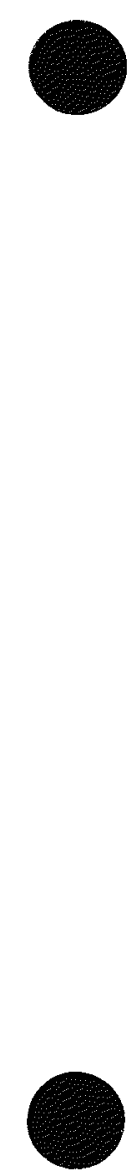

- 


\section{AGING ASSESSMENT GUIDE BATTERIES}

\section{Observations on the aging of batteries}

- Cracking of containers is an aging concern.

- Degradation of plates and internal busses is accelerated by excessive temperature and charging, or when contaminants are introduced into the battery.

- Environmental factors such as temperature, humidity, dirt, and chemicals affect battery performance.

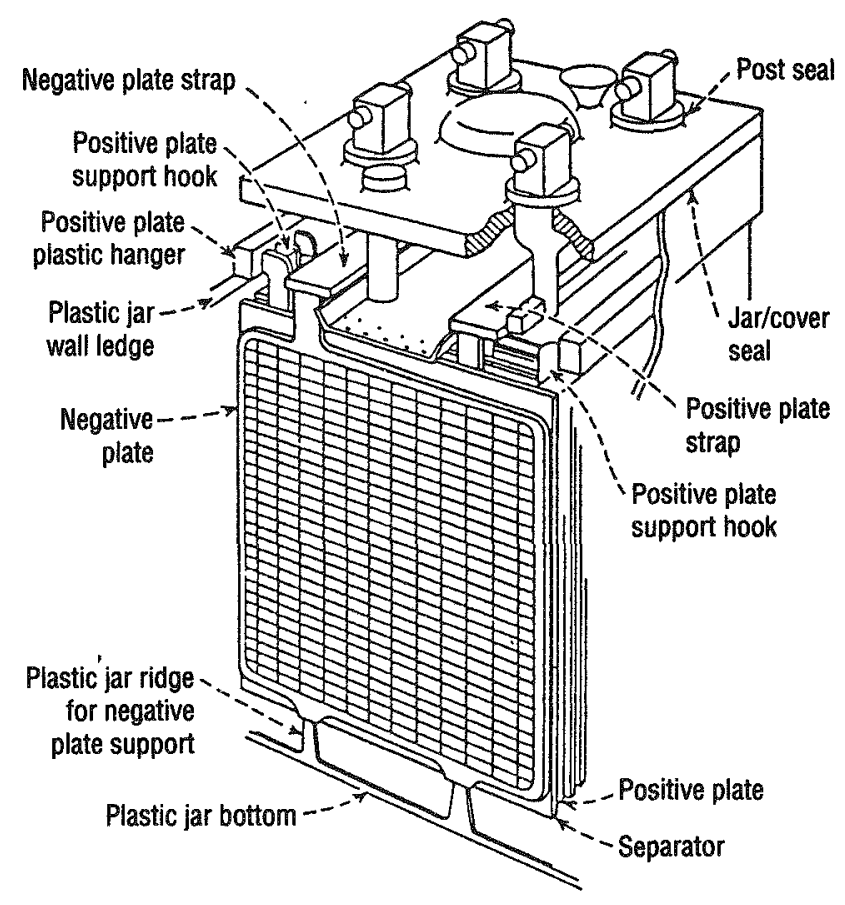

Typical Lead-Acid Battery

\section{RECOMMENDATIONS FOR INSPECTION} Operating Parameters Routinely Observed

1. Float voltage

2. Charger output current and voltage

3. Electrolyte levels

4. Ambient temperature

5. Pilot cell voltage, specific gravity, and electrolyte temperature

6. Specific gravity of each cell

7. Voltage of each cell and total battery terminal voltage

8. Electrolyte temperature in representative cells

9. Cell-to-cell and terminal connection resistance

\section{External Indicators or Causes of Age}

\section{Degradation}

1. General appearance and cleanliness of battery, battery rack, and area

2. Cracks of cells or leakage of electrolyte

3 . Evidence of corrosion at terminals, connectors, or racks

4. Condition of ventilation equipment

5. Individual cell condition

6. Tightness of bolted connections

7. Integrity of the battery rack

\section{MAINTENANCE RECOMMENDATIONS}

1. When any cell electrolyte reaches the lowlevel line, add water to bring all cells to the high-level line.
2. Retorque and retest connectors when loose connections or high resistance readings are obtained. 
3. Clean terminals if corrosion is noted.

4. Determine cause and correct the condition when cell temperatures deviate more than $3^{\circ} \mathrm{C}$ from each other.

5. Clean cells or connectors when dirt is noted.

6. Adjust float voltage when it is outside of the recommended operating range.
7. Perform equalizing charge when specific gravity of a cell is more than 0.010 below the average of all cells, when the average specific gravity is more the 0.010 from the average at installation, or if any cell voltage is below 2.13 volts at the time of inspection.

\section{OPERATIONS RECOMMENDATIONS}

1. The voltage temperature, and specific gravity are measured and recorded periodically.

2. Operating rounds include observations of the battery room ventilation.
3. Alarm response procedures address the operator's action to abnormal battery conditions.

\section{DESIGN/TEST RECOMMENDATIONS}

1. Periodic capacity tests are performed to verify that the battery meets design requirements and manufacturer's rating.

2. Operating parameters are monitored, recorded, and evaluated when performing required surveillance testing.
3. Batteries are replaced at the end of the recommended service life and when capacity is below $80 \%$ of manufacturer's rating. 


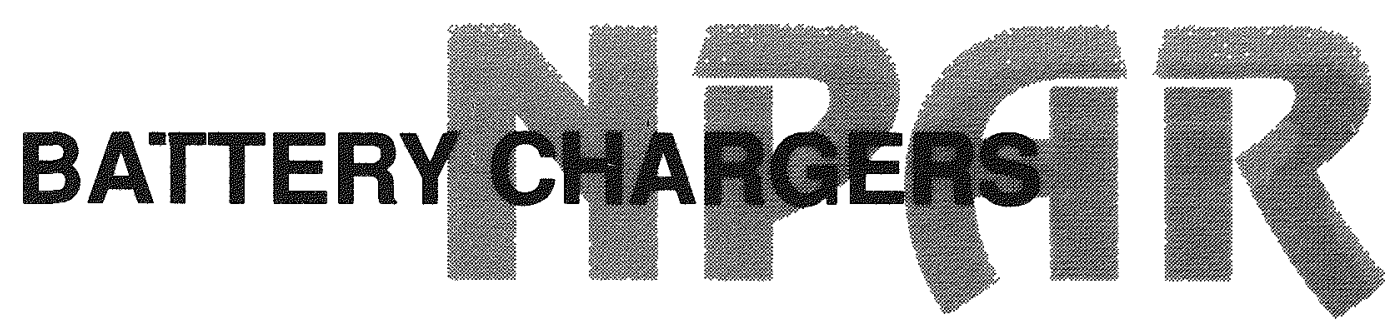

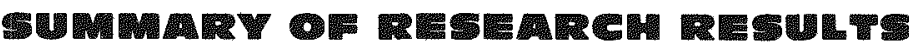

FUNCTIONAL DESCRIPTION/BACKGROUND Battery chargers convert ac to dc to provide power to dc driven equipment and components, as well as to maintain the standby battery fully charged. The battery charger components most susceptible to aging are capacitors, transformers, inductors, diodes and thyristors. High voltage, current, humidity, or temperature will decrease the life of these components. A failed or degraded battery charger which is not detected and corrected in a timely manner could result in depletion of its associated battery and a partial loss of station de power.

\section{BASED ON MPAR REPORTS:}

1. NUREG/CR-4564, Operating Experience and Aging-Seismic Assessment of Battery Chargers and Inverters, 6/86.

2. NUREG/CR-5051, Detecting and Mit- igating Battery Charger and Inverter Aging, 8/88.

3. NUREG/CR-5192, Testing of a Naturally Aged Battery Charger and Inverter, 9/88.
AGING RELATED ISSUES The small number of battery charger failures reported in the LER data base which were attributed to component degradation indicates that, to date, the aging impact is minimal. This may be due to adequate attention being applied at the plant level. However, the charger contains many components identical to those found in inverters, where aging is important. The potential therefore exists for future age-related failures of battery chargers, including the following failure modes:

1. DEGRADED VOLTAGE: Failures of components within the voltage regulation circuitry can result in voltage fluctuations which affect operation of equipment supplied by dc power. Degradation of potentiometers that establish the equalize and float voltages can also have this effect.

2. EXCESSIVE RIPPLE: Failures in the filter network (capacitors and inductors) can create abnormally high ripple voltages on the charger output. This can result in the failure of sensitive electronic instrumentation and can create overheating of the supplied battery.

3. LOSS OF VOLTAGE OUTPUT: Battery charger fuse or circuit breaker operation in reaction to normal plant electrical transients and switching have rendered the charger inoperable. The thermal fatigue of fuses with time could increase their propensity to fail in this manner. 
OPERATING EXPERIENCE Chargers are susceptible to failures from overheating and loose connections. Because of their complexity, failures due to personnel error are high. For approximately $40 \%$ of the total failures, the cause was not delineated.
IDENTIFIED FAILURE CAUSES

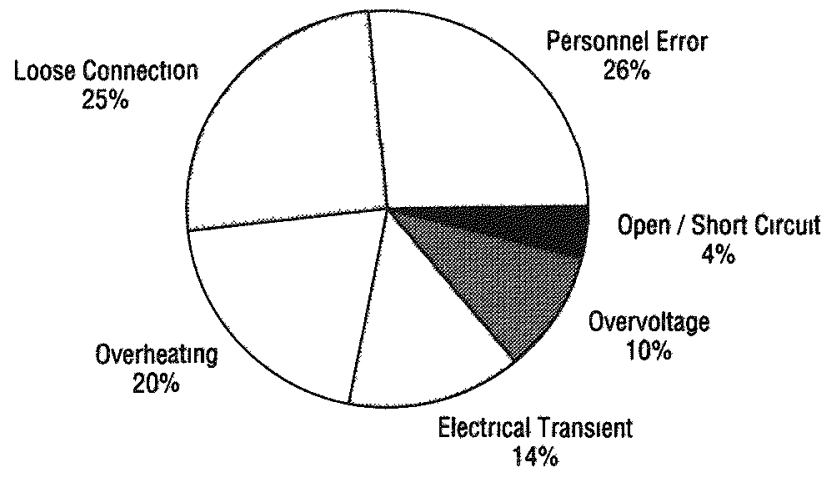

Percent of Faílures - LERs 1976 to 1986

\section{RESEARCH RECOMMENDATIONS}

Design The solid-state type charger is most widely used, ( $75 \%$ of chargers) and is the only type qualified to industry standards. The magnetic amplifier and controlled ferroresonant types comprise the remaining population. The following design related solutions primarily address the solid state charger.

1. Battery charger degradation or fallure should be annunciated before a decrease in the dc bus voltage occurs. Annunciation of high and low charger output voltage and current are appropriate.

2. Because of its susceptibility to stresses from plant electrical transients, surge suppression schemes should be employed on the power supply to the charger. Auto or isolation transformers i.e., SOLA, have been effective.

3. The availability of a standby battery charger increases the reliability for maintaining the batteries in a fully charged condition.

Maintenance \& Monitoring The battery charger is comprised of several types of subcomponents which require periodic maintenance and monitoring. These components include filter capacitors, thyristors (SCRs), transformers, circuit breakers, and relays. In addition, output metering should be calibrated to permit accurate, routine monitoring.

1. FILTER CAPACITORS: Capacitors have a limited service life ( 5 to 10 years) based on the operating temperature and applied voltage. Degradation can be detected through measurement of capacitance or equivalent series resistance, or by deterioration of circuit waveforms. Periodic replacement may also be performed.

2. THYRISTORS (SCRs): Large thyristors used in the rectification process are sensitive to temperature. Heat sinks are installed to transfer heat away from these devices. The heat sink surfaces should be periodically cleaned to maintain their design rating. In addition, the connection between the SCR and heat sink should be torque checked.

3. MAGNETICS (TRANSFORMERS AND INDUCTORS): The life of transformers and inductors (chokes) is directly related to their insulation condition. Therefore, the periodic monitoring of insulation resistance (meggar) and winding temperature, is recommended.

4. CIRCUIT BREAKERS AND RELAYS: Periodic manual operation and calibration of the circuit breakers and protective relays (high temperature, abnormal voltage) are necessary to ensure proper operation of these important devices.

5. PANEL METERS: Instrumentation on a battery charger front panel often includes output voltage and load current. These readings are used by operators on a regular basis to determine equipment operability. Regular calibration is necessary for reasonable accuracy. 
Periodic Testing Technical specifications require that capacity testing be performed on the station battery and its associated battery charger. For the charger, the test interval is typically every refueling. The capacity test simulates the the maximum possible loads, which generally occur when the charger must supply the station dc loads while recharging the depleted battery. During capacity testing, the following additional activities are recommended to determine the charger's condition:

1. The cabinet temperature should be monitored, as well as selected temperature sensitive components.
2. Monitoring the circuit waveforms is recommended to verify proper equipment operation. Changes in waveshape could alert personnel to potential problems, as well as provide troubleshooting guidance. Obtaining waveshape and temperature data at a consistent load is important for trending.

3. Measurement of the ripple voltage on the dc output during periodic testing is important. This value should not exceed $2 \%$ of the rated voltage. Damage to the station battery could result.

\section{REFERENCES}

1. IEEE 650-1991, IEEE Standard for Qualification of Class $1 \mathrm{E}$ Static Battery Chargers and Inverters for Nuclear Power Generating Stations.

2. Information Notice 84-84, rev. 1, Deficiencies in Ferro-resonant Transformers, $4 / 85$.
3. NEMA PE5-1983, Constant Potential Type Electric Utility Battery Chargers.

4. Regulatory Guide 1.32, Criteria for Safety Related Electric Power Systems for Nuclear Plants. 

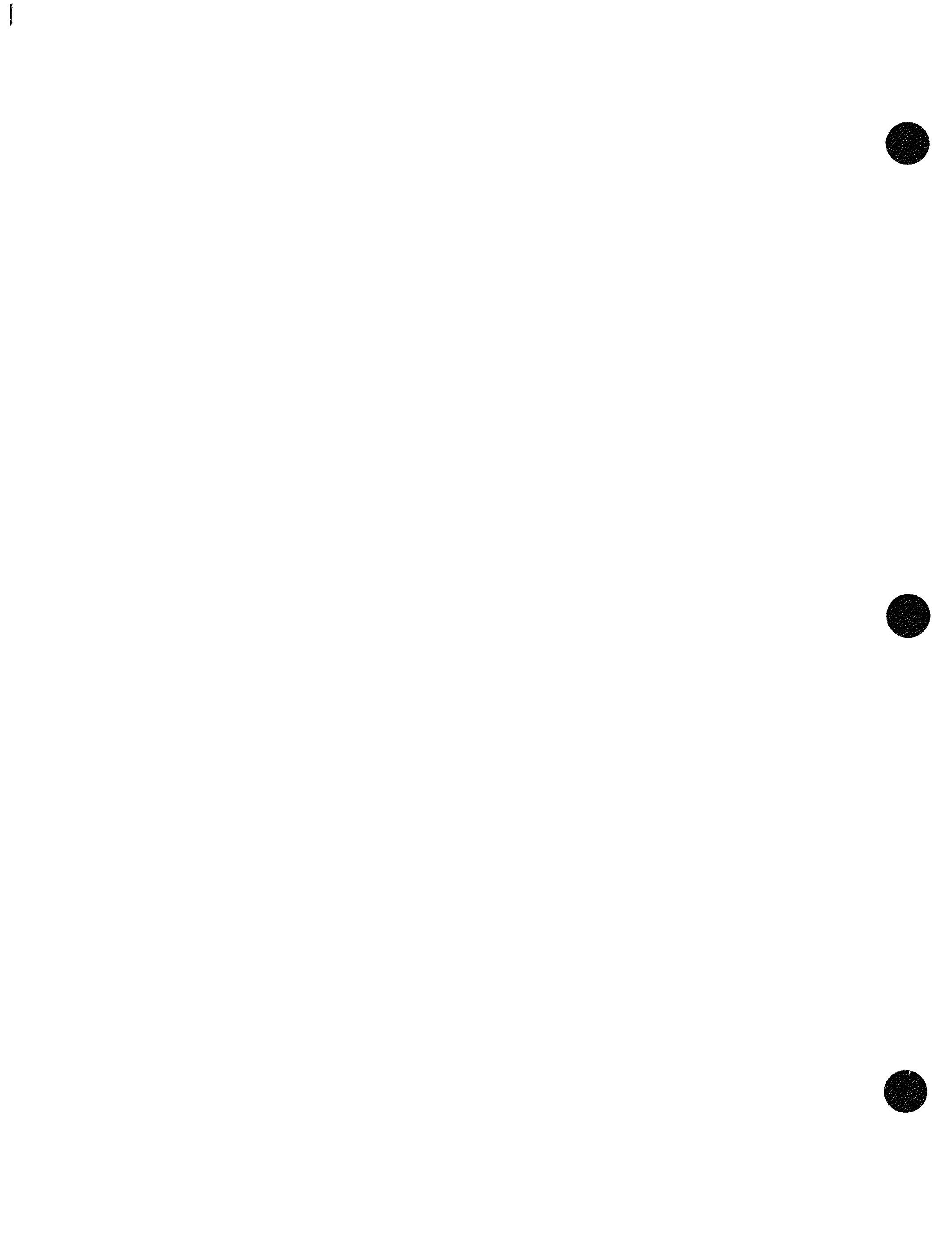

\section{.}
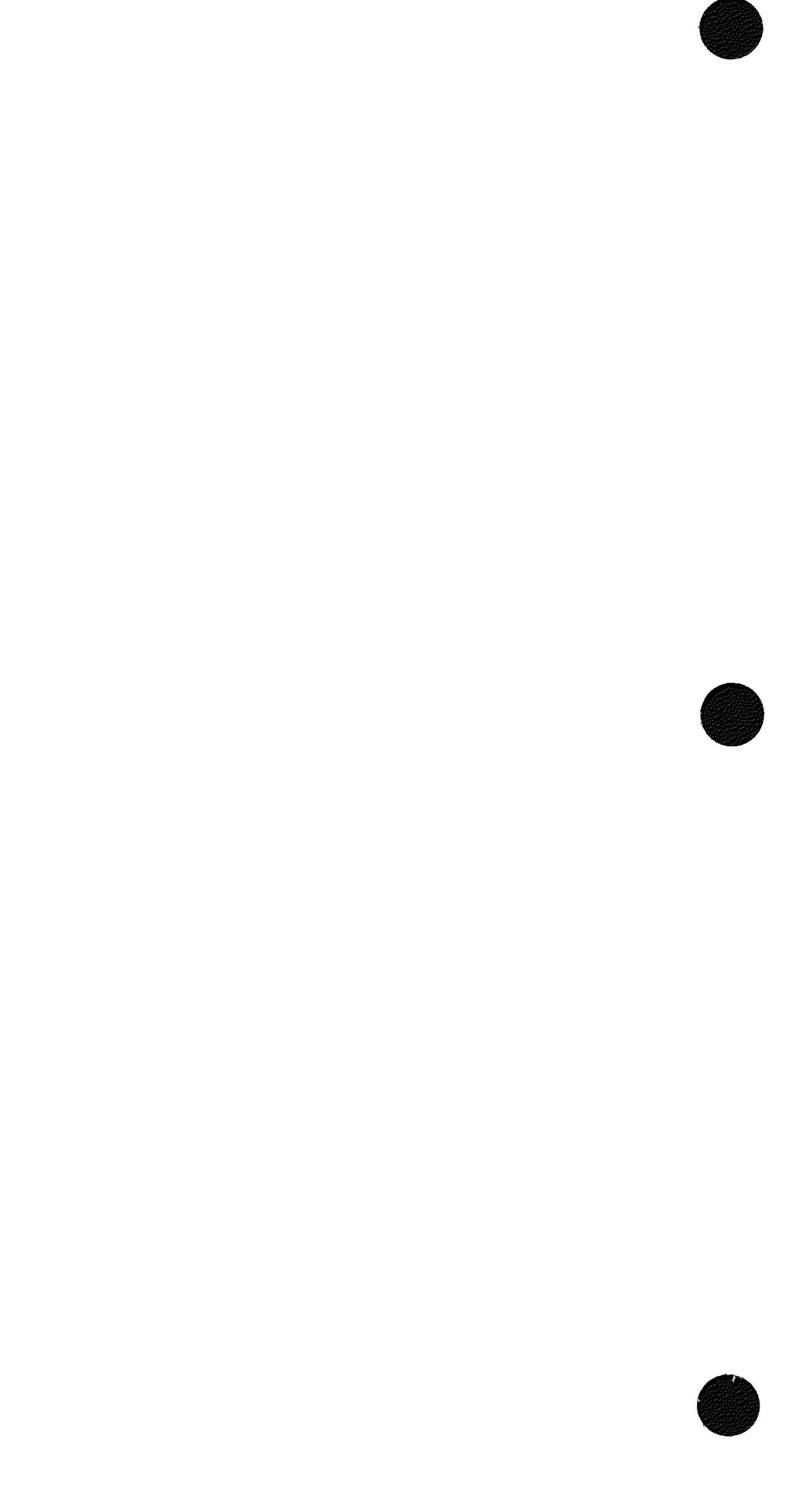


\section{AGING ASSESSMENT GUIDE BATTERY CHARGERS}

Observations on the aging of battery chargers

- Limited service life of electrolytic capacitors; temperature dependent

- Excessive ripple in charger output can cause degradation of the battery

- Charger failure has no immediate effect on plant safety, but should be given prompt attention

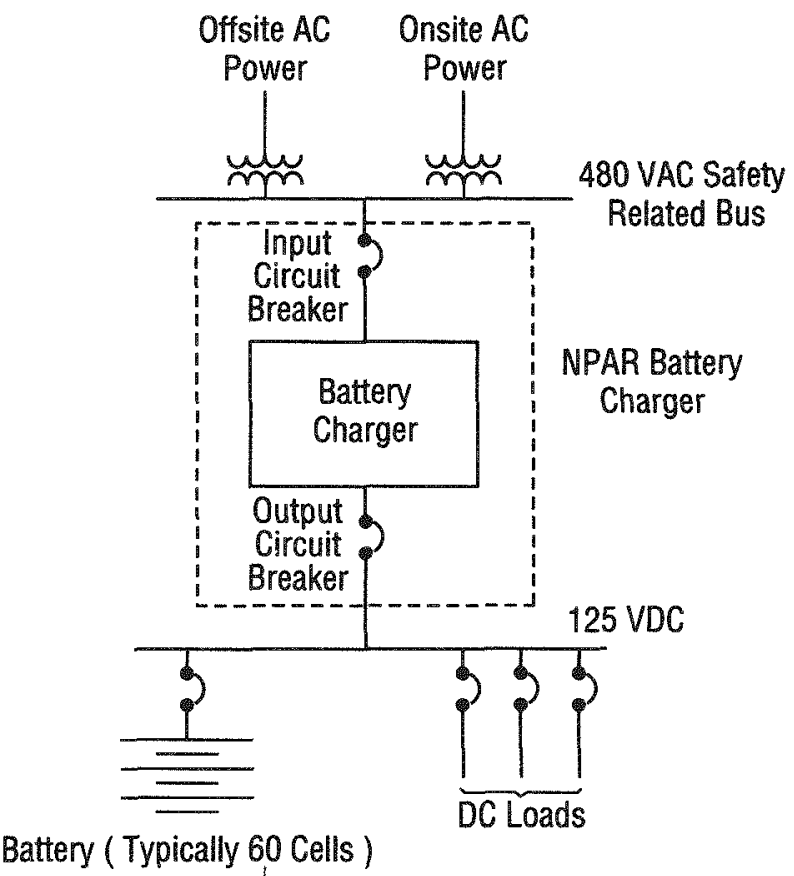

Battery ( Typically 60 Cells)

\section{RECOMMEMDATIONS FOR INSPECTION}

Erternal

1. The identification of positive output current.

2. No unusual meter oscillation or electrical hum is apparent.

3. The charger output voltage is correct.

4. The cooling air filters are not clogged.

5. The ambient temperature of the room is less than $90 \mathrm{~F}$.

\section{Internal}

1. There are no signs of overheating.

2. The capacitors are not bulging or leaking oil.

3. The panels are clean, especially SCR heat transfer surfaces.

\section{MAINTENANCE RECOMMENDATIONS}

1. Periodic inspections are performed and include cleaning \& checks of connection tightness.

2. Preventive maintenance is conducted at least once per cycle and includes calibration of panel meters and alarm/trip relays.
3. The personnel responsible for maintenance have been specifically trained on this equipment. 


$6 \quad$ BATTERY CHARGERS

\section{OPERATIONS RECOMMENDATIONS}

1. The daily logs or round sheets include recording of the charger output voltage and current.

2. The operating procedures address the response to a battery charger failure.
3. Periodic checks are made to insure proper electrical alignment. The normal supply to the dc bus is from the charger.

\section{DESIGN/TEST RECOMMENDATIONS}

1. Capacity testing is performed in accordance with the technical specifications (typically, every refueling)

2. Circuit waveforms are observed and recorded to verify proper operation of key components. Comparison of waveforms to previous testing is recommended.

3. Capacity testing, even for standby chargers, represents worst case load situations.

\section{OTHER RECOMMENDATIONS}

1. Replacement or testing of all filter capacitors should be considered when one fails. (Same stress)

2. Modifications affecting the dc bus should include an evaluation of the impact on the battery charger.
3. The structural integrity of the chargers should be periodically checked, based on seismic requirements and vulnerability. 

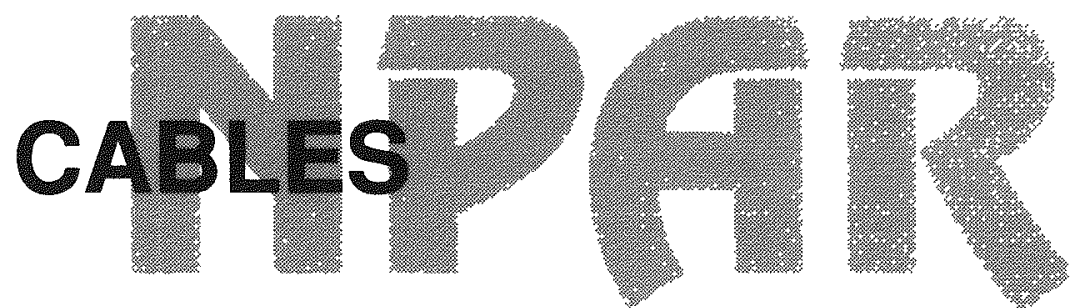

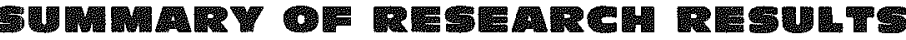

FUNCTIONAL DESCRIPTIONBBACKROUND Cable degradation during normal service, usually manifested as insulation and jacket embrittlement, occurs primarily from thermal and radiation aging. The historical impact of cable-related failures during normal operation is low. The major concern is that failures of deteriorated cables might be induced during accident conditions. Cables that are located in mild plant environments are not subject to a significant number of random failures and therefore are of relatively little concern. Only minimal cable inspection and maintenance, if any, is routinely performed at most plants.

\section{BASED ON NPAR REPORTS:}

1. NUREG/CR-5461, Aging of Cables, Connections, and Electrical Penetration Assemblies Used in Nuclear Power Plants, 7/90.
2. NUREG/CR-5655, Submergence and High Temperature Steam Testing of Class $1 E$ Electrical Cables, 5/91.

\section{AGING RELATED ISSUES}

1. TEMPERATURE: Thermal effects occur from normal ambient conditions and from cable self-heating due to normal current loads. Excessive temperatures or moderate temperatures over a long period of time generally cause insulation embrittlement. Of particular concern are abnormally high environmental temperatures that may occur anywhere along the length of a cable.

2. RADIATION: Radiation effects occur from the normal ambient conditions along the length of a cable. Long-term radiation exposure generally causes insulation embrittlement. As for temperature, abnormally high radiation levels along part of a cable are of particular concern.
3. HUMIDITY: Humidity is not generally believed to affect cable insulating materials adversely, except for perhaps polyimide (Kapton) insulation. A humid environment, particularly in the presence of certain chemicals, may enhance conductor and connection corrosion.

4. MAINTENANCE DAMAGE: Cables that have embrittled as a result of aging may be subject to damage during maintenance handling. One cable manufacturer's experience is that about $90 \%$ of cable failures resulted from physical damage to cables.
OPERATING EXPERIENCE Cables have an excellent functional operating history in nuclear power plants. The number of failures as reflected by the LER data base is extremely small under normal operating conditions. The major concern with cables, however, is the performance of the aged cable when it is exposed to accident conditions. 


\begin{tabular}{l}
\hline 2 \\
RESEARCH RECOMAMEATIONS Mainte- \\
nance programs for cables are generally quite \\
limited, due largely to the high reliability of \\
cables under normal operational conditions \\
and the absence of any effective technique \\
to detect operational degradation. Recent \\
research has identified some techniques that \\
may ultimately prove beneficial for monitor- \\
ing cable operational degradation.
\end{tabular}

Periodic Testing Periodic tests may be either in situ tests or tests performed on small samples of material removed from the plant. The intent of the tests is to detect degradation and verify operability of the cable. In situ electrical measurements might be able to detect either global insulation deterioration or local deterioration or damage. They often suffer from the lack of a consistent ground plane, ambient condition variations along the length of the cable, and lack of sensitivity. Mechanical measurements measure the aged state of a cable only at the location tested, with the results extrapolated to a much longer length of the cable. In such cases, it is very important to know the location of the most severe aging conditions along the length of a cable.

1. Operational testing of a connected component is one method of assessing the current operability of a cable in a gross sense. This method will not detect degradation except in extreme cases. Further, no information about cable functionality under accident conditions is gained.

2. Insulation resistance (IR) tests are generally performed as a go/no-go test, although the actual value may be recorded. They are of limited value for assessing cable degradation, but some materials do show some IR trend with aging. Polarization index (the ratio of IR at two different times) may be performed along with IR measurements, but polarization index is also of limited value for assessing cable degradation.

3. Continuity tests may be used to assess the conductor resistance. Although they do not give any information on the aged condition of the insulation material, they may indicate corrosion or looseness of cable connections.
4. Various types of capacitance and dissipation factor measurements may be performed on cables. No good correlation with aging has been established for any of the measurements. In situ tests suffer from ambient condition changes, plant noise problems, and the lack of a consistent ground plane. Removing a cable sample for analysis permits a more accurate assessment (e.g., using time domain spectroscopy), but requires removal of specimens from the plant, with many associated problems. Time domain spectroscopy has shown some limited ability to assess the aged state of cables.

5. Partial discharge techniques detect microvoids in the insulation by detecting small discharges that occur at the voids. Whether this technique is useful for assessing the aged condition of a cable has never been thoroughly investigated.

6. High potential withstand testing measures the ultimate dielectric strength of a cable. Whether this technique is useful for assessing the aged condition of a cable has not yet been thoroughly investigated. The lack of an effective ground plane is a hindrance to performing such tests. In conduits, water or an ionizable gas added to the conduit can enhance the ground plane for high voltage tests.

7. Time domain reflectometry is useful for locating some cable defects once they have been identified. However, it does not give any information about the aged condition of a cable.

8. Elongation measurements are very effective for assessing the aged state of cable insulation. The measurement requires a sample to be removed from the plant, with the associated difficulties.

9. Tensile strength measurements have shown the ability to assess insulation deterioration for only a few materials. In general, a concurrently measured elongation would provide better information.

10. Hardness measurements have shown the ability to detect cable deterioration for a few materials, primarily jacket materials. Knowing the aged condition of a jacket material can give information about the underlying insulation, since 
both are exposed to the same ambient conditions. The test is nondestructive and can be performed in situ. The sensitivity of the method is not as good as indenter modulus measurements.

11. Modulus measurements using the EPRI/ Franklin cable indenter are similar to hardness measurements, but are more sensitive. As for hardness, the indenter has shown the ability to detect cable deterioration for a few materials, primarily jacket materials. It is also nondestructive and can be performed in situ. The sensitivity of the method becomes particularly good after a material has severely embrittled.

12. Bulk density of small samples may provide some information, but this technique has not yet been thoroughly investigated.

13. Flexing and visually examining a cable may indicate when a cable has deteriorated significantly. Since the insulation materials are usually more vulnerable to aging, a visual examination of the jacket may be able to indicate the need for replacement before the insulation has deteriorated to the point where it would be unable to perform in an accident environment.

Continuous Monitoring There are currently no known effective methods for continuous monitoring of cables.

Inspection Generic guidelines for routine inspections of cables are difficult to establish. Cables run throughout the plant, with many sections of cable not accessible for local inspection. Testing using some of the methods previously described may provide some beneficial information. Documentation of the visual condition of a cable near end devices when maintenance is performed on the end devices can be useful. Routine practice at some plants does include such an inspection, but the inspection may not be documented unless a problem is detected.
REFERENCES Because of the extensive amount of cable that is used in nuclear power plants and its obvious safety importance, extensive literature is available regarding cable deterioration and failure. A few relevant references are listed below. Additional references may be found in NUREG/CR-5461. 1. IEEE 383-1974, IEEE Standard for Type Test of Class $1 E$ Electric Cables, Field Splices, and Connections for Nuclear Power Generating Stations.

2. NUREG/CR-4091, The Effect of Alternative Aging and Accident Simulations on Polymer Properties.

3. NUREG/CR-3629, The Effect of Thermal and Irradiation Aging Simulation Procedures on Polymer Properties.
4. NUREG/CR-3538, The Effect of LOCA Simulation Procedures on Ethylene Propylene Rubber's Mechanical and Electrical Properties.

5. NUREG/CR-3588, The Effect of LOCA Simulation Procedures on CrossLinked Polyolefin Cable's Performance.

6. NUREG/CR-4257, Inspection, Surveillance, and Monitoring of Electrical Equipment Inside Containment of Nuclear Power Plants With Applications to Electrical Cables.

7. EPRI NP-3357, Condition Monitoring of Nuclear Plant Electrical Equipment. 

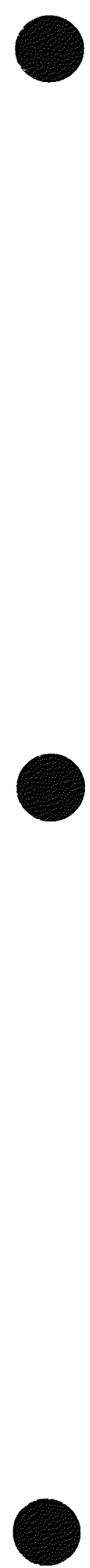


\section{AGING ASSESSMENT GUIDE CABLES}

Observations on the aging of cables

- Cables are highly reliable during normal operation.

- Greatest concern is aged cable failure in an accident environment.
- "Mild environment" cables are of little concern.

- Only minimal testing is normally performed.

\section{RECOMMENDATIONS FOR INSPECTION}

The following can be performed when maintenance is performed on an end device:

1. The cables near the end device are inspected for physical damage due to installation, operation, or maintenance.

2. The cables near the end device are checked for embrittlement when they are manipulated.
3. Any accessible connections are checked for integrity and verified to be free of corrosion.

4. Junction boxes and conduits near exposed cable connections are verified to be free of condensation.

\section{MAINTENANCE RECOMMENDATIONS}

No routine preventive maintenance is necessary for cables that are properly installed and applied. Periodic measurements to check and monitor cable condition may be useful, but the capabilities of various methods are still being investigated. 

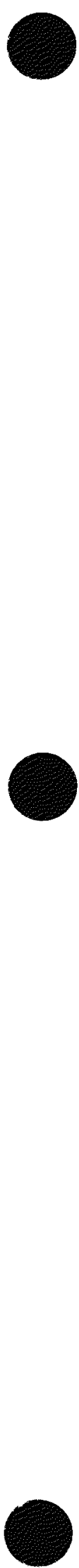

. 


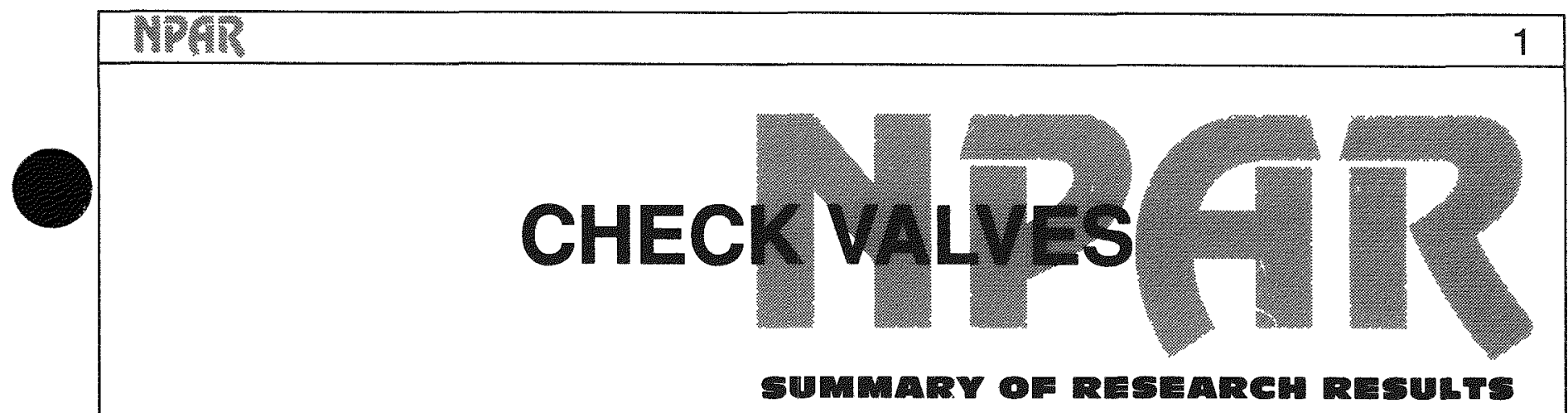

FUNCTIONAL DESCRIPTIOMBBACKCROUND The function of a check valve is simply to open to permit flow in one direction and to close to prevent flow in the other direction. Most check valves are self actuating - that is, they require no external mechanical or electrical signal to either open or close. As a result, most check valves have no capability to be actuated other than by changing flow through the valve. Several types of check valves are commonly used, such as the swingcheck, piston-lift, ball, stop-check, tilting-disc and duo-check designs. These valves are used extensively in nuclear power plant safety systems and balance-of-plant systems. Check valve failures have resulted in significant maintenance efforts and, on occasion, have resulted in water hammer, overpressurization of low-pressure systems, and damage to flow system components. Several diagnostic monitoring methods are now available for detecting check valve aging and service wear efforts (degradation), check valve failures, and undesirable operating modes.

\section{BASED ON MPAR REPORTS:}

1. NUREG/CR-4302 Vol. 1, Aging and Service Wear of Check Valves Used in Engineered Safety-Feature Systems of Nuclear Power Plants, 12/85.

2. NUREG/CR-4302 Vol. 2, Aging and Service Wear of Check Valves Used in Engineered Safety-Feature Systems of
Nuclear Power Plants - Aging Assessments and Monitoring Method Evaluations, 4/91.

3. NUREG/CR-5159, Prediction of Check Valve Pefformance and Degradation in Nuclear Power Plant Systems, 5/88.

\section{AGIMG RELATED ISSUES}

Check valves fail to perform their function according to five modes:

(1) Failure to open

(2) Failure to close

(3) Plugged (limited or no flow through a normally open valve)

(4) Reverse (internal) leakage

(5) External leakage
Several check valve sites are susceptible to aging-related degradation. These sites and the corresponding aging mechanisms are:

1. BODY ASSEMBLY: Body wear, erosion, corrosion; body rupture; fastener loosening, breakage.

2. INTERNALS: Hinge pin wear, erosion, corrosion; hinge pin fracture; hinge arm wear, fracture; disc nut loosening, tightening; disc nut breakage; disc wear, erosion, corrosion; seat wear, erosion, corrosion; foreign material.

3. SEALS: Cap gasket deterioration. 
OPERATING EXPERIENCE Since 1980 , numerous NRC Information Notices and Bulletins have been issued that identify check valve problems and recommend courses of action (see References).

Check valve failures have largely been attributed to severe degradation of internal parts (e.g., hinge pins, hinge arms, discs, and disc nut pins) resulting from instability (flutter) of check valve discs under normal plant operating conditions. Check valve instability may be a result of misapplication (using oversized valves) and exacerbated by low flow conditions and/or upstream flow disturbances.

Check valve problems have been further described and addressed by the Institute of Nuclear Power Operations (INPO) which in 1986, issued a significant operating experience report (SOER), numbered 86-03, which recognized the check valve problems facing the nuclear industry and recommended that nuclear power plants establish a preventive maintenance program to ensure check valve reliability. They (INPO) further recommend that the maintenance program include periodic testing, surveillance monitoring, and/or disassembly and inspection.

\section{RESEARCH RECOMMENDATIONS}

Disassembly and Inspection Utilities periodically disassemble and inspect in order to respond to NRC and INPO recommendations. While disassembly and inspection provides adequate information with regards to valve condition, there are a number of discourag- ing aspects associated with this approach. These include, for example, scheduling additional maintenance work during already busy outages, accounting for additional radiation exposure to maintenance personnel, and recognizing that valve reassembly errors can go undetected (for valves that

\section{SELECTED DIAGNOSTIC CAPABILITIES AND LIMITATIONS OF CHECK VALVE MONITORING METHODS ${ }^{a}$}

\begin{tabular}{|c|c|c|c|c|c|c|c|}
\hline Method & $\begin{array}{l}\text { Detects } \\
\text { valve } \\
\text { internal } \\
\text { leakage }\end{array}$ & $\begin{array}{l}\text { Detects } \\
\text { Internal } \\
\text { impacts }\end{array}$ & $\begin{array}{l}\text { Datects } \\
\text { fluttering } \\
\text { (no } \\
\text { impacts) }\end{array}$ & Nonintrusive & $\begin{array}{l}\text { Sensitivity } \\
\text { to ambient } \\
\text { conditions }\end{array}$ & $\begin{array}{l}\text { Monitors dise } \\
\text { position throughout } \\
\text { the full range of } \\
\text { dise travel }\end{array}$ & $\begin{array}{l}\text { Works } \\
\text { with } \\
\text { all fluids }\end{array}$ \\
\hline $\begin{array}{l}\text { Acoustic } \\
\text { emission }\end{array}$ & Yes & Yes & No & Yes & $\begin{array}{l}\text { Sensilive to } \\
\text { externally } \\
\text { generated } \\
\text { noise/vibration }\end{array}$ & No & Yes \\
\hline $\begin{array}{l}\text { Ultrasonic } \\
\text { inspection }\end{array}$ & No & $\begin{array}{l}\text { Yes } \\
\text { (indirectly) }\end{array}$ & Yes & Yes & Unknown & $\begin{array}{l}\text { Not in all cases - } \\
\text { because of limited } \\
\text { viewing angle of } \\
\text { transducer }\end{array}$ & $\begin{array}{l}\text { No - low } \\
\text { densily fluid } \\
\text { (e.g., air or } \\
\text { steam) may } \\
\text { result in severe } \\
\text { attenuation } \\
\text { of signals }\end{array}$ \\
\hline $\begin{array}{l}\text { Internal } \\
\text { Permanent } \\
\text { Magnet } \\
\text { Techniques }\end{array}$ & No & $\begin{array}{l}\text { Yes } \\
\text { (indirectly) }\end{array}$ & Yes & $\begin{array}{l}\text { No - requires } \\
\text { initial installation } \\
\text { of permanent } \\
\text { magnet inside the } \\
\text { value }\end{array}$ & $\begin{array}{l}\text { Sensitive to } \\
\text { nearby external } \\
\text { magnetic flelds } \\
\text { (e.g.. from motors) }\end{array}$ & Yes & Yes \\
\hline $\begin{array}{l}\text { External } \\
\text { AC and DC } \\
\text { Magnelic } \\
\text { Techniques }\end{array}$ & No & $\begin{array}{l}\text { Yes } \\
\text { (Indirectly) }\end{array}$ & Yes & Yes & $\begin{array}{l}\text { DC Melhod - } \\
\text { Sensitive to } \\
\text { nearby external } \\
\text { magnetic fields } \\
\text { (e.g., from motors) }\end{array}$ & Yes & Yes \\
\hline
\end{tabular}

\footnotetext{
'Radiography and pressure noise analysis methods are not summarized in this table. This table does not reflect othar attributes such as cost, ease of use, etc.

Temperature and radiation effects are unkown.
} 
cannot be tested with flow). The need to improve the knowledge of check valve operating condition without requiring disassembly led to the development of several check valve diagnostic techniques.

Monitoring Methods The check valve monitoring methods that are presently available can provide diagnostic information useful in determining the condition of the valve (e.g., integrity of internal parts), and its operating state (stable or unstable). These methods utilize different transducers and principles of operation; hence, they provide different capabilities and suffer from different limitations. Available monitoring methods are summarized in the previous table along with selected diagnostic capabilities and limitations.

None of the methods examined can, by themselves, monitor the position and motion of valve internals and valve leakage; however, the combination of acoustic emission with either of the other methods yields a monitoring system that succeeds in providing the means to determine vital check valve operational information.

\section{REFERENCES}

1. ERPI NP-5479, Application for Check Valves in Nuclear Power Plants.

2. Information Notice 90-03, Malfunction of Borg-Warner Bolted Bonnet Check Valves Caused by Failure of the Swing Arm.

3. Information Notice 89-62, Malfunction of Borg-Warner Pressure Seal Bonnet Check Valves Caused by Vertical Misalignment of Disc.

4. Information Notice 88-85, Broken Retaining Block Studs on Anchor Darling Check Valves.

5. Information Notice 88-70, Check Valve Inservice Testing Program Deficiencies.

6. Information Notice 86-09, Failure of Check and Stop Check Valves Subjected to Low Flow Conditions.

7. Information Notice 86-01, Failure of Main Feedwater Check Valves Causes Loss of Feedwater System Integrity and Water-Hammer Damage.

8. Information Notice 84-12, Failure of Soft Seat Valve Seals.

9. Information Notice 84-06, Steam Binding of Auxiliary Feedwater Pumps.

10. Information Notice 83-54, Common Mode Failure of Main Steam Isolation Nonreturn Check Valves.

11. Information Notice 83-06, Nonidentical Replacement Parts.

12. Information Notice 82-35, Failure of Three Check Valves on High Pressure Injection Lines to Pass Flow.
13. Information Notice 82-26, RCIC and HPCI Turbine Exhaust Check Valve Failures.

14. Information Notice $82-20$, Check Valve Problems.

15. Information Notice 82-08, Check Valve Failures on Diesel Generator Engine 'Cooling Systems.

16. Information Notice 81-35, Check Valve Failures.

17. Intormation Notice 81-30, Velan Swing Check Valves.

18. Information Notice 80-41, Failure of Swing Check Valve in the Decay Heat Removal System at Davis-Besse Unit No. 1.

19. NRC Bulletin 89-02, Stress Corrosion Cracking of High Hardness Type 410 Stainless Steel Internal Preloaded Bolting in Anchor Darling Model S350W Swing Check Valves or Valves of Similar Design.

20. NRC Bulletin 85-01, Steam Binding of Auxiliary Feedwater Pumps.

21. NRC Bulletin 83-03, Check Valve Failures in Raw Water Cooling Systems of Diesel Generators.

22. NRC Bulletin 80-01, Operability of Automatic Depressurization System (ADS) Valve Pneumatic Supply.

23. Recent Improvements in Check Valve Monitoring Methods, Proceedings of the 18th Water Reactor Safety Information Meeting, Rockville, Maryland, Oct. 22-24, 1990. 

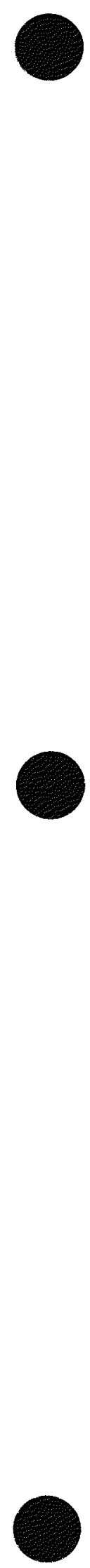


\section{AGING ASSESSMENT GUIDE CHECK VALVES}

\section{Observations on the aging of check valves}

- Degradation (wear, erosion, and corrosion) of check valve internal parts (e.g., hinge pins, hinge arms, discs, and disc nut pins) is an aging concern.

- Accelerated wearing of internal parts can result from instabilities (fluttering, tapping) under normal flow conditions due to misapplication (using oversized valves) and as a result of low flow conditions and/or upstream flow disturbances.

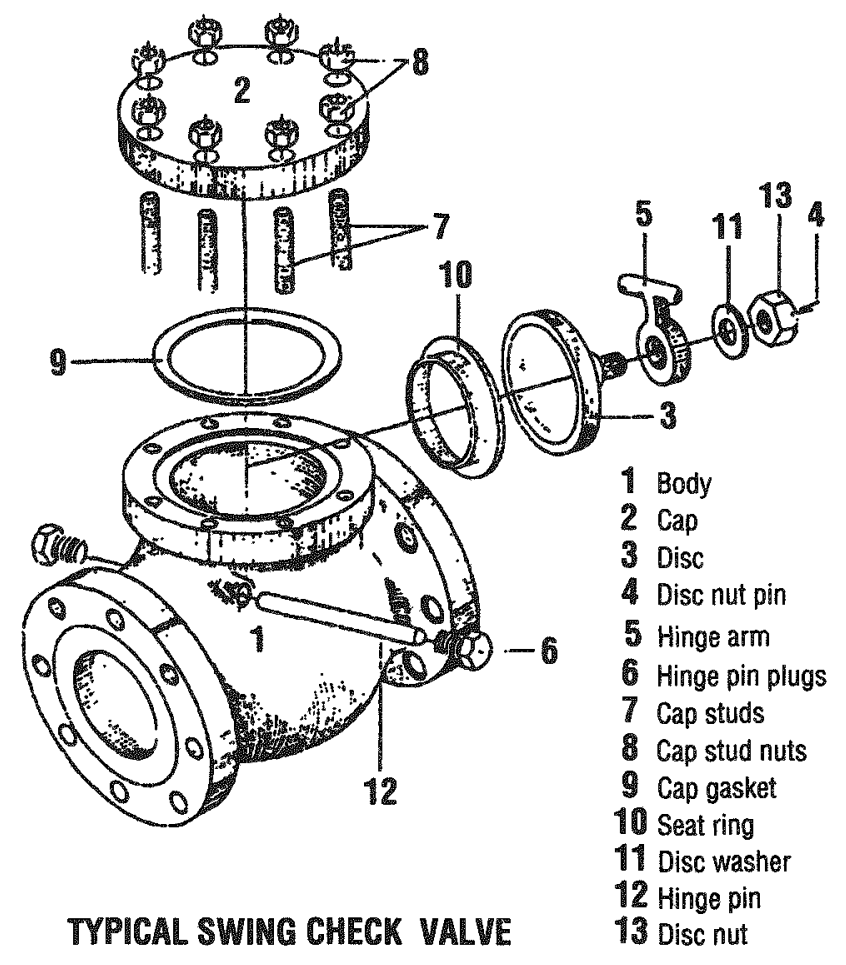

\section{RECOMMENDATIONS FOR INSPECTION}

\section{Required Tests}

Testing requirements for nuclear plant check valves are contained in the plant Technical Specifications and are in accordance with Section XI of the American Society of Mechanical Engineers (ASME) Boiler and Pressure Vessel Code (and more recently the ASME OM Code). This requiremment consists primarily of exercising the valve to verify obturator (e.g., disc) travel to the positions required to fulfill its safety function. Confirmation of obturator movement may be by visual observation, a position indicator (if available), observation of relevant pressures in the system, or other positive means. Some check valves used for containment isolation are also required to be tested in accordance with $10 \mathrm{CFR} 50$ Appendix J. These tests involve pressurizing downstream of the check valve and comparing leakage rates through the valve with the specified standard. Both of these required tests demonstrate check valve operability under test conditions but can not adequately detect and trend check valve degradation. ASME has formed a working group (OM-22) in order to develop a new standard for check valve testing.

Operating Parameters Routinely Observed Most check valves require no external mechanical or electrical signal to either open or close. As a result, most check valves have no capability to be actuated other than by changing flow through the valve. Thus, the only routinely observed parameters are external leakage and internal leakage (through a closed valve). Occasionally, 


6
unusual noise resulting from unstable
(tapping) internals may be observed.
External Indicators or Causes of Age
Degradation

1. Corrosion of valve body
2. Loosening of fasteners (e.g., bonnet bolts, hinge pin plugs)

3. Cap gasket deterioration (resulting in external leakage)

\section{MANTENANCE RECOMMMENDATIONS}

During scheduled downtime, continue to perform periodic disassembly and inspection of critical check valves (especially those determined to be operating in an unstable mode until an acceptable correlation can be made between nonintrusive diagnostic testing results and actual valve degradation. Once this correlation is established, disassembly and inspection intervals may be determined based on the results of nonin- trusive testing. Disassembly and inspection should include examinations of valve internal parts for wear, erosion, corrosion, cracking, loosening, tightening, etc., that would interfere with the freedom of movement and correct positioning of the internals or that may lead to fracture, breakage, or other catastrophic failure. Parts showing significant signs of aging or service wear should be replaced as necessary.

\section{OPERATIONS RECOMMENDATIONS}

Determine the operational mode (stable or unstable) for all critical check valves that are expected to remain open during typical plant operations. Utilize available nonintrusive monitoring methods such as acoustic emission or ultrasonic inspection. Valves operating in an unstable mode should be identified for near term disassembly and inspection.

\section{DESIGN/TEST RECOMMENDATIONS}

Periodic use of nonintrusive monitoring methods is recommended for critical valves that are known to be operating in an unstable mode. Selected diagnostic signature features obtained from nonintrusive examinations should be quantified and recorded for subsequent comparisons with actual service wear. 


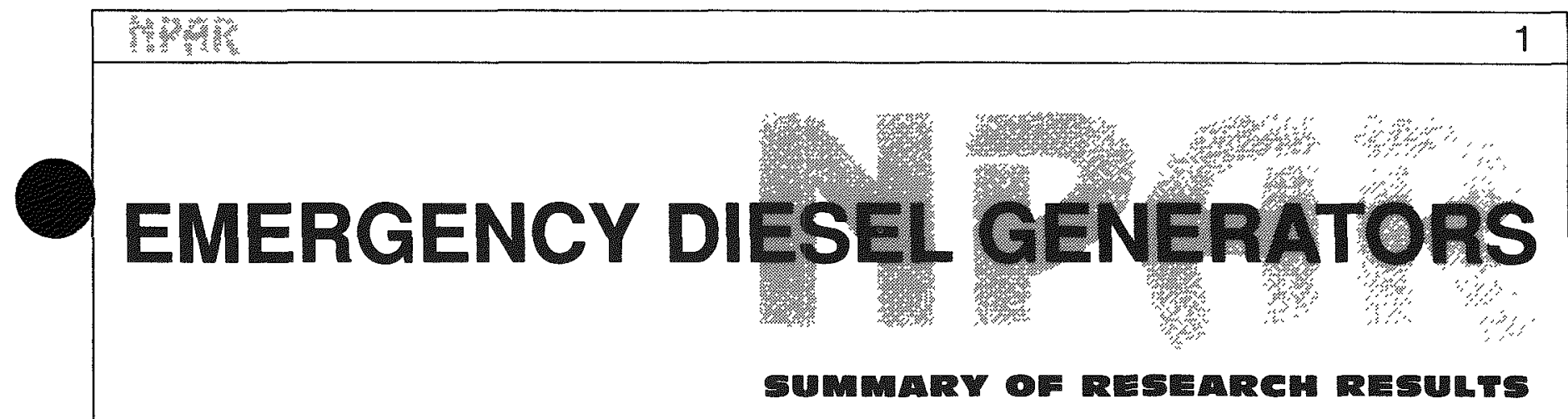

FUNCTIONAL DESCRIPTION/BACKGROUND The EDG system typically consists of at least two diesel generators, rated at 2,500 to 10,000 hp each. The potential serious consequences of an aging related failure of these EDG systems has directed renewed attention to potential improvements in testing, maintenance, and management so as to reduce aging stressors and improve reliability. Certain practices for testing and engine management lead to avoidable aging impacts. Elements for improvement have been identified in operations, Regulatory Guides, Standard Technical Specifications and plant procedures.

\section{BASED ON MPAR REPORTS:}

1. NUREG/CR-4590, Volumes 1 and 2, Aging of Nuclear Station Diesel Generators: Evaluation of Operating and Expert Experience, 6/87.
2. NUREG/CR-5057, Aging Mitigation and Improved Programs for Nuclear Service Diesel Generators, 10/89.
AGING RELATED ISSUES Aging is a concern of EDG systems. The evaluation of multiple data bases showed that more than $50 \%$ of the failures were attributed to aging. Different aging mechanisms are present, related to the operating status of the system. While in standby, the aging mechanisms are:

- Corrosion

- Set point drift

- Chemical attack from fuel and lube oils

- Environment, dust, microbial growth, etc.
While the system is operating the aging mechanisms include:

- Vibration

- Thermal and mechanical shock

- Excessive operating loads

- Operating environment

Operational aging stressors are enhanced by the synergistic influences of the current starting, engine loading, and technical specification requirements.
OPERATING EXPERIENCE The effect of each EDG failure on system performance was determined from the NPAR data base developed for the EDG system. Over half of the failures were judged to be related to aging and about one-third resulted in the loss of function. Failures typically did not occur in either the engine or the generator, but occurred chiefly in the supporting instru- ments and mechanical components of the engine sub-systems. The I \& $\mathrm{C}$ component of failures was about $30 \%$ while the lubrication, fuel oil, cooling and starting subsystems each contributed about $10 \%$ to the additional failures observed. Failures charged to the engine and generator directly were less than $15 \%$. 
FAILURE MECHANISMS A failure mechanism is the physical, chemical, or other process by which a component or system degrades or fails. Since the EDG system is a complete small power plant with standby and operational modes, there are many different failure mechanisms. For the EDG system one failure cause such as engine vibration can lead to several mechanisms such as piping metal fatigue or abnormal pump wear.

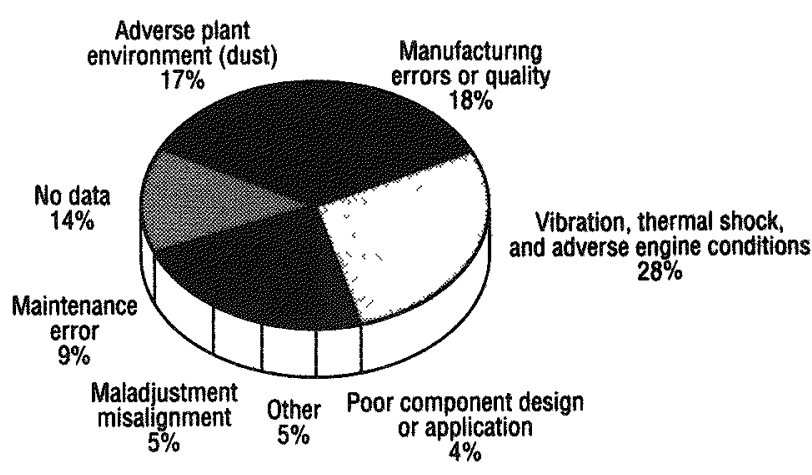

will abort an engine run and some of these prove to be simple instrument errors.

Common failure modes are leakage, loss of electrical contact or signal, filter blockage, injector fouling, flow blockage, and mechanical binding.

recorded as a failure because of a 14-sec. start rather than a required 10 -sec. start. In addition, there are about 2 dozen signals that

FAILURE MODES A failure mode is the manner in which a component fails and these are very diverse for the EDG system. For the EDG system many failure modes are somewhat misleading. A failure to start could be

\section{Understanding and Managing Aging of Diesel Generators}

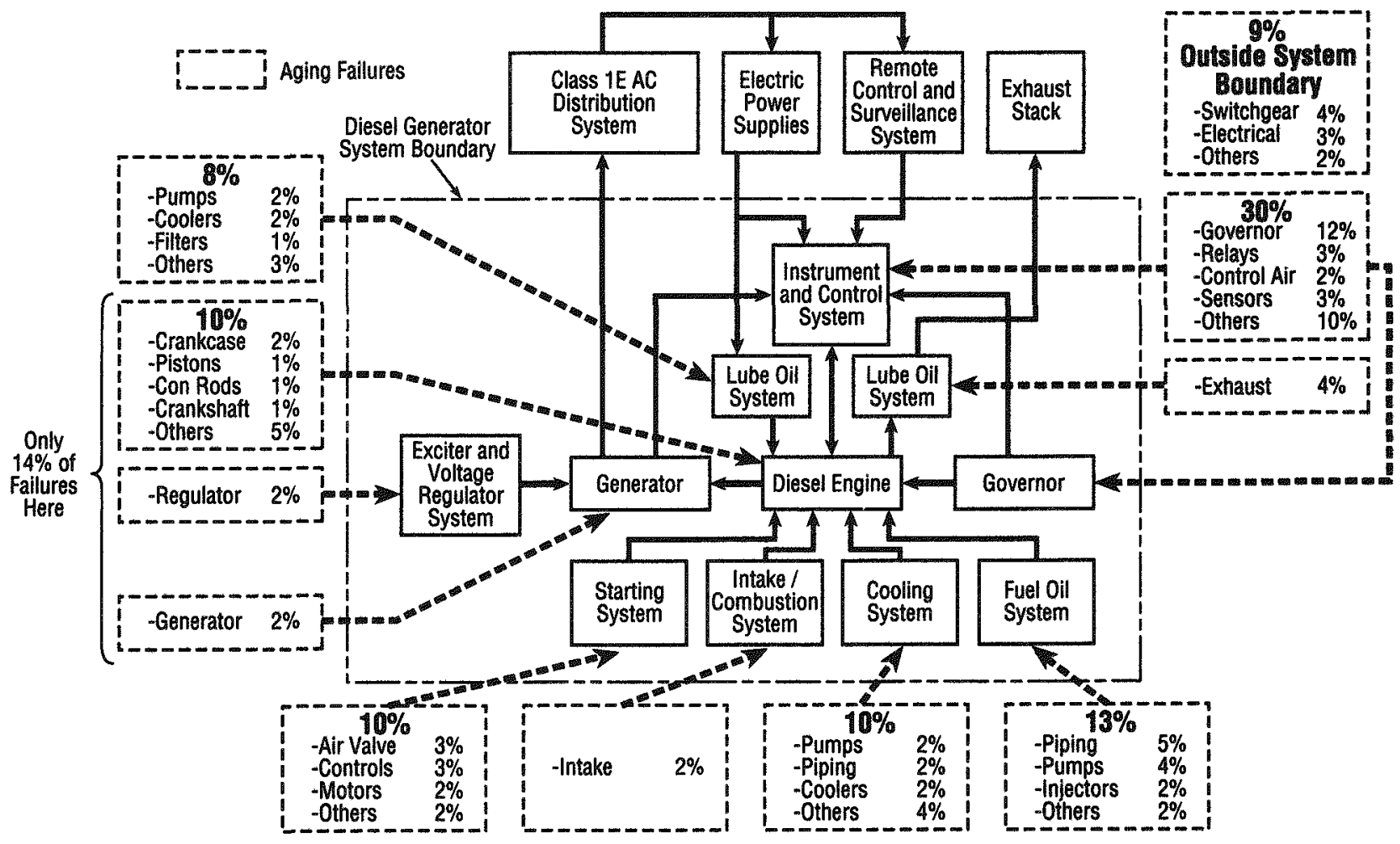


RESEARCH RECOMMENDATIONS The operational readiness of the EDG system can best be assured by a monthly "health checkup" and by changing certain harmful engine management practices. The monthly testing program should be redirectd to a monitoring objective to obtain data on about 25 available EDG operating parameters that could indicate degraded performance or impending component failure. NUREG/CR5057 identifies the complete list of parameters and their chief uses for the recommended monitoring program. The test program and engine management should include prelubrication, slow loading, longer run times, and post-test gradual load reduction and cooldown practices.

EDG system management changes that would result in the most beneficial engine improvements for aging mitigation and corresponding reliability improvements are:

- Significantly reduce the number of system starts
- Gradually add load to the system during test sequences, about 10-20 minutes

- Reduce test loads to $90 \%$ of continuous or the plant emergency EDG load, whichever is less

- Increase EDG start time to 25-30 second range

- Eliminate short run times and excessive idle time, and

- Include trending of the more important engine and generator operating parameters in the management program.

Preventive Maintenance Seals, gaskets and other components with short qualified life should be replaced at prescribed intervals. Activities such as cleaning, lubrication, instrument and sensor calibration should be periodically conducted. However, periodic intrusive inspections including component disassembly should be reconsidered. Reliability may be improved by discontinuing such practices and using the monitoring and trending data and analysis results to identify maintenance needs.

\section{REFERENCES}

1. PNL-7516, Technical Evaluation Report, Emergency Diesel Generator Technical Specification Study Results, 3/91.

2. Generic Letter 83-41, Fast Cold Starts of Diesel Generators.

3. Generic Letter 84-15, Proposed Staff Actions Improve and Maintain Diesel Generator Reliability.
4. NUREG/CR-5078, A Reliability Program for Emergency Diesel Generators at Nuclear Power Plants, 1988.

5. Regulatory Guide 1.9, Revision 3 (Draft). Selection, Design, Qualifications, Testing, and Reliability of Emergency Diesel Generator Units Used as Class $1 E$ Onsite Electric Power Systems at Nuclear Power Plants, 1990. 

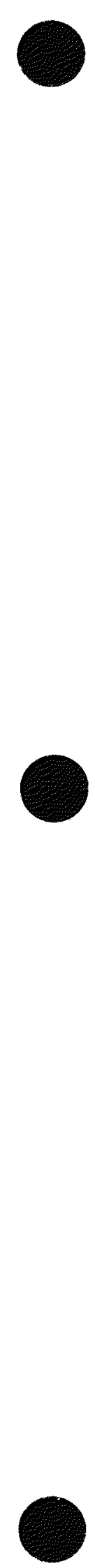


\section{AGING ASSESSMENT GUIDE EMERGENCY DIESEL GENERATORS}

\section{Observations on the aging of the Emergency Diesel Generator}

- Instrument and control equipment experienced the most failures in the NPAR data base.

- Normal engine vibration causes increased wear and fatigue on many engine components. Inspections may detect many incipient failures before loss-of-function occurs.

- Inspections for vibration loosening of fittings, fasteners, and wire and cable terminations will reduce potential failures.
- Monthly testing should incorporate monitoring and trending of available engine and generator operating parameters.

- Engine and generator disassembly only for inspection purposes may lead to additional failures.

- The engine governor should be included in a routine inspection and maintenance schedule.

\section{RECOMMENDATIONS FOR IMSPECTION}

1. When in the standby mode, the EDG system should be checked for oil and water leaks and proper standby engine temperatures.

2. When the EDG system is operating, visual inspection and careful attention to engine sounds for unusual noise helps detect abnormal engine conditions.
3. Important visual inspection details are described in NUREG/CR-5078 Vol. 2 and NUREG/CR-5057.

4. Visual observation of engine and generator pressure and temperature gages in a systematic process, is very important for system "health" monitoring.

\section{MAINENANCE RECOMMENDATIONS}

1. The monitoring and trending program should be based on existing engine gages and operating parameters.

2. NUREG/CR-5057 lists the important operating parameters and their uses for engine and generator maintenance and troubleshooting.

3. The engine governor should receive maintenance based on the manufacturer's recommendations. The manufacturer's training program, or equivalent, is useful.
4. Engine overhauls based on monitoring and trending information, or response to known defect conditions, gives better results than overhauls on a strictly periodic basis.

5. Maintenance training programs by engine manufacturer or by equivalent plant training is useful in recognizing aging induced problems and correcting them.

6. Plant maintenance directed at maintaining the condition of cooling water, lube 
oil, and fuel oil systems greatly increases system reliability.

7. Bacterial growth and microbiological attack in water and fuel oil systems need to be monitored and, as required, addressed by maintanance activities. 


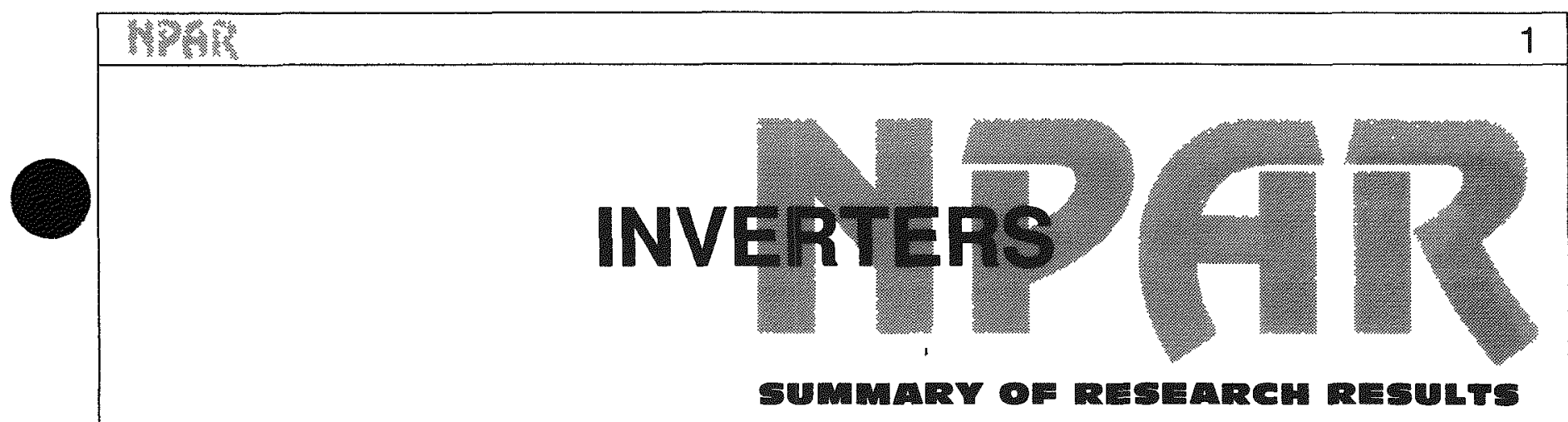

FUNCTIONAL DESCRIPTIOM/BACKGROUND Inverters are used in nuclear power plants to convert dc to ac power for instrumentation, controls, and other equipment necessary for power operation and safety. Research has shown that inverter perfor- mance will degrade with time due to the aging susceptibility of some components and materials. Inverters are complex devices which require Irained personnel using detailed procedures to assure their proper operation and maintenance.

\section{BASED ON NPAR REPORTS:}

1. NUREG/CR-4564, Operating Experience and Aging-Seismic Assessment of Battery Chargers and Inverters, 6/86.

2. NUREG/CR-5051, Detecting and Mit- igating Battery Charger and Inverter Aging, 8/88.

3. NUREG/CR-5192, Testing of a Naturally Aged Battery Charger and Inverter, 9/88.
AGIMG RELATED ISSUES A large percentage of inverter failures are due to hardware. Components susceptible to aging degradation are:

1. FILTER CAPACITORS: These components have experienced a limited service life (approximately 5 years) directly related to ambient temperature, applied voltage, and ripple current.

2. THYRISTORS (SCRs): Large SCRs used in the power conversion circuit generate heat which is designed to be dissipated through attached heat sinks. Improper torque of the SCR/heat sink connection has resulted in overheating and failure of the SCR.

3. FUSES: Fast acting fuses are used to protect inverter electronics and are subject to thermal fatigue. Depending on internal cabinet temperature and the proximity of the fuse rating to normal load current, expected life can vary from 5 to 25 years. As the fuses degrade, they are more susceptible to normal plant electrical transients such as starting motors and switching operations.
OPERATING EXPERIENCE The operating experience data demonstrates that inverter failures can impact plant safety and availbility. One of the most visible and dramatic effects of an inverter failure is reactor trip. From 1984 to 1986,57 reactor trips resulted from an inverter failure. In addition, safety injection (SI) system actuations, containment isolations, and safety system (HPCI \& $\mathrm{RCIC)}$ inoperability were directly linked to inverter failures.

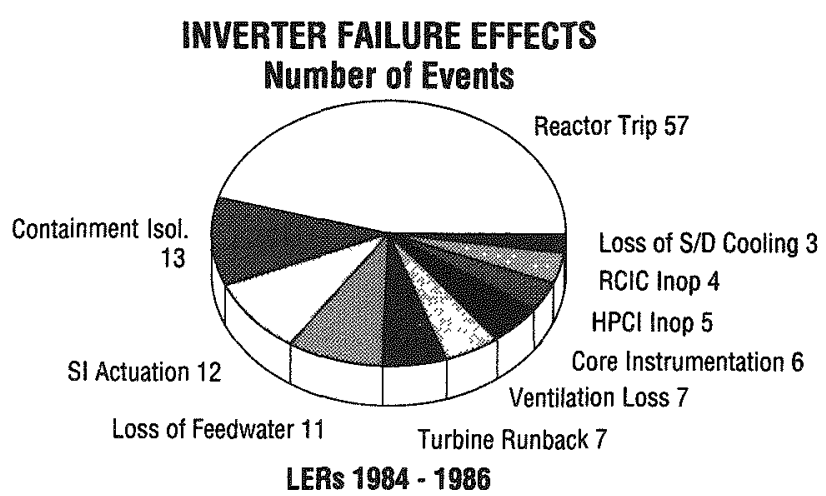


The analysis of data on operating experience accumulated over 12 years indicates that overheating, electrical transients, and errors by plant personnel are the leading causes of inverter failures. Such stresses result in the aging of critical components. The large percentage of unknown causes may be due to 'normal' electrical switching where inverter fuse or circuit breaker operation results.

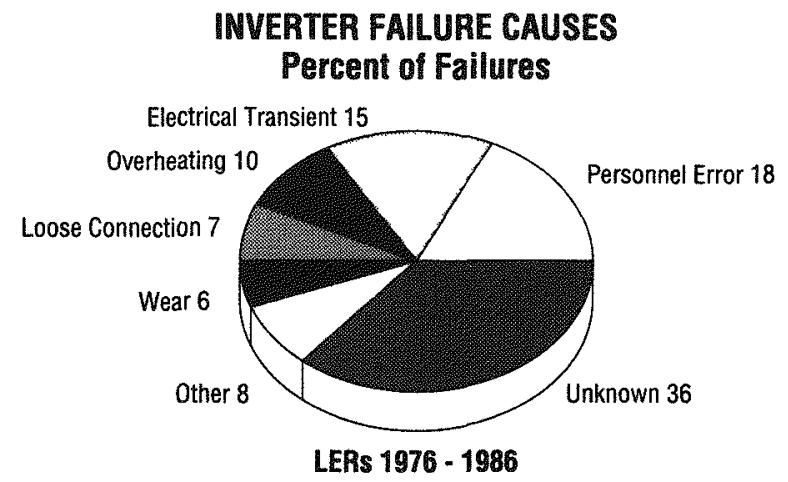

\section{RESEARCH RECOMMENDATIONS}

Design Four basic designs of inverters are used in the nuclear industry. Improvements were made in the more recently manufactured units, such as:

1. The use of an automatic transfer switch, which senses an inverter failure and switches to a backup power source without a detectable loss of power to vital equipment.

2. The installation of higher voltage and temperature rated components, especially capacitors and semiconductors. This makes these components less susceptible to operationally induced stresses.

3. Forced air cooling rather than natural convection cooled units tend to have less overheating problems. Several utilities have modified the inverters in this manner.

4. Additional monitoring capabilities, including annunciation of abnormal conditions, such as high temperature, are available in newer units.

Maintenance and Monitoring Based on the inverter's importance and the effects of its failure on plant safety and availability, a comprehensive maintenance program is recommended. This program should include inspection, testing, and preventive maintenance.

Inspection The inspection of an inverter by experienced personnel can provide a great deal of information about the equipment's overall condition.

1. While operating, observation of cyclical electrical hum, meter oscillation, or cooling fan noise can indicate an impending failure.

2. Component degradation due to overheating, and loose electrical and mechanical connections can be detected when the inverter is off-line.

3. Cleaning can minimize the risk of overheating. The wiping of SCR heat sinks and ventilation flow paths improves heat transfer away from temperature sensitive components.

Testing/Monitoring Periodic testing is necessary to verify that design parameters are obtainable under all conditions. The acceptance criteria for such testing should be based on specific plant and manufacturer information.

1. Overheating is an important cause of stress that can reduce the expected life of electrolytic capacitors, thyristors, and inductors. It is prudent to periodically monitor them to detect any increase in temperature.

2. The component's performance may change with time and can indicate degradation. Two parameters for detecting aging of electrolytic capacitors are an increase in the equivalent series resistance (ESR) or a decrease in capacitance.

3. Capacity testing is recommended, especially for standby inverters. This verifies that the inverter can supply design loads, and permits inspection monitoring techniques to be applied at rated conditions.

4. The automatic transfer switch should be tested to verify it is capable of transferring to the alternate supply without interrupting power to critical equipment. 
Preventive and Corrective Maintenance Specific requirements from the manufacturer should be incorporated into the maintenance program. These are based on the manufacturer's experience or are generated as a result of equipment qualification. Guidelines are also provided to restore the inverter to an operable condition following a failure.

1. Deviations from equipment qualification requirements require documented engineering analyses. Components which have been identified as having limited service lifes include capacitors, cooling fans, fuses, circuit breakers, and relays.

2. Replacement power electronics, such as SCRs, should be remounted to a cleaned heat sink surface at the torque specified by the vendor.

3. Loose power cable terminal contact surfaces should be cleaned before tightening.

4. Fuses identical in rating and design should be used.
REFERENCES These documents provide additional background information on inverters used in nuclear power plants.

1. AEOD Case Study Report C605, Operational Experience Involving Losses of Electrical Inverters, 12/86.

2. Information Notice 87-24, Operating Experience Involving Losses of Electrical Inverters.
3. Information Notice 88-57, Potential Loss of Safe Shutdown Equipment Due to Premature SCR Failures.

4. IEEE-650-1991, IEEE Standard for Qualification of Class $1 \mathrm{E}$ Static Battery Chargers and Inverters for Nuclear Power Generating Stations. 

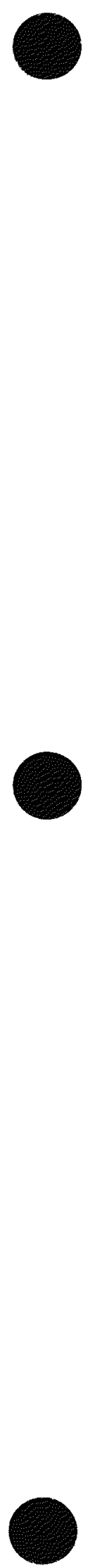

.

.

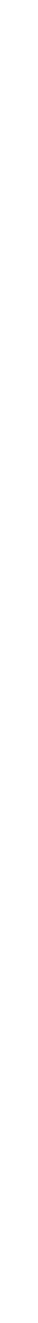




\section{AGING ASSESSMENT GUIDE INVERTERS}

\section{Observations on the Aging of Inverters}

- Limited service life of electrolytic capacitors; temperature dependent

- Use of automatic transfer switch can improve reliability of vital bus

- Inverter failure directly affects the operability of safety systems

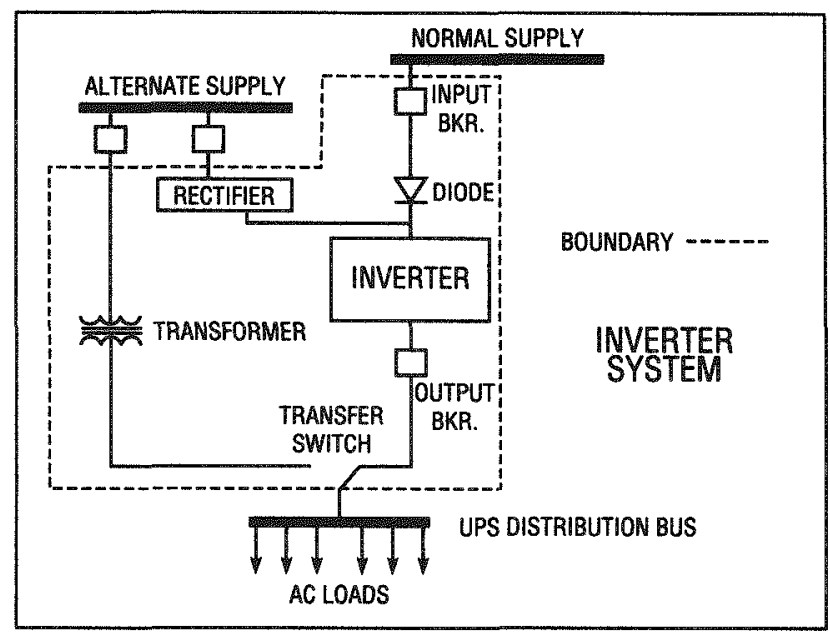

\section{RECOMMENDATIONS FOR INSPECTION}

1. minimal meter oscillation

2. no unusual electrical hum

3. cooling air filters are clean
4. no signs of overheating

5. capacitors not leaking or bulging

6. heat transfer surfaces are clean

\section{MAINTENANCE RECOMMENDATIONS}

1. Perform periodic inspections which include cleaning and check of connector tightness.

2. Preventive maintenance is conducted at least once per cycle and includes calibration, EQ related component replacement (electrolytic capacitors), and evaluation of circuit waveforms.

3. Personnel have been trained, and use approved procedures which have considered vendor recommendations.

\section{OPERATIONS RECOMMENDATIONS}

1. The daily logs or round sheets include recording the data on or observing inverter performance.

2. The operating procedures address the response to an inverter failure.
3. Periodic checks are made to insure proper electrical alignment - normal supply from the station battery.

\section{DESIGN/TEST ACTIVITIES}

1. The loading of the inverter for normal and postulated accident conditions is within the equipment's rating.

2. The static switch is functionally tested to assure an uninterruptible transfer to the alternate supply. 
3. Capacity testing, especially recommended for standby inverters, accurately reflects loads.
4. A protective device coordination exists between the inverter and its branch circuits.

\section{OTHER RECOMMENDATIONS}

1. Replacement or testing of all filter capacitors should be considered when one fails. (Same stress)

2. The ferro-resonant inverters (i.e., SCI, Westinghouse) use magnetic components for waveform shaping and voltage regulation. Special ferro-tuning techniques recommended by the manufacturer should be followed.
3. The pulse-width modulated inverters (i.e., Elgar, Cyberrex) generate a near sine wave output through electronic feedback. Photographing the wave shapes for timing and sequence should provide good troubleshooting information. 


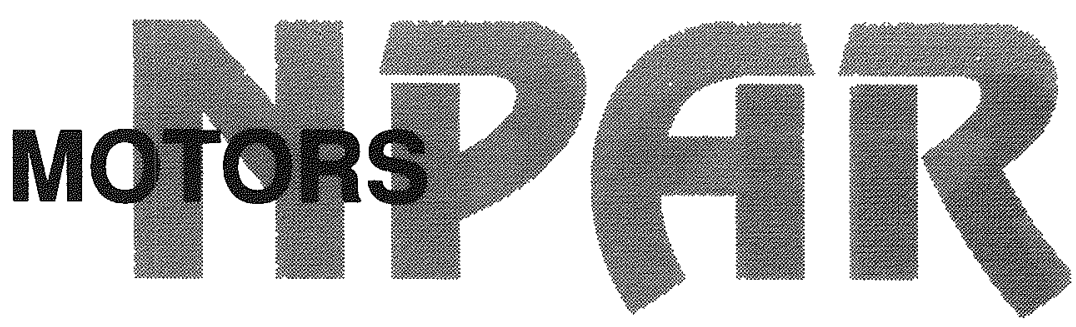

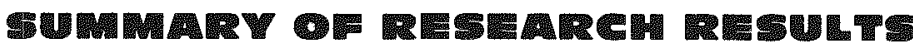

FUNCTIONAL DESCRIPTION/BACKCROUND Motor degradation due to aging and service wear decreases reliability and increases the potential for failure. The impact of motor failures on plant safety is significant since motors play a vital role in most safety systems.
The evaluation of motor performance in nuclear and non-nuclear industries and laboratory testing of aged motors has identified elements for consideration in planning maintenance program inspections and periodic testing of motor subcomponents.

\section{BASED ON MPAR REPORTS:}

1. NUREG/CR-4156, Operating Experience andAging-Seismic Assessment of Electric Motors, 6/85.
2. NUREG/CR-4939, Volumes 1,2,3; Improving Motor Reliability in Nuclear Power Plants, 11/87.
AGING RELATED ISSUES For smaller motors (under $200 \mathrm{hp}$ ), the stator insulating system and bearing assemblies are the subcomponents that most frequently failed. The major factors contributing to large motor failures include voltage surges and mechanical stresses due to centrifugal or magnetic forces.

1. INSULATING MATERIAL: Insulating material is primarily degraded by heating cycles of the winding due to starting, as well as overload conditions. Humid environments produce more rapid degradation in both cases.
2. BEARINGS: Bearing failures are primarily caused by deterioration of lubrication or mechanical misalignment.

3. TEMPERATURE: Thermal effects commonly result from excessive current which imposes self-heating and results in insulation failure.

4. VIBRATION: Vibration can originate from internal and external abnormalities, and is often caused by coupling misalignment, rotor imbalance, and loose parts.

5. MOISTURE: Humidity can reduce properties of electrical insulation. High humidity promotes dirt buildup on the windings, leading to overheating.
OPERATING EXPERIENCE Regardless of size and system application, motors are subject to stresses which may eventually cause failure. Stator-related failures are the highest having nearly an equal probability of occurrence for both pump and valve motors. Bearing failures are significantly higher for pump motors than for valve operators.

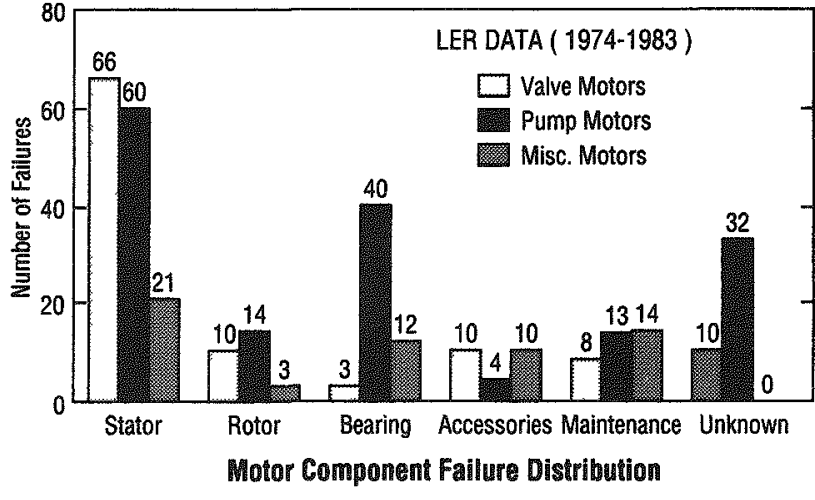


Large Motor Failures Classified By Insulation Type

For 250HP motors and above, class B insulation systems, which were used in safety \& non-safety applications at older plants \& non-safety applications at newer plants, have experienced the most failures. Most newer plants (post 1980) use class $\mathrm{F}$ or $\mathrm{H}$ insulation for safety systems.

\begin{tabular}{|c|c|c|c|c|c|c|c|c|c|c|c|c|}
\hline $\begin{array}{c}\text { INSULATION } \\
\text { CLASS }\end{array}$ & 1969 & 1970 & 1971 & 1972 & 1973 & 1974 & 1975 & 1976 & 1977 & 1978 & 1979 & 1982 \\
\hline A & - & 4 & 13 & 2 & 4 & 1 & 1 & 1 & - & - & - & 1 \\
\hline B & 19 & 19 & 28 & 13 & 26 & 20 & 21 & 53 & 26 & 29 & 34 & 42 \\
\hline F & 3 & 2 & 4 & 4 & 2 & 7 & 8 & 3 & 13 & 9 & 7 & 19 \\
\hline H & 1 & - & 3 & 2 & 1 & 1 & 1 & 1 & - & 4 & - & 7 \\
\hline OTHER & - & 1 & 5 & 2 & 2 & - & 2 & 1 & 6 & 1 & 3 & 3 \\
\hline TOTAL & 23 & 26 & 53 & 23 & 35 & 29 & 33 & 59 & 45 & 43 & 44 & 66 \\
\hline $\begin{array}{c}\text { Average } \\
\text { Service } \\
\text { Life }\end{array}$ & 4.7 & - & 5.7 & 6.2 & 5.7 & 3.6 & 4.3 & 3.2 & 5.1 & 6.1 & 6.2 & 12 \\
\hline
\end{tabular}

Average Service Life - Average Age at Time of Failure

RESEARCH RECOMMENDATIONS A preventive maintenance program should exist for motors important to plant safety and availability. To evaluate the performance of a motor, the PM program should include periodic testing, continuous monitoring, and inspection techniques.

Periodic Testing Periodic tests are in situ tests performed in the plant on the equipment at scheduled intervals to detect degradation and verify operability.

1. Insulation resistance (megger) tests are go/no go tests that are effective for the post maintenance check of a motor. They indicate the dryness of the insulation but are not useful for predicting overall insulation dielectric conditions.

2. A partial discharge test is used for large motors with a voltage rating above 500 volts, and can provide results which are useful for trending. It detects void growth and corona discharge in the insulation by measuring the discharge inception voltage, which decreases as the insulating material gets older.

3. Power factor or dissipation factor testing is used on high voltage motors and is suitable for monitoring average insulation condition.

4. During technical specification testing of pumps and valves, motor running current and bearing vibration should be measured and recorded. Where available, the winding and bearing temperatures should also be measured and trended.

5. Ac and dc leakage tests (hipot) have proven to be effective in locating faults, however, they have several shortcomings including the imposition of electrical stress. If used, it is recommended that the voltages be applied in small discrete steps up to the test voltage.

6. Voltage impulse or surge testing can detect turn shorts or hot spots in the insulating material in low voltage motors.

7. The chemical analysis of the lube oil will indicate excessive bearing wear or contamination within the lubricating system.

Continuous Monitoring Motors equipped with permanently installed devices should be monitored regularly. A baseline value should be developed for each parameter. Readings should be evaluated by comparison to baseline readings.

1. Parameters typically monitored are line/ phase current or voltage, winding and bearing temperatures, lube oil temperature, and bearing vibration signals.

2. Guidelines for the frequency of evaluating continuously monitored parameters for safety related motors are:

a. Line/phase current: 6 to 12 months b. Winding temperature: 3 to 6 months c. Bearing temperature: 1 to 3 months d. Lube oil temperature: 3 to 6 months e. Bearing vibration: 1 to 3 months

3. Bearing temperature and vibration measurements are proven methods for indicating degradation in bearing assemblies. A high temperature or vibration is a clear indication of bearing wear, misalignment, or other aging mechanisms. 
Inspection Motors, regardless of their sizes and types, should have a periodic inspection to evaluate their condition. The inspection program assures the operational readiness of motors between scheduled testing or maintenance.

\section{Point Inspection Program For Motors}

\begin{tabular}{|c|c|c|}
\hline & 1 & DIRT, DUST, \& CONTAMINANTS \\
\hline & $?$ & $\longrightarrow$ MOISTURE, WATER, GREASE \& OIL \\
\hline & 3 & - FRICTION \\
\hline GUARD & 4 & - VIBRATION / MOUNTINGS \\
\hline & 5 & EXTREME ENVIRONMENTAL CONDITIONS \\
\hline AGAINST & 6 & - CRACKS / CORROSION \\
\hline & 7 & - ELECTICAL STRESSES \\
\hline & 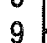 & HUMAN ERROR \\
\hline & 10 & CTION DATA \\
\hline
\end{tabular}

1. Dirt, dust, and contaminants may be removed by wiping the motor clean with a dry cloth. Regulated compressed air can be used to reach inaccessible areas.

2. Moisture intrusion into motor components significantly increases the probability of failures. Space heaters should be used to thoroughly dry the motor before it is returned to service.

3. Excessive belt tension, poor alignment, a bent shaft, excessive end bell thrust, or damaged bearings can result in friction and high noise levels.
4. Winding vibration can be caused by loose rotor bars or end rings, phase imbalance, or improper lubrication.

5. Humidity, temperature, radiation, and chemical spray can effect the motor's service life. When required to operate in post-accident conditions, the motor should be shielded as much as possible from potential severe environmental stresses.

6. Surface corrosion or cracks on the motor's components can be detected by a thorough visual inspection. High frequency vibration can initiate cracks or voids at high stress regions.

7. A good visual inspection of insulation surfaces for corona discharge (white and grey deposits) or burn marks can detect a degrading insulation.

8. Some components have a finite life because of their age and service wear, such as seals, bearings, gaskets, and carbon brushes. A typical life for bearings in small motors is ten years.

9. An inspection checklist performed by trained maintenance personnel can help eliminate many of the problems introduced by the human.

10. Logging the inspection activities and observations of motor conditions can provide insight into the motor's performance.
REFERENCES The universal applications of electric motors has resulted in a multitude of references. The following list reflects only a small sample:

1. IEEE Std. 334, Type Test of Continuous Duty Class $1 \mathrm{E}$ Motors for Nuclear Power Generating Stations.

2. IEEE Std. 432, Guide for Insulation Maintenance for Rotating Electrical Machinery.
3. EPRI NP-3416, A Guide for Developing Preventive Maintenance Programs in Electric Power Plants.

4. EPRI NP-3887, Life Expectancy of Motors in Mild Nuclear Plant Environments.

5. Information Notice 88-12, Overgreasing of Electric Motor Bearings.

6. IEEE 89TH0248-5-PWR, Maintenance Good Practices for Nuclear Power Plant Electrical Equipment. 

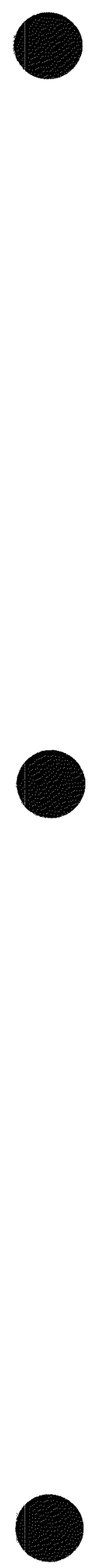


\section{AGING ASSESSMENT GUIDE MOTORS}

\section{Observations on the aging of electric motors}

- Stator/rotor winding insulation deterioration is an aging concern

- Bearing wear is accelerated by improper lubrication or cooling

- Environmental factors such as humidity, dirt, and heat effect motor operating performance

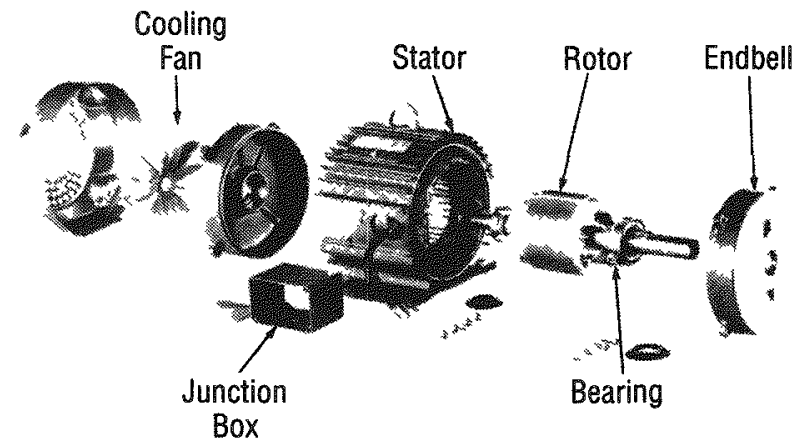

ELECTRIC MOTOR

\section{RECOMMENDATIONS FOR INSPECTION} Operating Parameters Routinely Observed

1. Bearing vibration and temperature

2. Lube oil level and appearance

3. Winding temperature (permanently installed detectors may be recorded by plant computer or data logger)

4. Motor line current-concern for motor overload

5. High noise level-indicator of poor alignment, excessive friction
External Indicators or Causes of Age Degradation

1. Humidity - the space heaters should be energized on standby motors

2. Dust \& Dirt Buildup - internal air temperature may be too high due to blocked air passages or dirty filters

3. Ambient Temperature - motor insulation class (rating) limits safe ambient temperature

4. Corrosion or surface cracks

5. Loose mechanical connections

\section{MAINTENANCE RECOMMENDATIONS}

1. During scheduled downtime, ventilation openings, filters, and winding insulation are cleaned.

2. Vibration levels are measured and evaluated routinely.

3. There is a greasing schedule for antifriction bearings. Oil changes for sleeve bearings are similarly scheduled.
4. Oil leaks are corrected expeditiously to avoid winding contamination.

5. Manufacturer recommended maintenance such as replacing seals or carbon brushes are evaluated and incorporated into the maintenance program.

\section{OPERATIONS RECOMMENDATIONS}

1. The line current is measured and recorded periodically during motor operation.

2. Operating rounds include observations of space heater energization for standby motors.
3. Operating procedures contain guidance for the number of starts permitted over a given time.

4. Alarm response procedures address the operator's action to abnormal motor conditions. 


\begin{tabular}{|c|c|}
\hline $\mathrm{MO}$ & 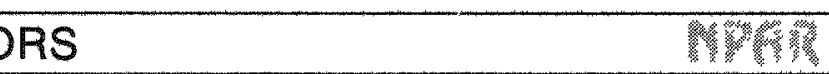 \\
\hline $\begin{array}{l}\text { DESIGN/TEST RECOMMENDATIONS } \\
\text { 1. Periodic surge tests or partial discharge } \\
\text { (corona) tests are conducted to monitor } \\
\text { age-related deterioration. } \\
\text { 2. Large motor operating hours are moni- } \\
\text { tored (elapsed time counter on } \\
\text { switchgear). } \\
\text { 3. Motor operating parameters are moni- } \\
\text { tored, recorded, and evaluated, when }\end{array}$ & $\begin{array}{l}\text { performing required surveillance testing } \\
\text { on pumps and valves. } \\
\text { 4. AC/DC leakage (hipot) testing is not } \\
\text { recommended. } \\
\text { 5. An engineering evaluation of baseline } \\
\text { readings for bearing vibration, motor } \\
\text { winding temperature, and rated current } \\
\text { values has been completed. }\end{array}$ \\
\hline
\end{tabular}




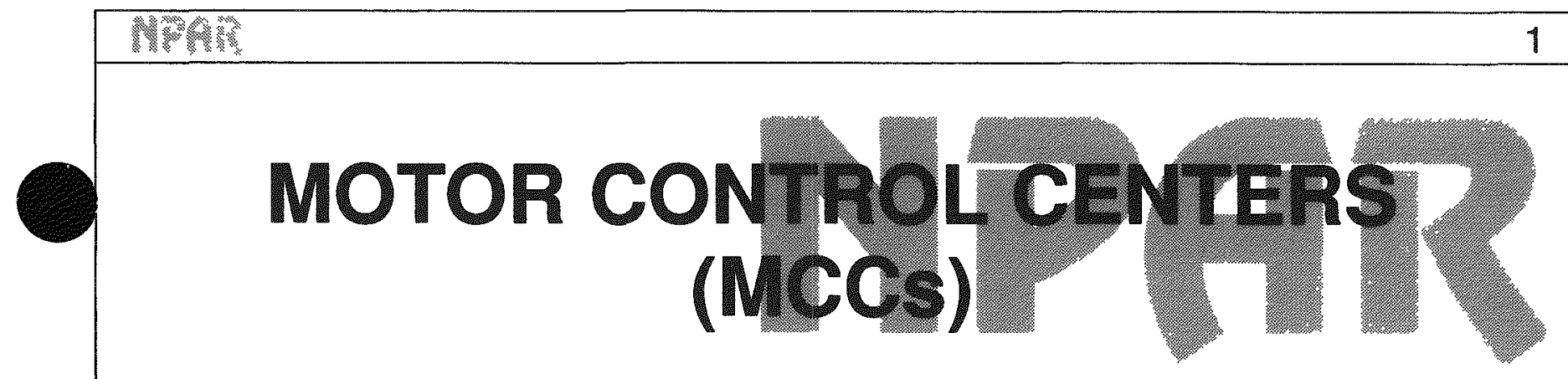

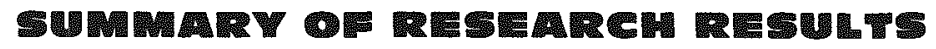

FUNGTONAL DESCRIPTIONBACKGROUND Motor Control Centers (MCCs) are low voltage (less than 600 volts) controllers that start and stop, provide continuous power to, and protect motors that drive pumps and motor operated valves. Typically, a motor controller unit consists of a molded case circuit breaker, a magnetic contactor, a transformer, relays and thermal overload devices. Age-related degradation of these subcomponents has impacted safety system availability and operation.

\section{BASED ON MPAR REPORT:}

1. NUREG/CR-5053, Operating Experience and Aging Assessment of Motor Control Centers, $7 / 88$.

\section{AGING RELATED ISSUES}

1. The most frequent cause of MCC failure was the buildup of dirt or other foreign substances that caused the electrical device to stick.

2. More failures occurred in systems that function intermittently rather than continuously.
3. The starter contactor may fail to close due to a non-uniform magnetic driving force caused by impeded armature motion.

4. Most age-related failures are attributed to the circuit breaker and relay subcomponents. Setpoint drift and contact surface degradation are two dominant failure modes.
OPERATIMG EXPERIENCE Operational data on nuclear plant components shows there have been significant failures of molded case circuit breakers, relays, and magnetic contactors used in MCCs. The combination of circuit breakers and relays contribute to about $50 \%$ of all reported MCC failures. Subcomponent contribution to MCC inoperability, along with the breakdown of the dominant failure modes, are illustrated.

\section{SUBCOMPONENT \\ Circuit Breaker}

Relays

\section{FAILURE MODE CONTRIBUTION}

Failed to close $-32 \%$

Tripped - $19 \%$

Would not operate - $17 \%$

Failed to open $-9 \%$

Failed to close $-23 \%$

Falled to open - $21 \%$

Would not operate - $19 \%$

Out of adjustment $-11 \%$ 


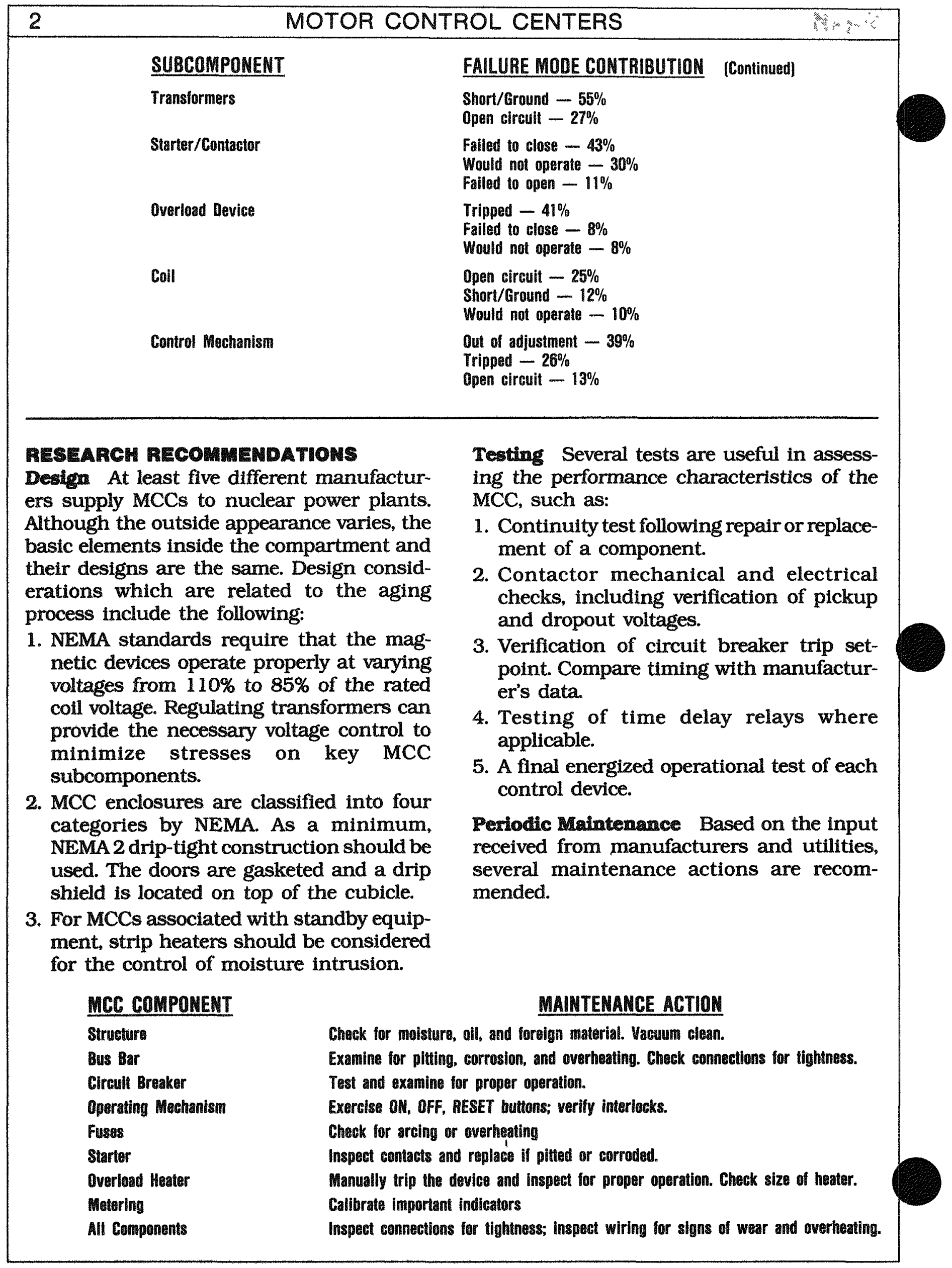




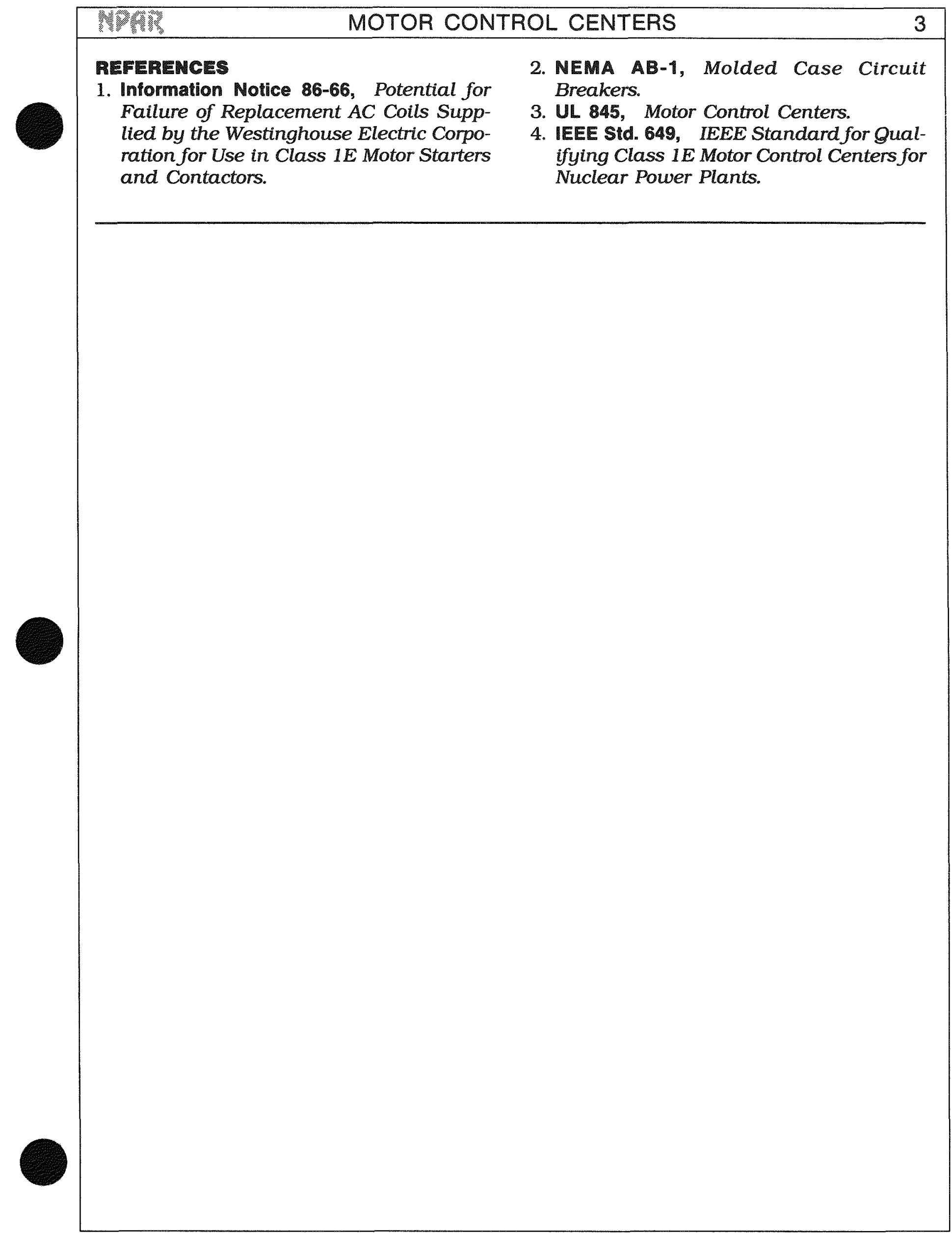



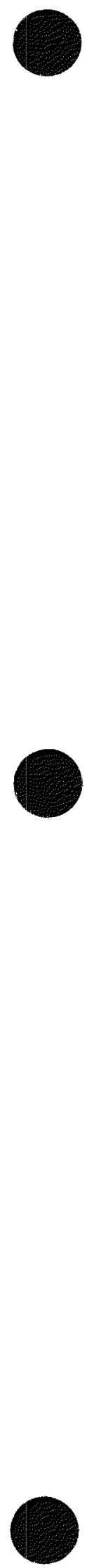


\section{AGING ASSESSMENT GUIDE MOTOR CONTROL CENTERS (MCCS)}

\section{Observations on the aging of MCCs}

- About 50\% of the MCC failures were due to circuit breakers and relays

- Most vendors recommend an annual maintenance interval for MCCs

- Buildup of dirt is the leading cause of MCC failure (sticking)
System Status At MCC Failure

Based on NPRDS 1974 to 1986

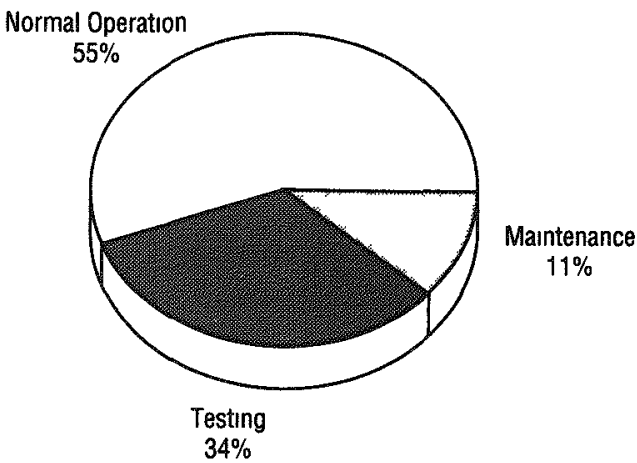

\section{RECOMMENDATIONS FOR INSPECTION}

\section{(Primarily Internal)}

1. There are no signs of overheating.

2. The MCC is clean, especially the contact surfaces.
3. There is no moisture, oil, and foreign material.

4. The cubicle is in an operable status.

\section{MAINTENANCE RECOMMENDATIONS}

1. A physical inspection of the MCC should be conducted periodically including:

a. check the terminal block condition and connection tightness.

b. check the condition of the mechanical linkages and electrical insulation.

c. check that there is no moisture, oil, and foreign material

d. examine contacts and fuses for pitting, corrosion, and signs of overheating.
2. Preventive maintenance should include the following activities:

a. calibration of metering and verification of the size of the overload heater.

b. exercise the operating mechanism, including the manual trip button.

c. an insulation test (megger) is recommended following the completion of maintenance.

d. check the pickup and dropout voltages to monitor deterioration of coils.

\section{DESIGN/TEST RECOMMEMDATIONS}

1. A cycle counter is useful for determining PM frequency. The wear on many parts is directly related to the number of operating cycles.

2. The trip setpoint of the circuit breaker should be checked at least every five years to minimize the effects of setpoint drift.
3. Because of the effect of the motor applications on the sizing of the overload heater, documentation should exist to support the selected value.

4. Compliance with the technical specifications at some plants requires that a functional test of $10 \%$ of the MCCs be conducted along with preventive maintenance on each MCC breaker every 5 years. Additional testing is required if a failure occurs. 


\section{OTHER RECOMMENDATIONS}

1. The daily logs or round sheets should include observations of MCC status and condition, especially those located in harsh environments. 


\section{0}

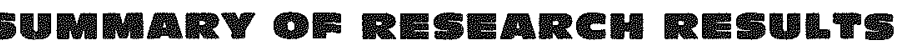

FUNCTIONAL DESCRIPTION/BACKGROUND Motor-operated valves (MOVs) are used extensively in nuclear power plants in safetyrelated and balance-of-plant systems. The most commonly used valve types are gate, globe, and butterfly valves. MOV failures have resulted in significant maintenance efforts and, on occasion, have compromised the operational readiness of critical safety-related systems. Several diagnostic monitoring systems have been developed specifically for detecting MOV aging and service wear effects (degradation), failures, and switch setting problems.

\section{BASED ON NPAR REPORTS:}

1. NUREG/CR-4234 Vol. 1, Aging and Service Wear of Electric Motor-Operated Valves Used in Engineered SafetyFeature Systems of Nuclear Power Plants, 6/85.
2. NUREG/CR-4234 Vol.2, Aging and Service Wear of Electric Motor-Operated Valves Used in Engineered SafetyFeature Systems of Nuclear Power Plants - Aging Assessments and Monitoring Method Evaluations, 8/89.
AGIMG RELATED ISSUES MOVS fail to perform their function according to five modes:

(1) Failure to open

(2) Failure to close

(3) Plugged (limited or no flow through a normally open valve)

(4) Reverse (internal) leakage

(5) External leakage

Several MOV sites are susceptible to agingrelated degradation. These sites and the corresponding aging mechanisms are:

\section{MOTOR OPERATOR GEARBOX ASSEM-} BLY: Gear wear; shaft wear, distortion; fastener loosening; stem nut wear; stem lock nut loosening; spring pack response change; drive sleeve wear; clutch mechanism wear; seal wear, deterioration; bearing wear, corrosion; lubricant degradation, hardening.
2. MOTOR OPERATOR SWITCHES: Contact pitting, corrosion; gear/cam wear; insulation (electrical) breakdown; fastener loosening; grease hardening.

3. ELECTRIC MOTOR ASSEMBLY: Bearing wear, corrosion; insulation (electrical) breakdown.

4. VALVE: Obturator wear, corrosion; obturator guide wear, corrosion; yoke bushing wear; valve stem wear, distortion; body erosion, corrosion; fastener loosening; valve seat wear, corrosion; bonnet seal deterioration; stem packing wear, deterioration.

MOVs are also known to be adversely affected by inappropriate maintenance such as incorrect stem packing tightness, incorrect switch settings (torque switch, limit switch, torque bypass switch), insufficient or excessive lubrication, incorrectly installed spring pack (e.g., incorrect pre-load, gap, etc.), and others. 


\begin{tabular}{|c|c|}
\hline MOTOR-OPE & TED VALVES \\
\hline $\begin{array}{l}\text { OPERATING EXPERIENCE Since 1980, } \\
\text { numerous NRC Information Notices and } \\
\text { Bulletins have been issued that identify MOV } \\
\text { problems and recommend courses of action } \\
\text { (see References). Bulletin 85-03 (issued } \\
\text { November 1985) and its supplement (issued } \\
\text { April 1988) recommend that utilities develop } \\
\text { and implement a program to ensure that } \\
\text { switch settings for MOVs in several specified } \\
\text { safety-related systems are selected, set, and } \\
\text { maintained so that the MOVs will operate } \\
\text { under design-basis conditions for the life of } \\
\text { the plant. }\end{array}$ & $\begin{array}{l}\text { In June, } 1989 \text {, the NRC issued Generic Letter } \\
\text { (GL) } 89-10 \text { "Safety-Related Motor-Operated } \\
\text { Valve Testing and Surveillance", which } \\
\text { supersedes the recommendations in Bulletin } \\
85-03 \text { and its supplement. GL } 89-10 \text { extends } \\
\text { the scope of Bulletin } 85-03 \text { to include all } \\
\text { safety-related MOVs as well as all position- } \\
\text { changeable MOVs in safety-related systems. } \\
\text { The GL includes the following list of } 33 \\
\text { common MOV misadjustments, and de- } \\
\text { graded conditions discovered by utilities } \\
\text { from their experiences, including their } \\
\text { efforts to comply with Bulletin 85-03. }\end{array}$ \\
\hline
\end{tabular}

\section{SUMMARY OF COMMON MOTOR-OPERATED VALVE DEFICIENCIES, MISADJUSTMENTS, AND DEGRADED CONDITIOHS (FROM NRC GENERIC LETTER 89-10)}

\author{
1. Incorrecl torque switch bypass setting \\ 2. Incorrect torque switch setting \\ 3. Unbalanced torque switch \\ 4. Spring pack gap or incorrect spring pack preload \\ 5. Incorrect stem packing tightness \\ 6. Excessive inertia \\ 7. Lonse or tight stem-nut locknut \\ 8. Ineorrect limit switch settings \\ g. Stem wear \\ 10. Bent ar broken stem \\ 11. Worn or broken gears \\ 12. Grease problems (hardening, migration into spring pack, lack of \\ grease, excessive grease, contamination, non-specified grease] \\ 13. Motor insulation or rotor degradation \\ 14. Ineorrect wire size or degraded wiring \\ 15. Disk/seat binding fincludes thermal binding) \\ 16. Water in internal parts or deterioration therefrom \\ 17. Motor undersized ffor degraded voltage conditions or other conditions]
}

18. Incorrect valve position indication

19. Misadjustment or failure of handwheel declutch mechanism

20. Relay problems fincorrect relays, dirt in relays, deteriorated relays, miswired relays)

21. Incorrect thermal overload switch settings

22. Worn or broken bearings

23. Broken or cracked limit switch and torque switch components

24. Missing or modified torque switch limiter plate

25. Improperly sized actuators

26. Hydraulic lockup

27. Incorrect metallic materials for gears, keys, bolts, shafts, etc.

28. Degraded voltage (within design basis]

29. Defective motor control legic

30. Excessive seating or backseating force application

31. Incorrect reassembly or adjustment after maintenance and/or testing 32. Unauthorized modifications or adjustments

33. Torque switch or limit switch binding

\section{RESEARCH RECOMMENDATIONS}

Disassembly and Inspection Disassembly and inspection provides adequate information with regards to valve and motor operator condition; however, there are a number of discouraging aspects associated with this approach. These include, for example, scheduling additional maintenance work during already busy outages and accounting for additional radiation exposure to maintenance personnel. The need to improve the knowledge of MOV operating condition without requiring disassembly led to the development of several MOV diagnostic techniques.

Available Monitoring Methods The issuance of Bulletin 85-03, its supplement, and
GL 89-10 has accelerated the development and commercialization of MOV monitoring systems. Several of these systems have recently been modified in order to provide specific capabilities needed to resolve GL 8910.

MOV monitoring systems operate by making measurements of one or more MOV parameters and providing graphical displays (signatures) for manual and/or automated analyses. These signatures provide detailed quantitative information related to the condition of the motor, motor operator, and valve across a wide range of levels including:

- mean values

- gross variations during a valve stroke

- short time duration events (transients)

- periodic events 
MOV monitoring systems have primarily been used thus far to assist maintenance personnel in setting MOV switches properly; however, they also provide information useful in assessing MOV aging and service wear. The sensitivity and selectivity available from these systems provide the capability to identify both the type and location of an MOV problem so that corrective actions can be carried out quickly and efficiently.

These systems generally monitor one or more of the following parameters:

- Valve stem position, torque, and thrust

- Spring pack displacment

- Time of actuation of all control switches

- Motor current, voltage, and power

- Actuator vibration

- Actuator output torque

While many of the commercially available MOV diagnostic systems monitor similar parameters (e.g., motor current, spring pack displacement, etc.), they utilize different transducers and signal conditioning equipment and provide varying levels of signature analysis (interpretation).

Only one MOV measurable parameter, motor current, is monitored by all commercial systems. Motor current monitoring may be performed remotely and nonintrusively and provides much information related to the condition of the motor, operator, and valve (although the level of information extracted from MOV motor current signals varies from system to system).

Valve stem thrust is also commonly monitored. Most systems employ sensors that either monitor stem thrust (stem strain) directly or monitor the reaction forces in other structures (e.g., yoke, bolts, etc.). Stem thrust monitoring using one of these techniques is generally more accurate than an indirect method such as deriving stem thrust from other measurements since the relationship between stem thrust and other measurable parameters (such as spring pack displacement, motor current, etc.) can vary over time due to changes in lubrication, gear mesh friction, etc.

Since each MOV measurable parameter provides different (and complementary) information, the simultaneous monitoring of more than one of these parameters can provide additional diagnostic details unavailable from any one measurement. For example, an unusually high running current may indicate inceased running loads, although the precise source of the increase may be difficult to determine from motor current measurements alone. A simultaneously observed increase in stem thrust would suggest that the increase in running load was due to the valve (e.g., from increased packing tightness or from increased rubbing within the valve) rather than from within the motor operator. Conversely, if stem thrust levels are normal, increased friction from gears, bearings, etc. within the motor operator may be the cause. In that regard, the MOV diagnostics provided by these commercial systems are strongly based on concurrent analyses of several signatures.

These systems can be used effectively to respond to most of the deficiencies, misadjustments, and degraded conditions listed in GL 89-10. The diagnostic accuracy of these systems, however, are all dependent (in varying degrees) on the skill of the person using the system. It is likely that a few of the deficient conditions listed in GL 89-10 will be detected only by on-site inspections (in some cases involving disassembly). Such conditions include: "grease problems", "water in internal parts", "incorrect valve position indication", "broken or cracked switch components", and "incorrect metallic materials", except in those cases where these deficiencies adversely affect one or more of the parameters monitored by these systems. The MOV monitoring systems now available should be useful in resolving MOV issues that concern the NRC and the nuclear industry. The last few years have seen a dramatic increase in the number of systems available and in their capabilities. With their continued use and development, the ability to identify and quantify MOV aging and service wear effect will improve. These systems not only provide the utilities a means of determining MOV operability, but offer the tools necessary for carrying out predictive maintenance. 


\section{REFERENCES}

1. Information Notice 79-03, Limitorque Valve Geared Limit Switch Lubricant'

2. Information Notice 81-08, Repetitive Failure of Limitorque Operator Motor-toShaft Keys.

3. Information Notice 82-10, Follow-Up Symptomatic Repairs to Assure Resolution of the Operator Problems.

4. Information Notice 83-02, Limitorque $H O B C, H 1 B C, H 2 B C$, and H3BC Gearheads.

5. Information Notice 83-46, CommonMode Valve Failures Degrade Surry's Recirculation Spray Subsystem.

6. Information Notice 83-53, Primary Containment Isolation Valve Discrepancies.

7. Information Notice 83-55, Misapplication of Valves by Throttling Beyond Design Range.

8. Information Notice 83-70, VibrationInduced Valve Failures. (Also 83-70 Supplement 1)

9. Information Notice 84-10, MotorOperated Valve Torque Switches Set Below the Manufacturer's Recommended Value.

10. Information Notice 84-13, Potential Deficiency in Motor-Operated Valve Control Circuits and Annunciation.

11. Information Notice 84-36, Loosening of Locking Nut on Limitorque Operator.

12. Information Notice 84-48, Failure of Rockwell International Globe Valves. (Also 84-48 Supplement 1)

13. Information Notice 85-20, Motor-Operated Valve Failures Due to Hammering Effect. (Also 85-20 Supplement 1)

14. Information Notice 85-22, Failure of Limitorque Motor-Operated Valves Resulting From Incorrect Installation of Pinion Gear.

15. Information Notice 85-59, Valve Stem Corrosion Failures.

16. Information Notice 85-67, Valve Shaft to Actuator Key May Fall Out of Place When Mounted Below Horizontal Axis.

17. Information Notice 86-02; Failure of Valve Operator Motor During Environmental Qualification Testing.
18. Information Notice 86-03, Potential Deficiencies in Environmental Qualification of Limitorque Motor Valve Operator Wiring.

19. Information Notice 86-11, Inadequate Service Water Protection Against Core Melt Frequency.

20. Information Notice 86-29, Effects of Changing Motor-Operator Switch Settings.

21. Information Notice 86-71, Recent Identified Problems with Limitorque Motor Operators.

22. Information Notice 86-93, IEB 85-03 Evaluation of Motor Operator Identifies Improper Torque Switch Settings.

23. Information Notice 87-08, Degraded Motor Leads in Limitorque Motor Operators.

24. Information Notice 87-40, Backseating Valves Routinely to Prevent Packing Leakage.

25. Information Notice 88-72, Inadequacies in design of dc motor-operated valves.

26. Information Notice 89-11, Failure of $d c$ motor-operated valves to develop rated torque because of improper cable sizing.

27. Information Notice 89-88, Recent NRCsponsored testing of motor-operated valves.

28. Information Notice 90-21, Potential failure of motor-operated butterfly valves to operate because valve seat friction was underestimated.

29. Information Notice 90-40, Results of NRC-sponsored testing of motoroperated valves.

30. NRC Bulletin 81-02, Failure of Gate Type Valves to Close Against Differential Pressure. (Also 81-02 Supplement 1)

31. NRC Bulletin 85-03, Motor-Operated Valve Common Mode Failures During Plant Transients Due to Improper Switch Settings. (Also 85-03 Supplement 1)

32. Generic Letter 89-10, Safety-Related Motor-Operated Valve Testing and Surveillance. 


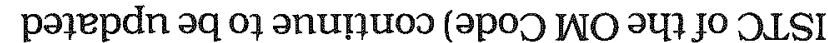

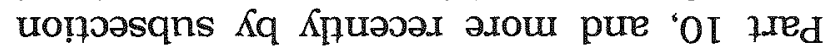

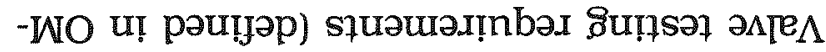

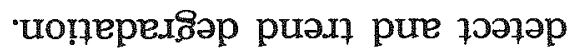

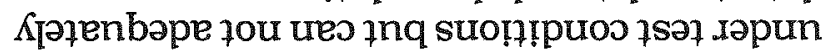

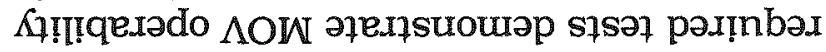

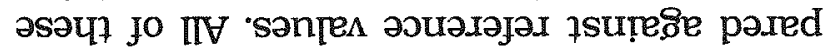

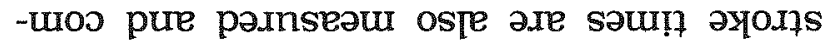

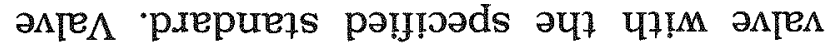

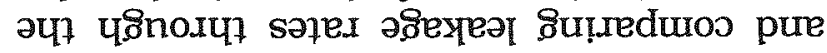

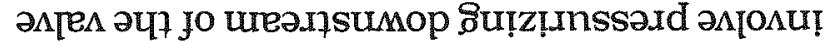

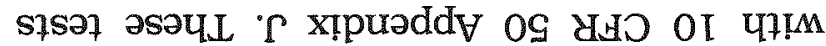

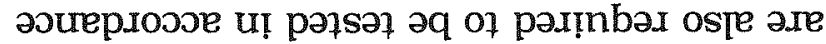

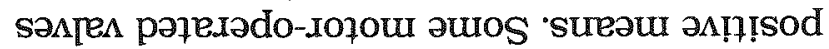

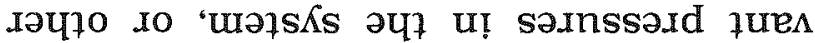

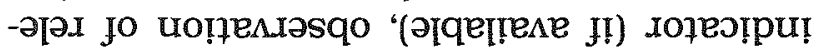

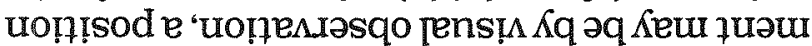

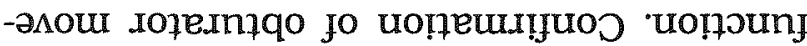

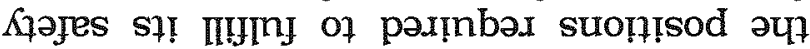

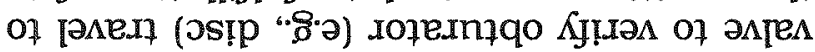

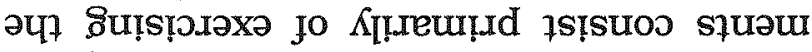

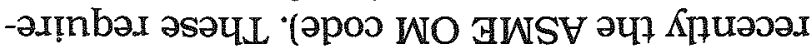

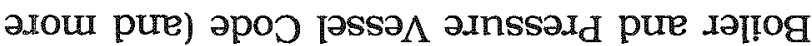

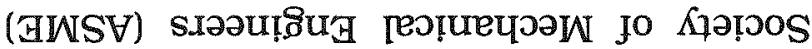

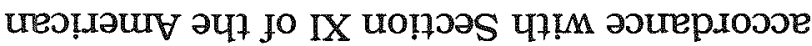



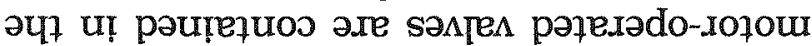

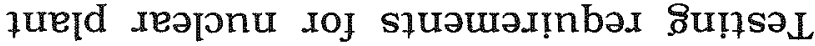
ฐุธวป pammbay

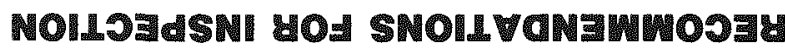

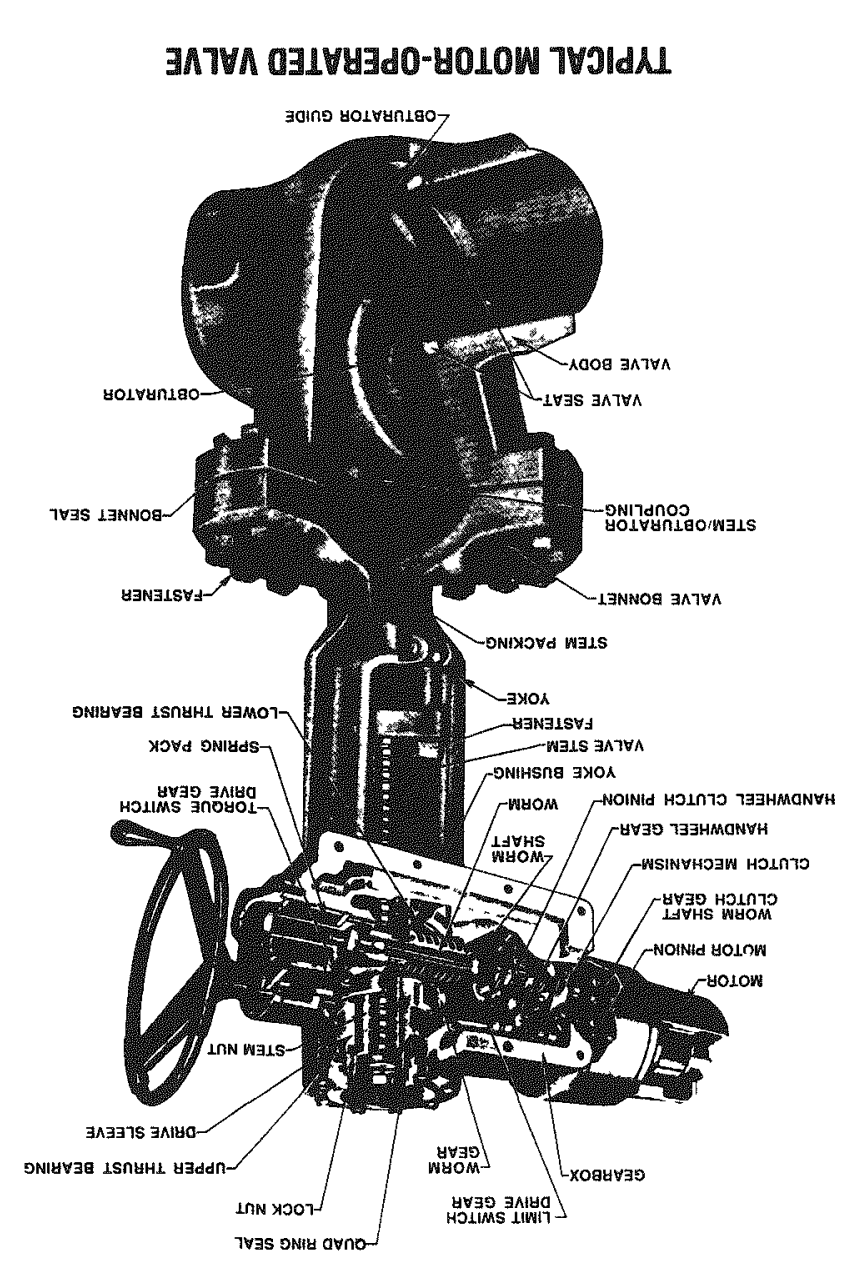

'sıачро puto '('о7а

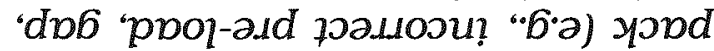
Gunds pallopsu! fpoadoou! 'uo!l -poulqni anissaoxa do łua!onghsu!

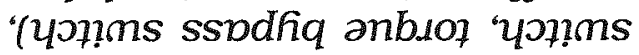
71un 'uon!ms anbio7) s6umpas yonms

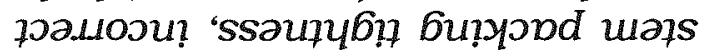
poa.uoou! sp yons asupuapu?pu appludouddou! fiq pąวaffo fipas - 1 anpo aq of umouY osip alD s

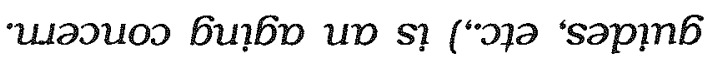
'slopounqo 'saypinms 's6ulnoaq 's.pa6 "6'a) sqipd ppuapu? anๆpa pup sopplado dopou fo (uolsollos pup 'uo!sola 'snam) uompppıbad -

SanIEn poredodomionou 10

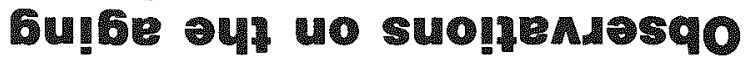

\section{S $\exists \wedge 7 \forall \wedge$ a $\exists \perp \forall y \exists d 0-40 \perp O W$}

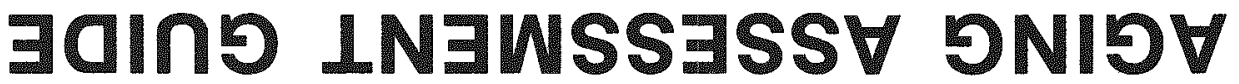


as valve operational characteristics are better understood. The OM-10 working group is currently addressing several potential technical changes in these requirements including acceptance criteria and trending of test results. The ASME is developing OM-Part 8 to provide guidance for the proper performance of valve actuators. In addition, a MOV maintenance "good practices" document was prepared by the Institute of Electrical and Electronics Engineers (IEEE), working group 3.3.

Operating Parameters Routinely Observed Routinely observed parameters, in the past, have been those that were required to be monitored such as stroke times, valve obturator position, and internal leakage (through a closed valve). Recent NRC Infor- mation Notices, Bulletins, and Generic Letters have led to a more comprehensive list of monitored parameters, such as valve stem thrust, motor current, spring pack deflection. etc., that are obtainable through the use of monitoring systems outlined in the NPAR SUMMARY OF RESEARCH RESULTS.

\section{External Indicators or Causes of Age Degradation}

1. Corrosion of valve body

2. Loosening of fasteners (e.g., bonnet bolts, operator upper thrust plate, packing gland, ...)

3. Seal and packing gland wear or deterioration (resulting in external leakage of grease or process fluid)

4. Valve stem wear, distortion

\section{MAINTENANCE RECOMMENDATIONS}

During scheduled downtime, continue to perform periodic surveillance testing using available diagnostic systems. Continue disassembly and inspection of critical MOVs until an acceptable correlation can be made between diagnostic testing results and actual valve degradations. Once this correlation is established, disassembly and inspection intervals may be determined based on the results of diagnostic testing. Disassembly and inspection should include examination of valve internal parts for wear, erosion, corrosion, cracking, loosening, tightening, etc., especially those deficiences, misadjustments, and degraded conditions outlined in GL 89-10. Parts showing significant signs of aging or service wear should be replaced as necessary.

\section{OPERATIONS RECOMMENDATIONS}

1. Since MOVs are generally designed for intermittent use, the number of consecutive valve actuations should be minimized in order to reduce the chance of motor overheating.
2. Over-tightening the stem packing gland bolts (e.g., in order to stop an external fluid leak) should be avoided. The use of "cheater bars" to assist manual valve closures should be discouraged.

\section{DESIGN/TEST RECOMMENDATIONS}

Continued periodic use of diagnostic monitoring techniques is recommended. When possible, data from more than one valve actuation should be recorded and examined for reproducibility. Selected diagnostic signature features obtained from these tests should be quantified and recorded for subsequent comparisions with actual service wear. 


\section{POWER-OPERATED RELIEF VALVES (PORVS) AND BLOCK VALVES

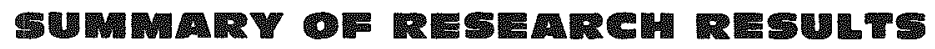

FURCTIONAL DESCRIPTION/BACKGROUND The TMI-2 accident focused attention on the reliability of PORVs and block valves - the malfunction of the PORV at TMI-2 contributed to the severity of the accident. On numerous occasions, as reported in NUREG/CR-4692,
PORVs have stuck open when these valves were called upon to function during plant operation. Also, there are PORVs in many operating plants with leakage problems so that the plants must be operated with the upstream block valves in the closed position.

\section{BASED ON MPAR REPORT:}

1. NUREG/CR-4692, Operating Experience Review of Failures of Power Operated Relief Valves and Block Valves in Nuclear Power Plants, 10/87.

AGIMG RELATED ISSUES Most PORV mechanical failures are caused by highpressure steam/water cutting the valve seat/ plug interface, eventually leading to leakage. Other problems for PORVs include packing leakage from aging, heat, and pressure and galling of moving parts. Internal leakage is the most common PORV mechanical failure mode. This is leakage through the valve seat into the valve outlet tailpipe.

For PORV controls, degradation of the air or electrical actuation controls prevents operation of the PORV when required.
OPERATING EXPERIENCE A survey of nuclear plant operating experience for PORV and $\mathrm{BV}$ failures yielded 230 events occurring from 1971 to mid-1986, including PORV, PORV BVs, and their associated controls. 101 events involved mechanical failure or degradation of the PORV; 91 events were attributable to the PORV controls. Six events involved the design or fabrication of PORVs. Although the root cause of the majority of the identified failures could not be determined, the proximate cause appeared to be wear, galling, or steam/water cutting of the valve disk and seat. The' Dresser/Crosby type PORV design accounted for $45 \%$ of the PORV mechanical failure events. The close tolerances and greater number of moving parts exposed to steam in these designs can make them susceptible to failure.

The air-operated (spring-closure) type PORV designs appeared less susceptible to catastrophic (stuck-open) failure than the pilotoperated relief design. However, a substantial number of events (over $70 \%$ ) describing failed or degraded PORV controls involved problems with the air/nitrogen control components required to operate the air-operated (spring-closure) PORV. Seventy-six percent of the PORV mechanical failures surveyed in the report were judged as degraded. Operator and 
maintenance errors were involved in only $18 \%$ (41) of the events; of these, 6 events were drawing or administrative error, and 25 were mechanical or electrical maintenance mistakes.
RESEARCH RECOMMENDATIONS PORVS (and block valves) could be included in an operational quality assurance program that is in compliance with 10 CFR Part 50, Appendix B. Periodic testing in accordance with Subsection IWV of Section XI of the ASME Code could effect a reduction in PORV failures. Additionally, advanced diagnostic techniques could be applied to better monitor PORV condition.
Based on a review of failure events, the greatest safety benefit could be achieved by using PORV designs that are resistant to sticking open. A new PORV design from Target Rock and improvements incorporated in a new Crosby/Garrett design may provide higher reliability, but neither has been in service long enough to provide long-term operating experience.

\section{REFERENCES}

1. EPRI NP-2292, PWR Safety and Relief Valve Test Program Valve Selection/ Justification Report.

2. NUREG/CR-4999, Estimation of Risk Reduction from Improved PORV Reliability in PWRs.
3. NUREG-1316, Technical Findings and Regulatory Analysis Related to Generic Issue 70. 


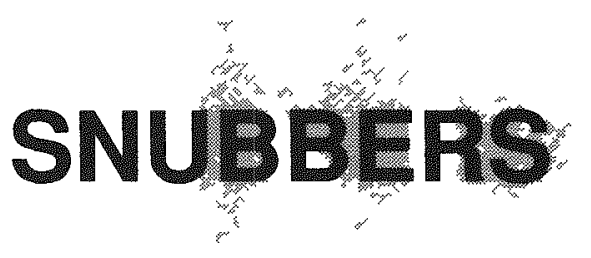

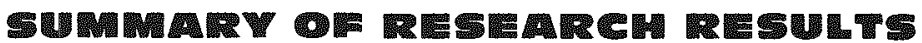

FUNCTIONAL DESCRIPTIONBBACKGROUND Snubbers, both hydraulic and mechanical, provide restraint of undesirable dynamic loads on piping and equipment in nuclear power plants (NPPs), while allowing free thermal motion under normal operating conditions. Snubbers are subject to agerelated degradation that can adversely effect their performance in both the dynamic and passive modes. Maintenance and service-life monitoring guidelines have been developed that are useful to manage the effects of aging in snubbers.
The incidence of snubber failures has been moderated through the use of statistically based testing and examination plans specified in plant technical specifications. Although in-service inspection (ISI) requirements still exist, service-life monitoring programs have minimized the number of aging-related failures by ensuring that snubbers are repaired, refurbished, or replaced through conscientious maintenance procedures.

\section{BASED ON MPAR REPORTS:}

1. NUREG/CR-4279, Aging and Service Wear of Hydraulic and Mechanical Snubbers Used on Safety Related Piping and Components of Nuclear Powr Plants, $2 / 86$.
2. NUREG/CR-5386, Basis for Snubber Aging Research: Nuclear Plant Aging Research Program, 1/90.
ACING RELATED ISSUES Snubbers are subject to a number of age-related degradation modes that depend on both environmental influences and degradation mechanisms indigenous to the snubber design. The most common environmental influences on snubber degradation modes are:

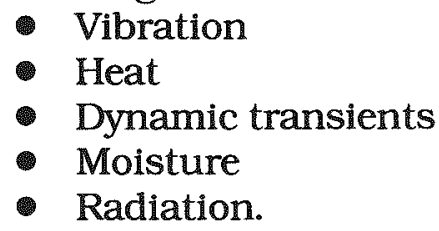

Some of these degradation mechanisms are being addressed by improved snubber design and materials.

For mechanical snubbers, deformation of parts, wear, fretting, corrosion of internal parts, and solidification of lubricants are some of the more common degradation mechanisms. Such degradation can result in increased resistance to movement or jamming in the passive mode (the most frequent failure mode for mechanical snubbers). The snubber activation threshold can also be changed.

The primary degradation mechanism for hydraulic snubbers is the gradual relaxation of low pressure sealing force. This relaxation can lead to loss of hydraulic fluid, resulting in failure to function in the active mode (the primary failure mode for hydraulic snubbers). Another concern for hydraulic snubbers is degradation of the hydraulic fluid affecting the snubber's control valve preformance in both the active and passive modes. 
Wear and fretting caused by vibration can lead to loosening of fastners and an increase in clearances between mating parts for both hydraulic and mechanical snubbers.
OPERATING EXPERIENCE Based on a review of service data for typical plants, roughly $50 \%$ of all snubber failures have been caused by age-related influences. A primary contributor to non-age-related failures has been maintenance errors.

Vibration and heat are the dominant environmental influences resulting in aging degradation. The effects of radiation on snubber service is significantly less than was originally anticipated in early stages of NPP design.

The majority of failures for both hydraulic and mechanical snubbers occurred in the early stages of plant operation. There were a number of contributors to these early failures, including incompatibility with the operating environment, damage during construction, and restrictive acceptance criteria. For most plants, the incidence of snubber failures has significantly decreased since the first one or two operating cycles. The level of age-related degradation in snubbers varies from plant to plant; this is most likely due to variations in snubber designs, materials, and operating environments.

Service data made available through NPAR research, including data provided by the Snubber Utility Group (SNUG), indicates an average visual examination failure rate of $1 \%$, and an average functional test failure rate between $7 \%$ and $10 \%$. These rates apply to both mechanical and hydraulic snubbers.

Hydraulic Snubbers Manufacturers' recommendations for service life for hydraulic snubbers have generally been conservative ( 10 to 20 years). With the exception of isolated cases where snubbers are subjected to severe operating environments, such as excessive heat, seal degradation in hydraulic snubbers has been minimal for most plants. In contrast to mechanical snubbers, the propensity for drag force in hydraulic snubbers to increase in service is low. There are some indications that long-term degradation of hydraulic snubber seals is retarded by their immersion in the silicone hydraulic fluid. Continuous high amplitude vibration can result in fluid gelation in hydraulic snubbers; this can affect control valve performance.

Mechanical Snubbers The forty-year service life initially projected by manufacturers of mechanical snubbers, on the other hand, may be somewhat unrealistic. Recent operating data indicate that mechanical snubbers can degrade with time in even moderate operating environments. The smaller mechanical snubbers appear to be most prone to failure. Snubbers used on small piping branches that are attached to larger pipes or components are particularly vulnerable.
RESEARCH RECOMMENDATIONS In general, degradation of snubbers in severe operating environments should be monitored by surveillance and maintenance methods. Comprehensive root cause evaluations of snubber failures can also provide valuable information to reduce failures. Identifying snubber failure mechanisms may require disassembling the snubber and inspecting its parts. Diagnostic tests using variations in test parameters may also be helpful to identify the failure mechanism.
Hand stroking is a useful method for evaluating snubbers for freedom of movement. This is particularly useful for evaluating snubbers suspected of exposure to high dynamic loads. Another method that is useful in this regard is rotation of the snubbers about their spherical bearings.

Long term degradation of snubbers in moderate operating environments can be minimized by monitoring representative snubber samples exposed to that environ- 


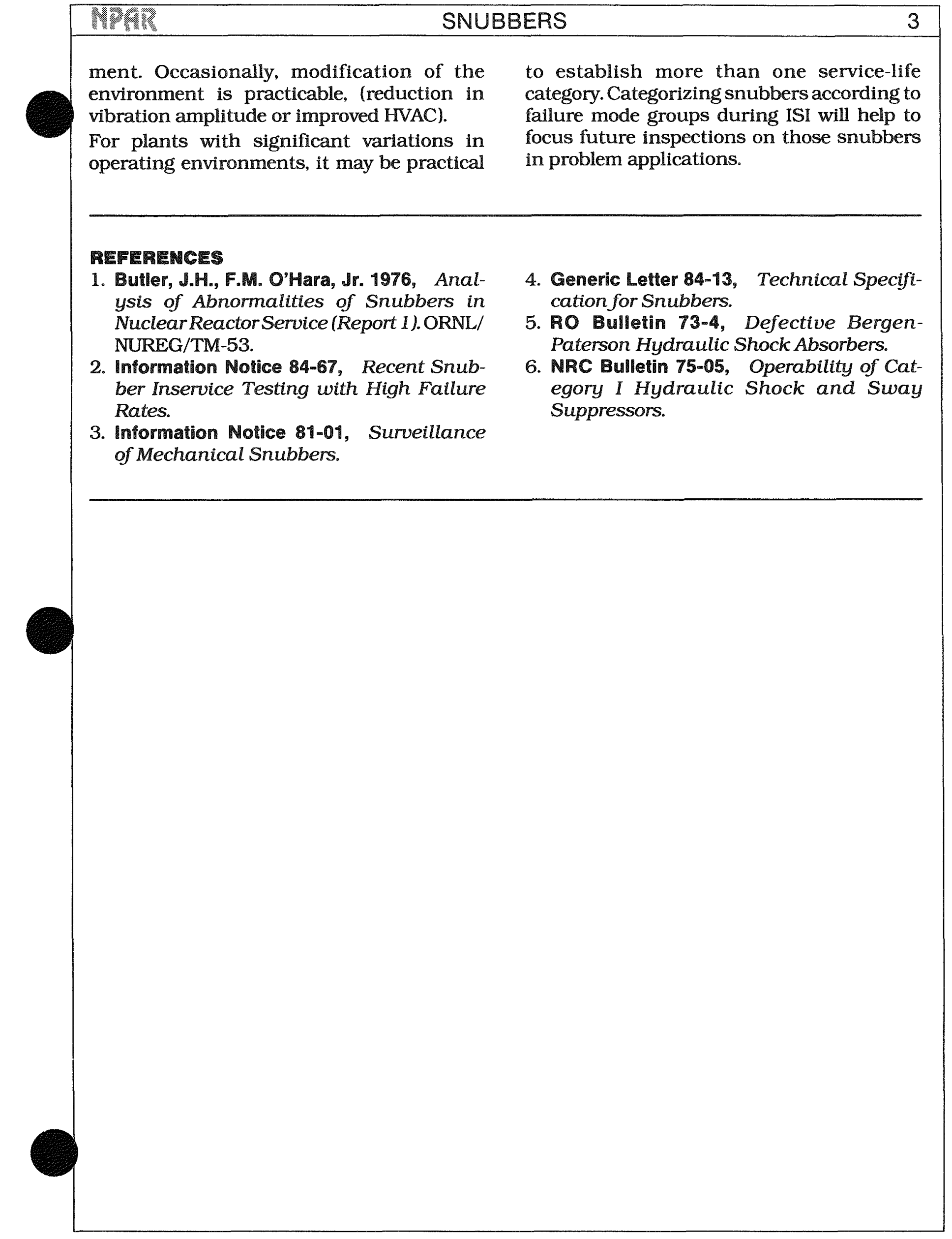


-
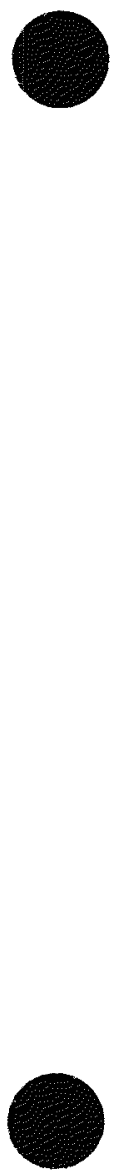


\section{AGING ASSESSMENT GUIDE SNUBBERS}

\section{Observations on the aging of snubbers}

- Roughly $50 \%$ of all snubber failures are aging-related.

- Snubber degradation due to the service environment can be sudden or gradual.

- Snubber availability can be optimized by concentrating inspection and preventive maintenance activities on those snubbers exposed to severe operating environments.

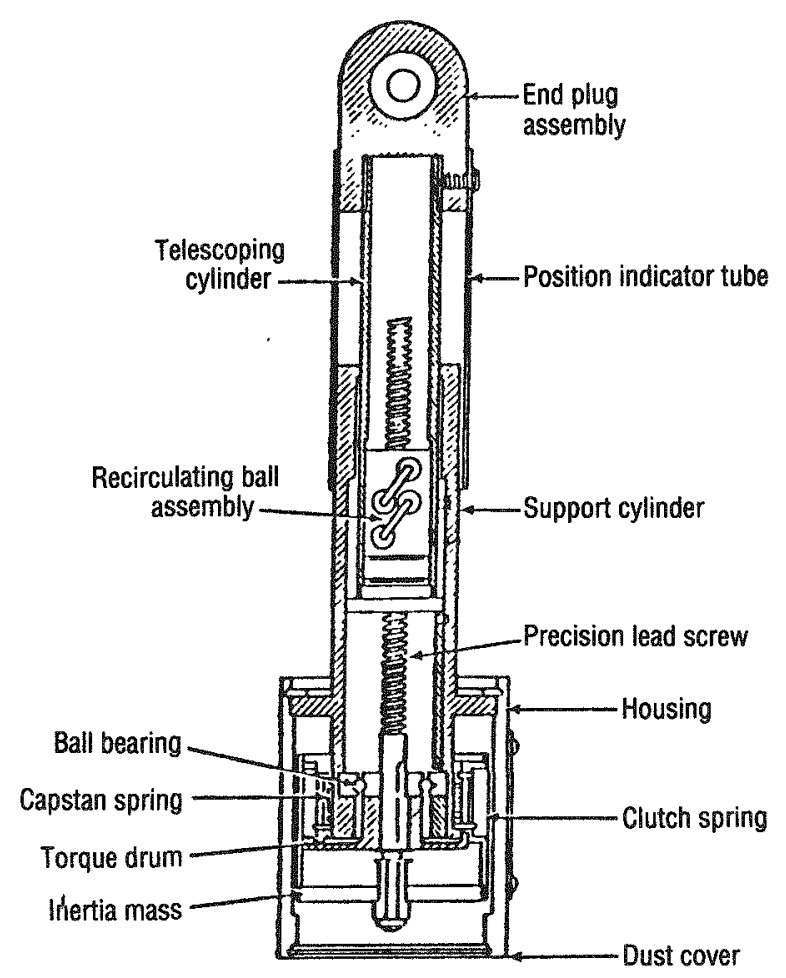

TYPICAL MECHANICAL SNUBBER

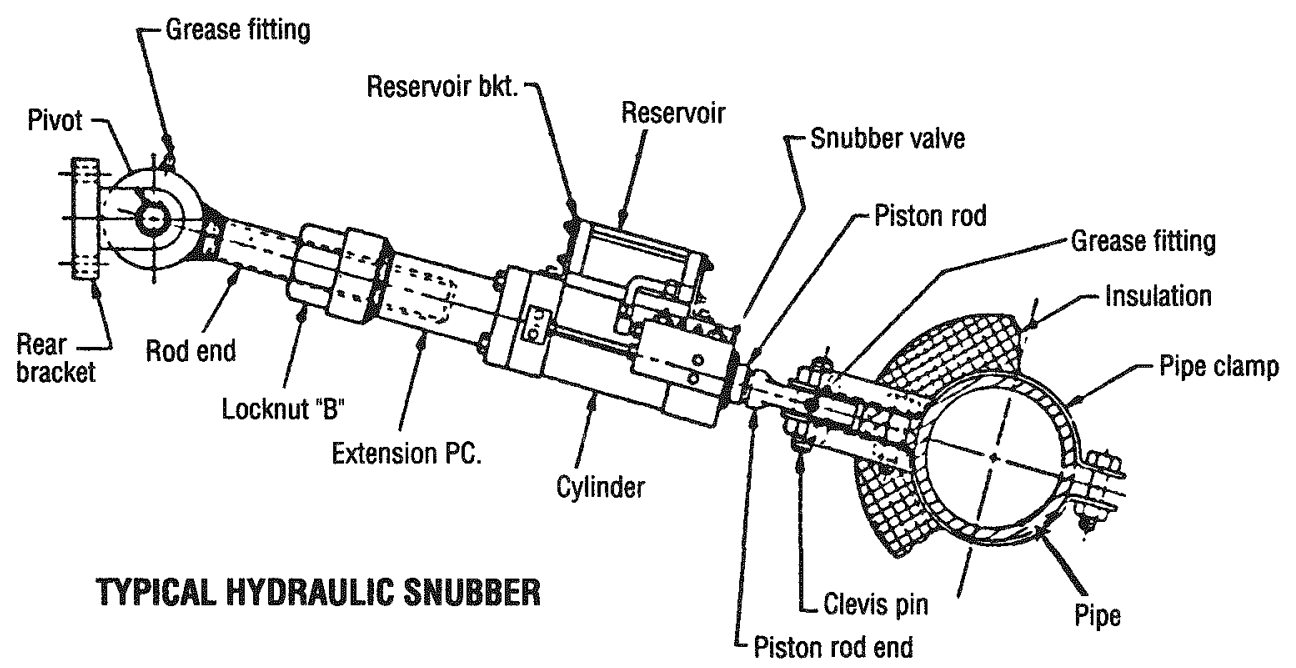

\section{RECOMMENDATIONS FOR INSPECTION}

1. Visual examination is more useful for monitoring age-related degradation in hydraulic snubbers than for mechanical snubbers.
2. Visual examination attributes indicating age-related degradation in hydraulic snubbers include:
a. reservoir fluid level
b. evidence of fluid leakage 


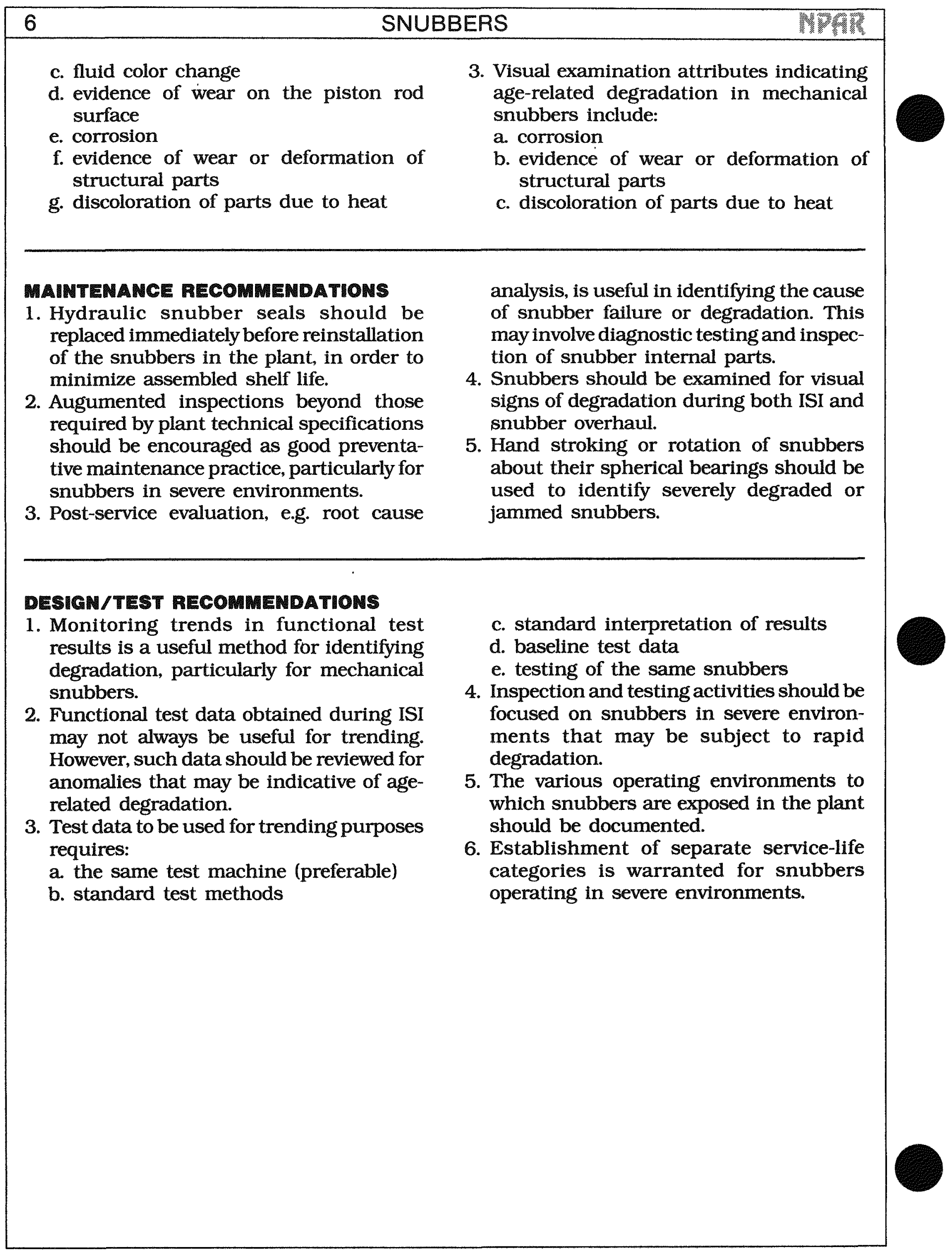




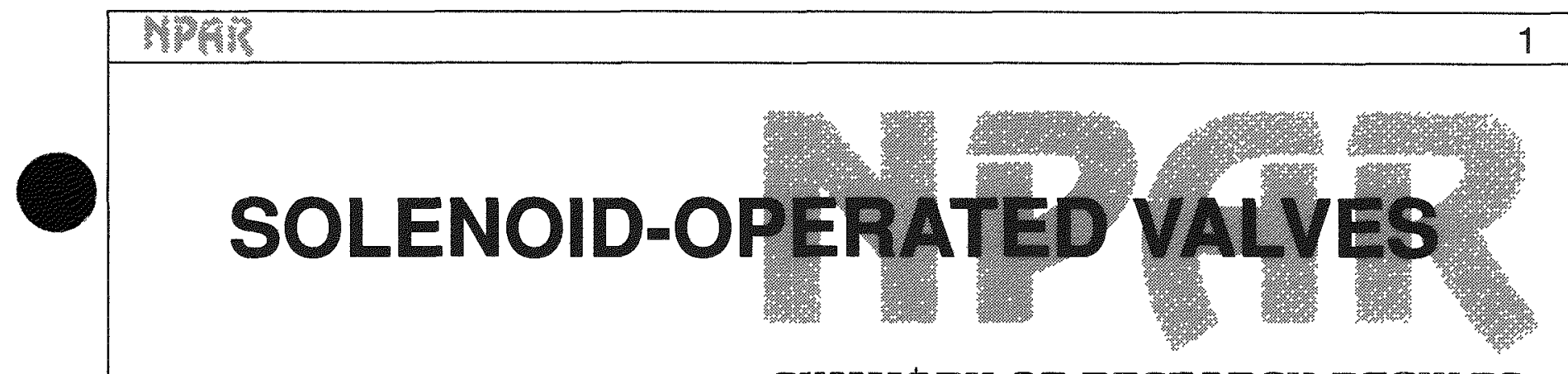

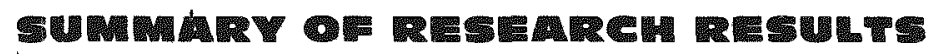

FUMCTIONAL DESCRIPTION/BACKGROUND Solenoid-operated valves (SOVs) are used by the thousands throughout nuclear power plants, often being subcomponents of safetyrelated systems such as containment isolation valve actuators, BWR control rod scram systems, and PWR safety injection systems. Though relatively simple and robust devices, their presence in systems important to safely requires an especially high degree of assur- ance that they are ready to perform their required function under all anticipated plant conditions. Evaluation of SOV performance in the nuclear industry and laboratory study of SOV electromechanical properties have identified elements for an effective maintenance program comprised of careful inspections, periodic replacement of limited-life components, and special condition-revealing in-place tests.

\section{BASED ON NPAR REPORTS:}

1. NUREG/CR-5141, Aging and Qualification Research on Solenoid Operated Valves, $8 / 88$.

2. NUREG/CR-4819, Vol. 1, Aging and Service Wear of Solenoid-Operated Valves Used in Safety Systems of Nuclear Power Plants: Operating Experience and Failure Identification, 3/87.
3. NUREG/CR-4819, Vol. 2, Aging and Service Wear of Solenoid-Operated Valves Used in Safety Systems of Nuclear Power Plants: Monitoring Methods Evaluation, in preparation.
AGIMG RELATED ISSUES Operating experience shows that SOV malfunctions have been caused both by electrical deterioration of the solenoid coil and its leadwires and by mechanical, chemical, and radiation degradation of certain valve internal parts.

1. INSULATING MATERIAL: Dielectric strength of the polymer insulation surrounding individual copper wires comprising the solenoid coil is lost when material properties change as a result of excessive exposure to radiation (mostly gamma, but for some equipment locations neutrons may also be important), prolonged operation at high temperatures (elevated ambient temperature; excessive self heating due to restricted air flow), or moisture intrusion (from dripping water or a nearby steam leak).

2. ELASTOMERIC COMPONENTS: O-rings, diaphragms, gaskets and seals, and molded core seats are susceptible to chemical attack (by petroleum-based lubricants, for example) and have limited tolerance for nuclear radiation or for prolonged operation at high temperatures. Continued exposure to such stressors will result in material damage that may be manifested as swelling, cracking, loss of tensile strength and elasticity, 
stickiness, or a tendency of the elastomer to take a permanent set under compression.

3. METALLIC COMPONENTS: Valve internal parts such as the core and core return spring, core tube and guide, and the discholder subassembly are subject to frictional mechanical wear and to metal fatigue cracking, although these mecha- nisms are likely to be important contributors to SOV malfunctioning only for valves that are continually cycled.

High-cycle metal fatigue at the valve orifice may also occur in valves designed to close at high differential pressure, since these will be equipped with a strong core return spring.
OPERATING EXPERIENCE Estimated SOV failure rates, compiled from several sources, are listed in the accompanying table, which does not distinguish among size, energization mode ( $\mathrm{dc}$ or ac), valve opening status (NO, NC), manufacturer, model, or type of construction of the SOVs. It is seen that recent (1985-89) NPRDS-reported failure experience, combined with a demand figure based on quarterly testing requirements, indicates an experimental failure rate that is about 8 times greater than earlier estimates developed using WASH-1400 and NUREG1150 methodologies. Likewise, the failure rate estimated for the period 1985-89 appears to be 100 times greater than had been estimated in another study for the period 1978-84, but this difference could be due to the use of different data screening criteria and therefore may not be significant.

It must be noted that the NPRDS failure records include only failures of the SOVs themselves, not failures of NPRDS-reportable components that are, in fact, attributable to malperformance of unrecognized SOVs present within the reportable component or system. However, it is true that only some unestimated fraction of the SOV failures reported to NPRDS are aging-related.

ESTIMATES OF SOV FAILURES TO OPERATE (from NUREG-1275, Vol. 6)

\begin{tabular}{|c|c|}
\hline SOURCE & $\begin{array}{l}\text { ESTIMATED } \\
\text { FAILURE RATE }\end{array}$ \\
\hline $\begin{array}{l}\text { WASH-1400 } \\
\text { (Tables III 2-1, 2-2) }\end{array}$ & $1 \times 10.3 /$ demand \\
\hline $\begin{array}{l}\text { NUREG-1275, Vol.6, } \\
\text { assuming quarterly testing }\end{array}$ & 7.1 to $8.7 \times 10^{-3} /$ demand \\
\hline $\begin{array}{l}\text { NUREG-1150 } \\
\text { mathodology NUREG/CR-4550, } \\
\text { Vol. } 1\end{array}$ & $1.0 \times 10^{-3} /$ demand \\
\hline Seabrook PRA & $2.4 \times 10^{-3} /$ demand \\
\hline $\begin{array}{l}\text { NUREG/CR-4550, Vol. } 6 \\
\text { (Grand Gulf PRA) }\end{array}$ & $1.6 \times 10^{-3} /$ demand \\
\hline $\begin{array}{l}\text { NUREG/CR-4819, Vol. } 1 \\
\text { (NPRDS data Sepi 1978-July 1984) }\end{array}$ & $7 \times 10^{-8} /$ hour \\
\hline $\begin{array}{l}\text { NUREG-1275, Vol. } 6 \\
\text { [NPRDS data Jan 1985-Dec 1989] }\end{array}$ & 6.5 to $7.9 \times 10^{-6} / \mathrm{hr}$ \\
\hline
\end{tabular}

RESEARCH RECOMMENDATIONS The first step is to make sure that SOVs have been properly selected (so that they are suitable for the application and operating environment in which they must perform) and properly installed (some types of SOVs have special positioning requirements). The second step in ensuring operability is to institute a maintenance program comprising thorough inspections, periodic replacement of limited-life components, and conditionindicating in-place tests.

Inspections Careful inspection of an SOV, even without quantitative measurement of performance parameters, can often provide useful indication of its condition (but not necessarily its operability). Four inspection techniques of successively increasing difficulty and intrusiveness have been found 
useful: (1) visual check (examine the SOV for evidence of discoloration or charred odor from overheating, obvious physical damage, stains or deposits from leaks, drips, or condensation, frayed wiring or cracked insulation); (2) audible check (lack of a solid "click" upon energizing/deenergizing the valve or the presence of a continued buzzing or rattling sound after energizing are signs of trouble); (3) operational check (an ability to initiate and terminate flow reliably, especially at the extremes of the valve's rated operating pressure and differential pressure limits, should be demonstrated); and (4) disassembly (though not always practical or desirable, this may be the only sure way to verify the absence of excessive wear of internal valve components and build-up of dirt or foreign materials, to ascertain the condition of the seats and other elastomers, and to verify free movement of the valve core).

Periodic Component Replacement Embodied in SOVs are two types of components that are likely to have limited service life in typical nuclear plant environments: elastomers and the solenoid coil itself. The effects produced by the presence of stressors, even at severity levels encountered in normal (nonaccident) environments, are described in the section entitled AGING RELATED ISSUES. The frequency with which elastomeric components and the solenoid coil require replacement will, of course, depend on the specific service conditions associated with the SOV in question. SOV manufacturers frequently offer recommendations for replacement of limited-life components at intervals determined by the number of valve operations, accumulated radiation dose, time in service at elevated temperatures, or a combination of these and other operational parameters. Equipment qualification programs also provide failure data which should be useful in formulating a component replacement strategy.

However, in view of the difficulty and cost of replacing specific components of an SOV that is already installed, many nuclear plants have adopted a practice of replacing the entire SOV periodically rather than rebuild- ing the valve in place. If the rebuild option is nonetheless chosen, it is imperative that all work be performed by qualified personnel, and postmaintenance testing of the SOV is recommended to demonstrate the adequacy of the component replacement work.

In-Place Tests In addition to the audible check and the operational check already described in the INSPECTIONS section, four condition-indicating tests can be performed without removing the valve from service and are theretore considered feasible for typical nuclear power plant applications. They are:

Internal leakage. Increased internal leakage rate is indicative of degraded valve seating surfaces, especially the elastomeric seats. For many SOVs this measurement can be performed with a hand-held flowmeter attached to the valve's exhaust port.

Speed of operation. Sluggish shifting of a SOV is indicative of buildup of foreign material within the valve, excessive mechanical wear of internal components, or chemically deteriorated valve seats.

Electrical power consumption. A marked change in solenoid current from its historical mean value is indicative of insulation degradation or failure within the solenoid coil or at the leadwire connections, or possibly a significant change in the operating temperature of the SOV (see below).

SOV temperature. Altered temperature of the valve and its solenoid coil may be caused by a change in process fluid or ambient temperatures, a change in electrical supply voltage, electrical insulation breakdown within the solenoid, or loose (high-resistance) connections. Regardless of its cause, any radical change in SOV operating temperature should be understood and its implications factored into the overall valve maintenance program. The temperature measurement may be made with a contact thermometer or may be performed electrically through knowledge of the temperature variation of resistance of the copper wire comprising the solenoid coil. 
REFERENCES The IEEE good-maintenance practices document and the EPRI program development guide listed below provide specific and general information, respectively, that is applicable to performance improvement of SOVs.

1. IEEE 89TH0248-5-PWR, Evaluation of Maintenance Related Practices for Sole- noid Operated Valves in Nuclear Power Generating Stations.

2. EPRI NP-3416, A Guide for Developing Preventive Maintenance Programs in Electric Power Plants.

3. NUREG-1275, Vol. 6, Operating Experience Feedback Report - SolenoidOperated Valve Problems. 


\section{AGING ASSESSMENT GUIDE SOLENOID-OPERATED VALVES (SOVS)}

Observations on the aging of solenoid-operated valves

- Swelling, cracking, and loss of strength/elasticity due to nuclear radiation, prolonged operation at high temperatures, and chemical attack are aging concerns for elastomeric SOV components such as seats, gaskets, O-rings, and diaphragms.

- Mechanical wear and/or fatigue cracking due to repeated valve cycling are aging concerns for metallic SOV components such as the valve core and its return spring, the disc-holder subassembly, and the valve orifice(s).

- Loss of dielectric strength from material damage due to nuclear radiation, prolonged operation at high temperatures, and moisture intrusion are aging concerns for the insulation covering the individual copper wires constituting the layered solenoid coil and for the insulated leadwires and their points of connection with the coil.

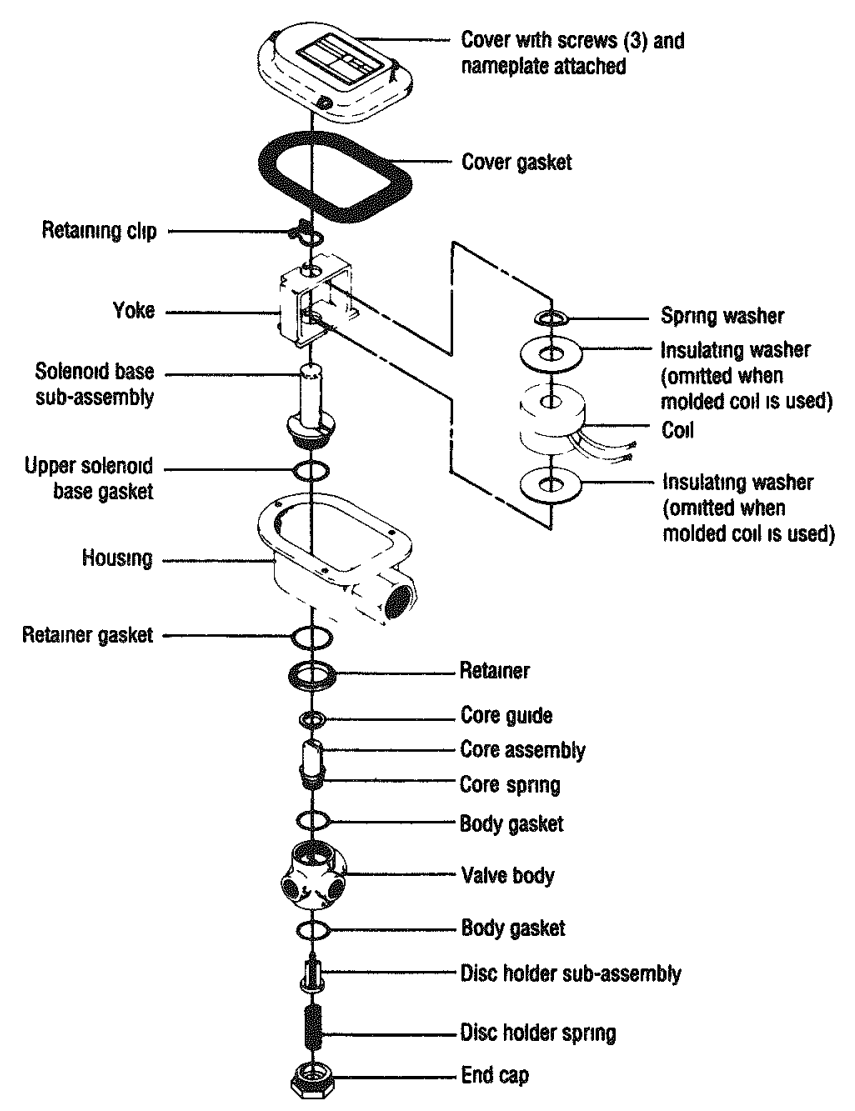

EXPLODED VIEW

OF SOLENOID-OPERATED VALVE

\section{RECOMMENDATIONS FOR INSPECTION} Operating Parameters Routinely Observed

1. Approximate temperature during operation (Is it too hot to touch?)

2. Presence of buzzing or rattling noise when energized (Is there suggestion of excessive mechanical wear of internal parts or improper maintenance?)
External Indicators or Causes of Age Degradation

1. Discoloration or charred odor from overheating

2. Stains or deposits from leaks, drips, or 'condensation

3. Frayed wiring or cracked insulation from excessive temperature or radiation environment

4. Carbonized tracks or smoke deposits from electrical arcing

5. Corrosion of valve body; evidence of leakage from valve couplings 


\begin{tabular}{|ll}
\hline 6 & SOLENOID-OPERATED VALVES MVE \\
\hline
\end{tabular}

MANTENANCE RECOMMENDATIONS

1. During scheduled downtime, perform (1) visual check, (2) audible check, and (3) operational check, as outlined in the NPAR SUMMARY OF RESEARCH RESULTS.

2. Replace limited-life components on a regular schedule that is based on SOV manufacturer's recommendations, equipment qualification test results, and the temperature/radiation/time history of the individual SOVs.

3. Check tightness of electrical connections and process fluid couplings routinely. Make sure that drain holes in electrical conduit supplying power to SOV are unobstructed.

\section{OPERATIONS RECOMMENDATIONS}

1. Actuate seldom-used SOVs whenever an opportunity to do so arises, since valves maintained in one position for extended periods of time are prone to sticking.

2. Record all cases of anomalous SOV performance, since such events may be precursors to recurrent and possibly more serious malperformance or failures. During scheduled downtime, take steps to determine root cause(s) of SOV malperformance.

3. Make sure that purity of the process fluid controlled by the SOV is maintained.

\section{DESIGN/TEST RECOMMENDATIONS}

1. Periodically review environmental conditions (ambient temperature and radiation field, actual solenoid coil temperature, process fluid temperature) at each SOV site to make sure that they lie within the manufacturer's recommended operating envelope for that valve model.

2. Periodically measure the voltage supplied to the SOVs to ensure that, for all plant conditions normally encountered, it lies within the range specified by the manufacturer.
3. If SOV operational problems occur, during the next scheduled downtime perform as many of the in-place tests outlined in the NPAR SUMMARY OF RESEARCH RESULTS as practicable (specifically, the internal leakage, speed of operation, electrical power consumption, and SOV temperature tests, as well as the audible check and the operational check). As a last resort, disassembly and accompanying visual inspection of internal SOV parts may be required to ascertain the nature of the problem and correct it. 


\section{AUXILIARY FEEDWATER (AFW)
SYSTEM}

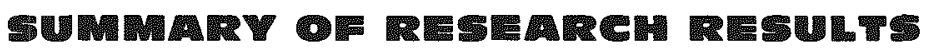

FUNCTIONAL DESCRIPTION/BACKGROUND The AFW System in a PWR provides a safetyrelated mechanism for the removal of stored and decay heat irom the reactor coolant system by the transfer of heat through the steam generators. It is routinely used at many plants in support of normal startup and shutdown, as well as in response to emergency reactor shutdown.

\section{BASED ON MPAR REPORT:}

1. NUREG/CR-5404, Auxiliary Feedwater

System Aging Study, 3/90.

AGING RELATED ISSUES The AFW system is operated in support of normal startup and shutdown sequences, in response to plant transients (its safety related function), and for testing. During normal operation, it is in standby. The components of the AFW system are exposed to a variety of internal environmental conditions, ranging from high temperature steam to low temperature raw water.
As a result, the system is subject to a broad range of aging mechanisms in standby, including (but not limited to) erosion, corrosion, and thermal fatique. Aging during system operation occurs from operating the system at relatively low-flow conditions, which results in accelerated wear of pumps due to hydraulically unstable conditions, and accelerated wear of check valves due to the flutter that accompanies low-flow operation.
OPERATING EXPERIENCE Failure data from NPRDS was reviewed to determine the components which were significant contributors to historical AFW system problems. Pump drivers were found to be the principal source of system degradation. Almost threefourths of the pump driver problems occurred with turbine drives.

The turbines, as a piece of mechanical hardware, have proven to be extremely rugged, but the control systems have fre.quently been unable to cope with the conditions demanded (rapid starts from cold conditions). Over half of the turbine drive problems were attributed to $I \& C$ or governor

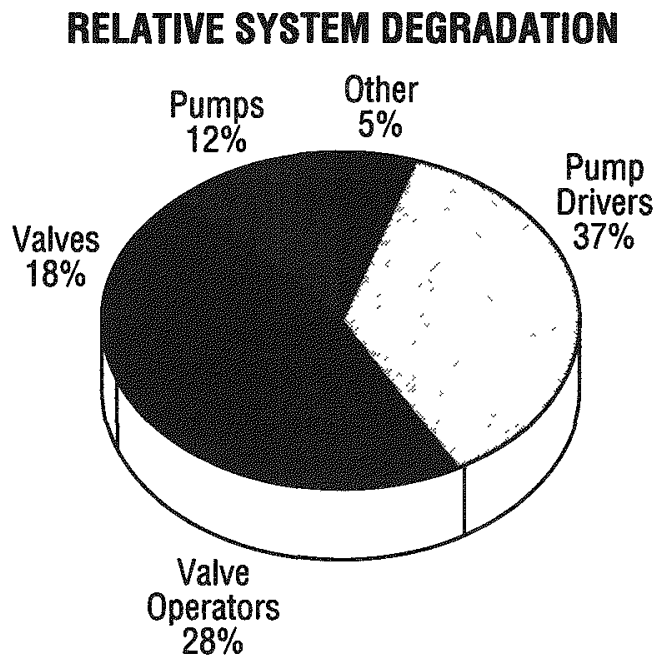


control system failures. Many of these failures occurred as the result of turbine speed control problems.

Less than half of all AFW system failures reported to the NPRDS database were detected as the result of programmatic monitoring practices. Almost one-fifth of the system degradation associated with failed components was detected during demand starts. Almost one-third of the degradation associated with turbine $\mathrm{I} \& \mathrm{C} /$ governor control failures were detected during demand start conditions.
Failure Mechanisms Failures within the AFW system are the result of individual component failures.

Typical components in the AFW system for which NPAR research has been performed are:

- Multistage centrifugal pumps

- Induction pump drive motors (100-1000 hp)

- Steam turbines and associated controls

- $\mathrm{AC}$ and DC motor-operated valves

- Air-operated valves

- Check valves

- Circuit breakers

- Instrumentation and control

NPAR research results summaries for individual components should be consulted for detailed failure mechanism discussions.
Failure Modes Fallure modes for AFW system components depend upon the precise operating requirements for the specific component.

Broadly speaking, the failure modes are:

- Failure of equipment to automatically actuate on demand

- Failure to deliver flow to an intact steam generator (SG)

- Fallure to isolate flow to a faulted SG

- Failure to provide adequate flow to remove residual heat from the reactor coolant system - Failure of components in the AFW system which degrade other systems (such as failure of SG to AFW turbine isolation valves which result in cross-tying of a faulted SG to an intact $\mathrm{SG}$ )
RESEARCM RECOMMENDATIONS The demonstration of the operational readiness of the AFW system depends upon a variety of testing and routine observations, including the following:

- Pump testing. The typical in-service test (IST) of an AFW pump is performed at lowflow conditions (through the minimum flow line). This testing provides little useful hydraulic performance information, and is damaging to the pump. Periodic (e.g., at each cold shutdown) full flow testing should be performed to verify hydraulic performance of the pump, as well as the full load performance of the pump driver (motor, turbine, or diesel). Pump hydraulic performance (head and flow), motor power, and machine vibration should be monitored and trended.

- Power operated valve testing. To the extent that AFW system power operated valve IST does not demonstrate design basis functionability of a valve, the testing should be supplemented by periodic testing under conditions that are as closely representative of design basis conditions (i.e., differential pressure, flow, etc.) as practical. Use of advanced diagnostic techniques, such as motor current signature analysis should be employed.

- Check valve testing. In addition to the check valve test requirements associated with the IST program, the use of advanced, non-intrusive diagnostic techniques should be employed. The pump discharge line should be periodically monitored by operators (e.g., once per shift) or continuously monitored with instrumentation (thermocouples with remote alarm or readout) to ensure that main feedwater is not backleaking. 


WW AUXILIARY FEEDWATER SYSTEM 3

- Turbine testing. In addition to performance testing of turbines done in conjuction with pump testing, the turbine governor and speed control system should be calibrated periodically (e.g., every refueling). Proper functioning of overspeed trip devices should be verified on a monthly or quarterly basis.

- Pipe examination. Portions of the AFW system piping are exposed to stagnant raw water at many plants (e.g., piping from the backup water supply). This line is seldom or never used, and may be subject to considerable corrosion or other degradation (for example, microbiologically induced corrosion or Asiatic clam infestation). Programmatic controls should be in place to either examine the pipe periodically or to prevent degradation.

\section{REFERENCES}

1. NRC Bulletin 88-04, Potential SafetyRelated Pump Loss.

2. NRC Bulletin 85-01, Steam Binding of Auxiliary Feedwater Pumps.

3. NRC Bulletin 85-03, Motor Operated Valve Common Mode Failures During Plant Transients Due to Improper Switch Settings.

4. Information Notice 86-01, Failure of Main Feedwater Check Valves Causes Loss of Feedwater System Integrity and Water-Hammer Damage.
5. Information Notice 86-09, Fallure of Check and Stop Check Valves Subjected to Low Flow Conditions.

6. Information Notice 86-14, Overspeed Trips of $A F W, H P C I$, and RCIC Turbines.

7. Information Notice 87-53, Auxiliary Feedwater Pump Trips Resulting from Low Suction Pressure.

8. Information Notice 90-76, Failure of Turbine Overspeed Trip Mechanism Because of Inadequate Spring Tension. 

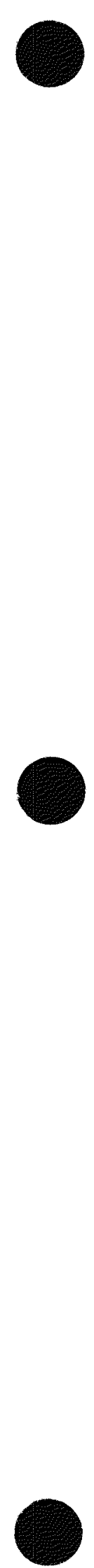


\section{AGING ASSESSMENT GUIDE AUXILIARY FEEDWATER (AFW) SYSTEM}

\section{Observations on the aging of the Auxiliary Feedwater (AFW) System}

- Pump Drivers and their controls have been the major sources of AFW system degradation.

- Current testing practices have not been totally effective in detecting AFW system component degradation and failures.

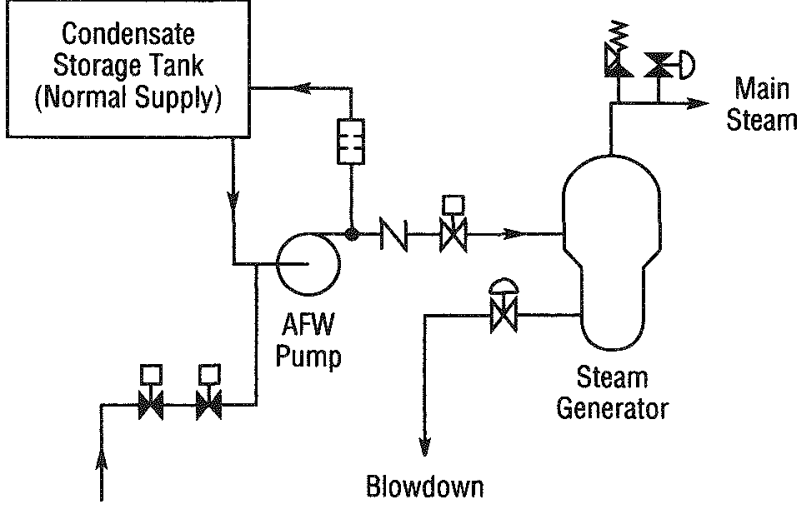

Service Water (Backup Supply)

\section{RECOMMENDATIONS FOR INSPECTION}

1. In the standby mode, the pump casings and the pump discharge piping should be periodically or continuously monitored for backleakage.

2. For plants in which long runs of the turbine steam supply piping is normally isolated, proper functioning of steam traps or condensate pots should be observed.
3. During system testing and operation, pump and system vibration and noise should be observed. Pump motor current and turbine speed should be monitored.

4. Components should be monitored for excessive leakage, including:

a) Pump packing or mechanical seals and

b) valve packing and gasket seals

\section{MAINTENANCE RECOMMENDATIOMS}

\section{ArW Pumps}

1. Measure and trend pump hydraulic performance at or near best efficiency point (BEP) flow rates (not just at minimum flow) at least once per fuel cycle

2. Monitor and trend pump bearing vibration in the frequency domain (track vibration level vs. vibration frequency). This should be done for both normal inservice testing and for the above recommended full flow tests

3. Perform lube oil analyses

\section{AFW Valves}

1. Periodically monitor motor operated valve condition using advanced diagnostic

techniques, such as motor current signature analysis

2. Periodically monitor check valves using non-intrusive diagnostic techniques such as ultrasonic, acoustic, or external magnetic flux signature analysis

\section{ArW Pump Drivers}

1. Measure and trend pump motor power during full flow (pump at or near its BEP) testing

2. Perform motor lube oil analyses

3. Periodically (once per fuel cycle) calibrate the turbine governor speed control system 


\begin{tabular}{|lll}
\hline 6 & AUXILIARY FEEDWATER SYSTEM MPCP \\
\hline
\end{tabular}

4. Perform periodic verification of turbine over-speed trip operability (monthly to quarterly)

5. Perform turbine lube oil/governor control oil analyses

6. Monitor and trend turbine/motor bearing vibration in the frequency domain

7. Observe turbine governor's ability to maintain the turbine at control speed without hunting (each time turbine is run) 


\section{COMPONENT (CCW) \\ SYS

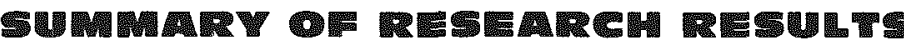

FUNCTIOMAL DESCRIPTION/BACKGROUMD The CCW System in a PWR is a continuously operating non-radioactive closed loop system used to remove heat from plant equipment, and transfer it to an open loop cooling system such as service water. Aging is a significant factor in failures of CCW systems (over $70 \%$ of the failures reported were related to aging). Fiffy percent of the failures resulted in degraded performance of the CCW system, while $27 \%$ caused a loss of redundancy. Using the time dependent failure rates calculated from the plant data, improvements in maintenance and monitoring methods may be required to prevent system unavailability from reaching an unacceptable level during the later years of plant life.

\section{BASED ON NPAR REPORTS:}

1. NUREG/CR-5052, Operating Experience and Aging Assessment of Component Cooling Water Systems in Pressurized Water Reactors, 7/88.
2. NUREG/CR-5693, Aging Assessment of Component Cooling Water Systems in Pressurized Water Reactors - Phase 2, $3 / 92$.
ACING RELATED ISSUES Leakage was the predominant mode of failure. Wear was the predominant failure mechanism. On a component level, valves were the most commonly reported component to fail. These were dominated by failure of the valve operators, followed by wear of the valve seats. Pump failures were dominated by seal and bearing failures, while heat exchanger

\section{AGING EFFECTS}

Erosion, wear, corrosion

Clogging, blocking, reduced flow

Vibration, misalignment, loose parts

Binding, distortion, rupture

Electrical short circuits, grounds, pitting

Setpoint drift, loose connections failures most frequently involved the tubes. Factors contributing to aging of these components along with the observed effects are summarized on the next page.

Under normal operating conditions, the stresses which contribute to CCW system aging, and the part of the system it most affects are summarized:

\section{COMPONENTS AFFECTED \\ Mechanical \\ Mechanical \\ Mechanical, electrical, instrumentation \& controls \\ Mechanical \\ Electrical, 1\&C \\ Electrical, I\&C}

OPERATING EXPERIENCE For each CCW component showing a significant number of failures, the data were examined to identify the specific subcomponents which failed. As illustrated below, pump seals and bearings contributed most to pump unavailability. 


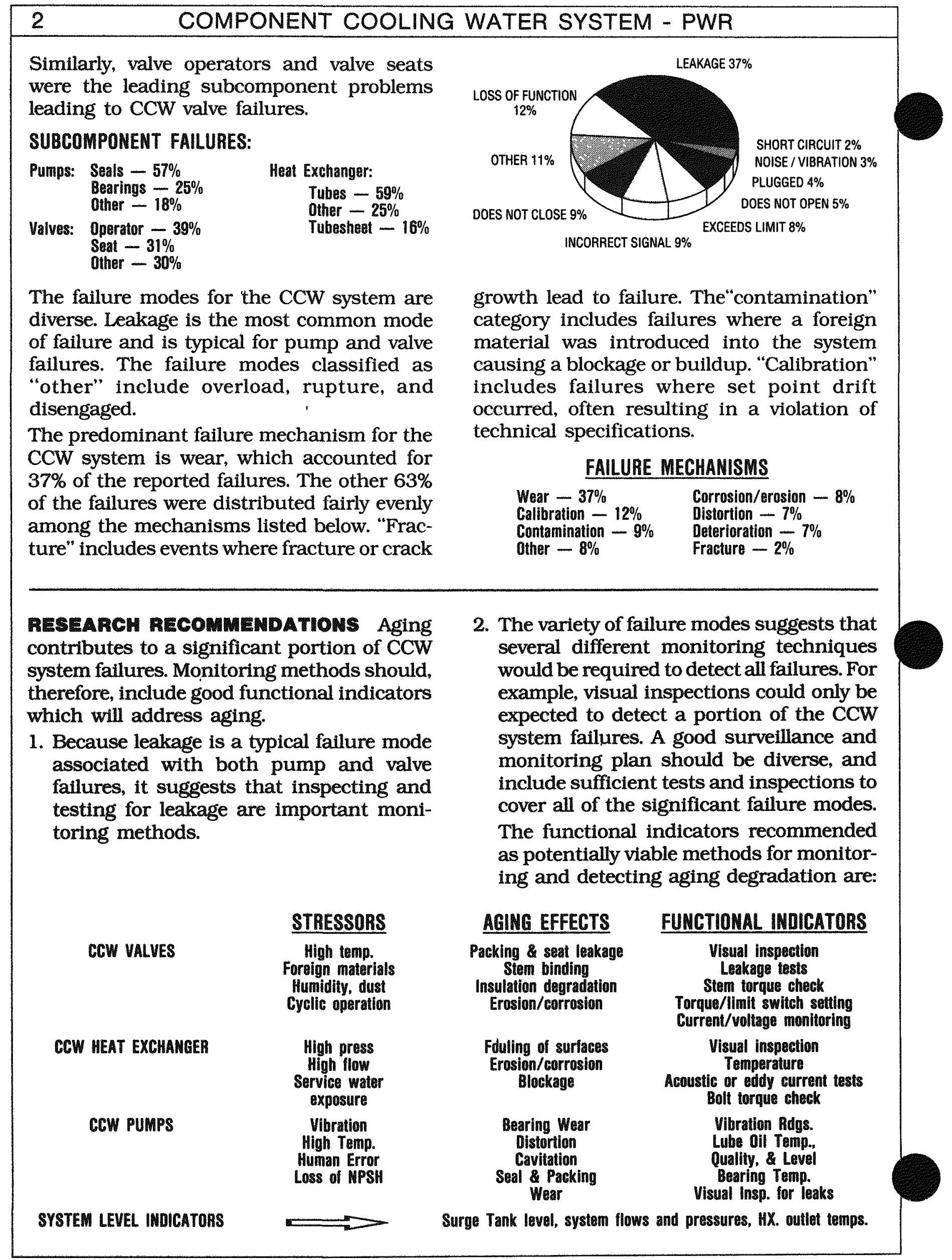




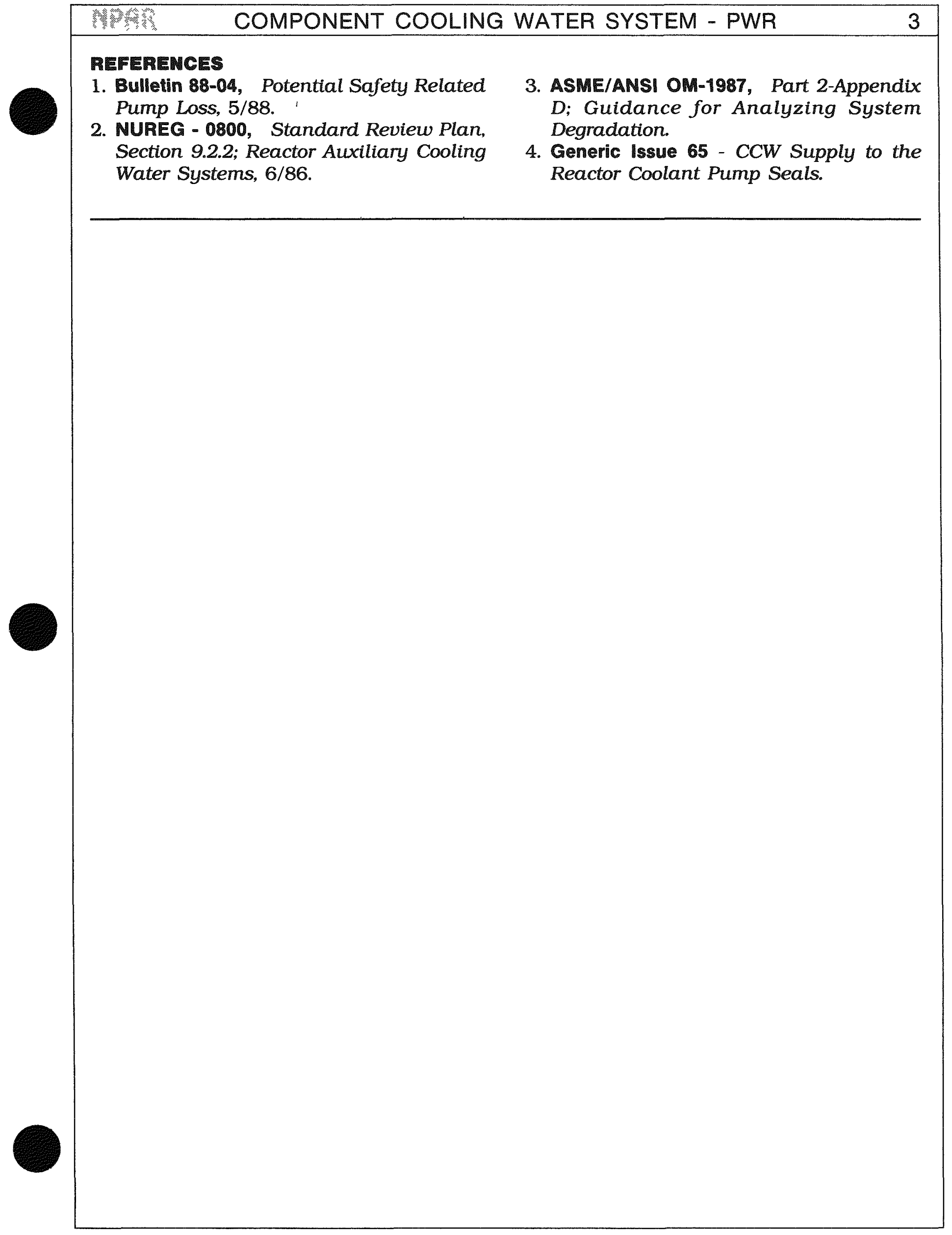



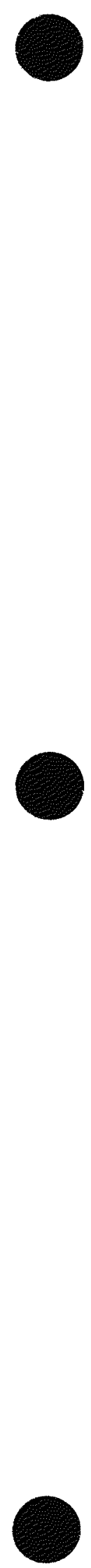


\section{AGING ASSESSMENT GUIDE COMPONENT COOLING WATER (CCW) SYSTEM - PWR}

\section{Observations on the aging of the Component Cooling Water System in PWRs}

- Function: Provide cooling water to various plant loads including HX's, pump seals, chillers and air coolers.

- Operating experience indicates increasing failure rates with age.
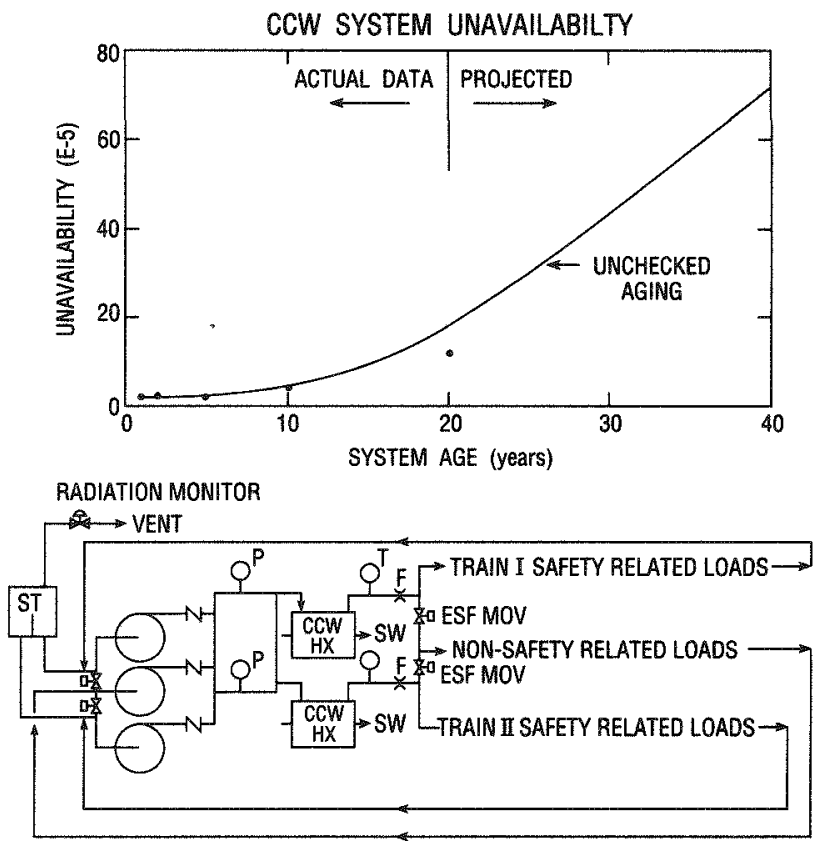

single component failure has little impact because of the extra redundancy. However, multiple component failures could affect both units. Differences in designs results in differences in emphasis and the priority of licensee resources.

\section{RECOMMENDATIONS FOR INSPECTION}

1. Major valves are monitored for leakage \& appearance.

2. Heat exchangers are inspected for leakage, temperature.
3. Check steady state flow to the following critical loads:

a. Reactor coolant pump (RCP) seals.

b. Residual Heat Removal (RHR) heat exchangers and pump seals.

c. Safety Injection (SI) pump \& motor coolers.

d. Chillers \& Containment coolers.

\section{MAINTENANCE RECOMMENDATIONS}

CCW Pumps:

1. Trend the pump's performance (flow, pressure)
2. Monitor the bearing temp. \& vibration (operator rounds)

3. Perform analysis of lube oil quality 


6 COMPONENT COOLING WATER SYSTEM - PWR

CCW Heat Exchangers:

1. Trend the inlet and outlet temperatures

2. Perform eddy current or acoustic testing (or equivalent) to determine tube sheet condition

\section{CCW Valves:}

1. Calibrate the control valves, check set points

2. Monitor the operator current/voltage
Other CCW System Activities:

1. The integrity of the piping should be checked periodically, especially main headers.

2. The instrumentation (controls, indicators) associated with modulating flow to equipment should be calibrated regularly.

3. The strainers in the system (pump suction) should be cleaned, based on differential pressure readings.

4. Water chemistry should be routinely checked, and chemical addition modified as necessary. 


\section{CONTROL ROD DAIVE (CRD)
SYSTEM-WESTINGHOUSEI \\ SURM}

FUNCTIONAL DESCRIPTIONBACKGROUND The Control Rod Drive (CRD) system performs an electro-mechanical conversion which enables reactivity command signals developed by the reactor control system, to accurately control the operation of magnetic jack type Control Rod Drive Mechanisms (CRDM) and, hence, the position of Rod Cluster Control Assemblies (RCCA) within the core. The major subassemblies bounded by the aging study of the Westinghouse CRD system include the RCCAs, CRDMs, Power and Logic cabinets, the Rod Position Indi- cation (RPI) system and the interconnecting cables and connectors. Analysis of plant operating data has shown that unchecked aging of CRD system components can cause system operability problems which may lead to unacceptable plant performance. A review of CRD system design characteristics and current maintenance practices, indicates that certain design modifications, and/or improved maintenance and monitoring techniques, may be warranted to adequately manage the age related degradation of this system.

\section{BASED ON MPAR REPORT:}

1. NUREG/CR-5555, Aging Assessment of the Westinghouse PWR Control Rod Drive System, 3/91.

ACIMG RELATED ISSUES Unexpected, abnormal wear of control rod cladding material, inability to move control rods on demand, dropped control rods, inaccurate RCCA position indications, and unnecessary challenges to plant safety protection equipment are among the operational events that have occurred as a result of age related component degradation within this system. The following table presents a summary of the leading aging related problems that have been identified for each major subassembly.
NPRDS DATA (1980-1989)

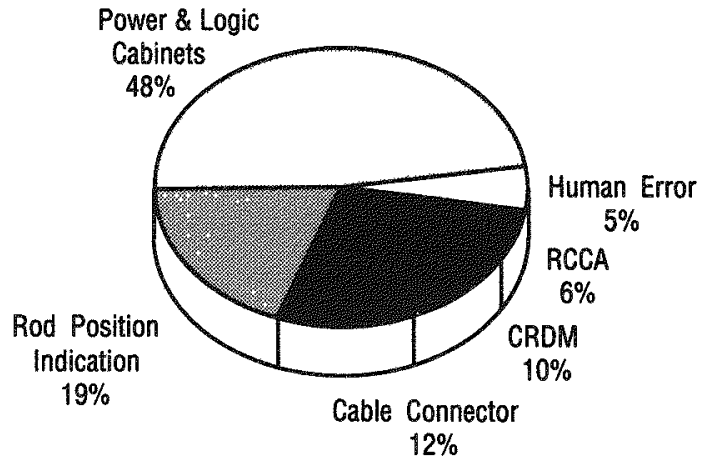




\begin{tabular}{|c|c|c|c|c|}
\hline RCAA & CROM & $\begin{array}{l}\text { POWER and LOGIC } \\
\text { CABINETS }\end{array}$ & RPI & $\begin{array}{l}\text { CABLE and } \\
\text { CONNECTORS }\end{array}$ \\
\hline Claudding wear & $\begin{array}{l}\text { Operating Coil bails } \\
\text { open/shorted due to } \\
\text { high temperature and/ } \\
\text { or exposure to pri- } \\
\text { mary coolant }\end{array}$ & $\begin{array}{l}\text { Overheating due to } \\
\text { inadequate ventilation } \\
\text { and/or dust buildup } \\
\text { on temperature sensi- } \\
\text { tive compenents and } \\
\text { heat sinks }\end{array}$ & $\begin{array}{l}\text { Callbration Drift - } \\
\text { Analog IRPI }\end{array}$ & $\begin{array}{l}\text { Poor connection due to } \\
\text { moisture intrusion and } \\
\text { corrosion }\end{array}$ \\
\hline $\begin{array}{l}\text { Spider Assembly vane } \\
\text { weld failure due to } \\
\text { cyclic fatigue }\end{array}$ & $\begin{array}{l}\text { Embrittlement of cast } \\
\text { housings }\end{array}$ & $\begin{array}{l}\text { Poor wiring, compo- } \\
\text { nent, or logic card } \\
\text { connections }\end{array}$ & $\begin{array}{l}\text { Poor wiring, compo- } \\
\text { nent, or logic card } \\
\text { connections }\end{array}$ & $\begin{array}{l}\text { Temperature degrada- } \\
\text { tion of in-containment } \\
\text { cables }\end{array}$ \\
\hline $\begin{array}{l}\text { Wear of RCAA to } \\
\text { CRDM coupling }\end{array}$ & Vent valve leakage & $\begin{array}{l}\text { Fuse failure due lo } \\
\text { age }\end{array}$ & $\begin{array}{l}\text { Detector Coil lails } \\
\text { open due to high tem- } \\
\text { perature or exposure } \\
\text { to primary coolant }\end{array}$ & $\begin{array}{l}\text { Wear of connector } \\
\text { mating pins due to } \\
\text { repetitive connections } \\
\text { during maintenance }\end{array}$ \\
\hline $\begin{array}{l}\text { Stress Corrosion } \\
\text { Cracking of reactor } \\
\text { internal components }\end{array}$ & $\begin{array}{l}\text { Latch Assembly mis- } \\
\text { stepping and/or bind- } \\
\text { ing due to debris in } \\
\text { primary coolant }\end{array}$ & $\begin{array}{l}\text { Loose/Poor mechani- } \\
\text { cal bond at fuse clip } \\
\text { due to repetitive lests }\end{array}$ & & \\
\hline
\end{tabular}

RESEARCH RECOMMENDATIONS Improvements in the areas of preventive maintenance, condition monitoring, and design should be considered for the Westinghouse CRD system.

\section{Design/Test}

1. Replacement of CRDM Operating Coil Stack connectors with a connector having greater resistance to moisture intrusion

2. Upgrade of Analog IRPI to digital multiplexing design

3. Improved ventilation of power and logic cabinets; reliance on outside air as source of cooling may not be sufficient during summer months in some geographical regions

4. Permanently installed test equipment to minimize influence of disconnecting and reconnecting components to perform testing

\section{Preventive Maintenance}

1. Periodic monitoring of ambient temperature within electrical equipment cabinets

2. Use of underwater TV cameras to conduct and document periodic inspections of normally inaccessible reactor internal components

3. Use of eddy current, profilometry and ultrasonics to determine the condition of critical welds and structural material

4. Development of NDT equipment and techniques to permit the remote inspection of all CRD housing welds, including interior housings (Current ASME inservice inspection requirement specifies that welds on $10 \%$ of the peripheral housings be inspected)

5. Use of CRDM operating coil current signature analysis to monitor the condition of power and logic cabinet components and coil integrity

6. Use of advanced diagnostic tools such as the Electronic Characterization and Diagnostics System (ECAD) to provide early detection of operating coil stack cable and connector problems 


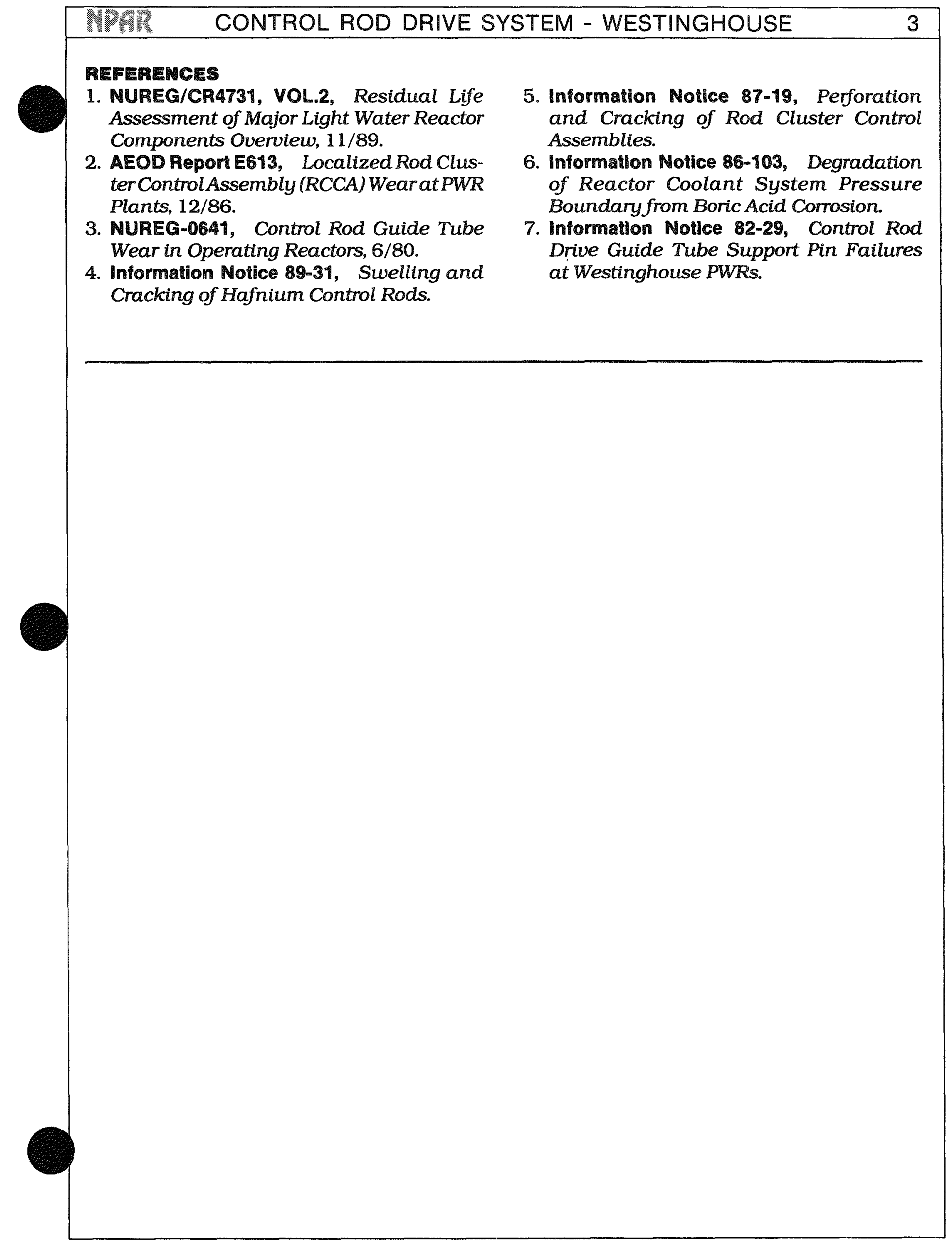



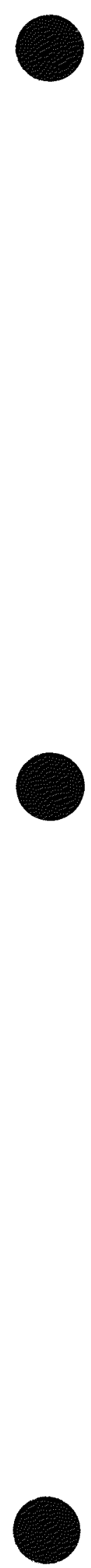


\section{AGING ASSESSMENT GUIDE CONTROL ROD DRIVE (CRD) SYSTEM - WESTINGHOUSE}

- Electrical and electronic components of the power and logic cabinets have experienced the most failures. Elevated temperature is a leading contributor to failure

- CRDM operating coil stack connectors are susceptible to corrosion of mating pin surfaces due to moisture intrusion.

- Unexpected wear of control rod cladding surfaces has been identified at several plants

- Cast CRDM housings are susceptible to cracking due to thermal embrittlement

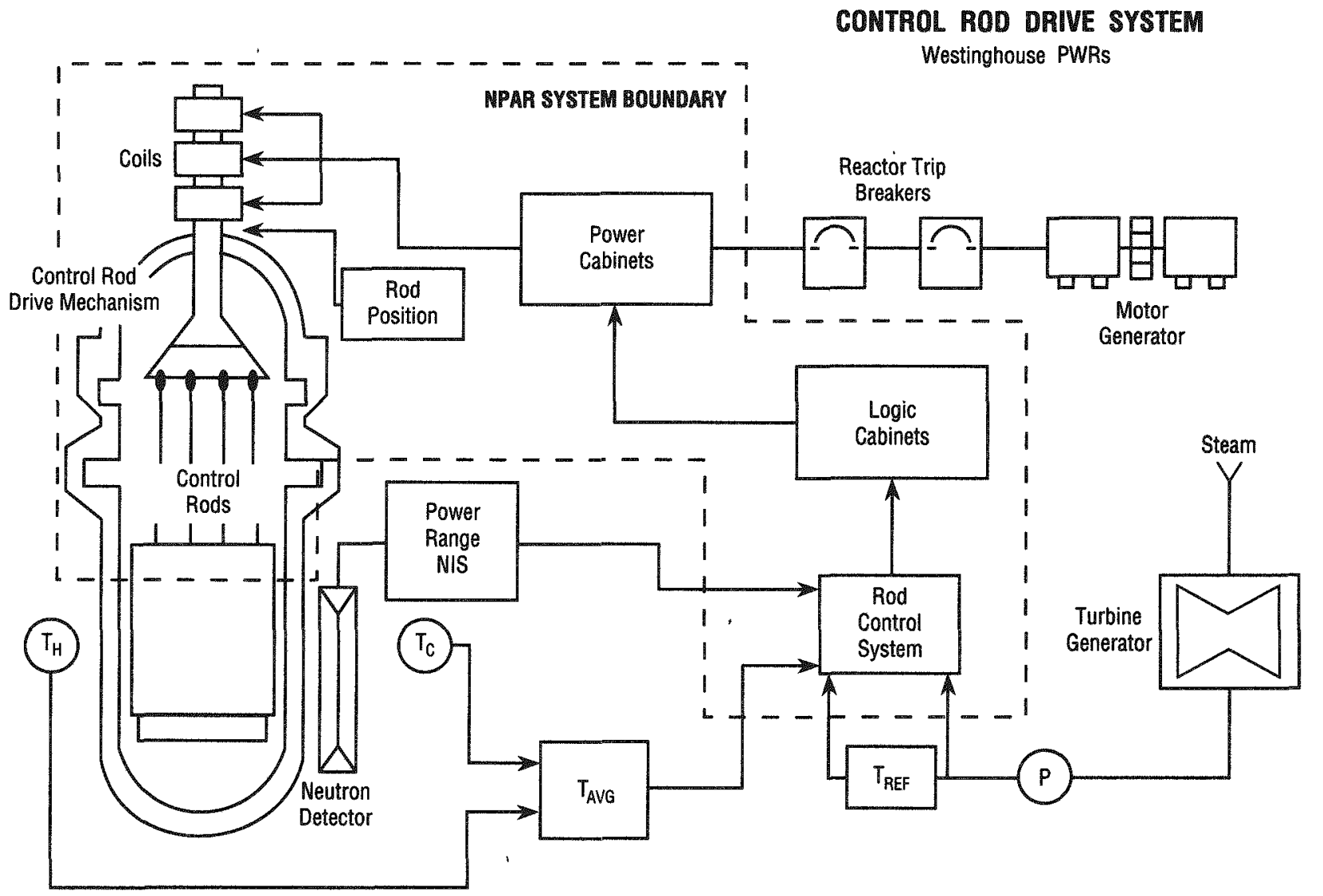

\section{RECOMMENDATIONS FOR INSPECTION}

1. Observation of panel internal temperatures is warranted. Environmental conditions within electrical equipment cabinets (temperature and humidity) should not exceed the vendor's recommendations. An accumulation of dirt or dust on certain components such as thyristors and their heat sinks can exacerbate this situation. 
2. Control room instrumentation including process computer printouts can be used to determine the adequacy of the ventilation in the upper head area. Abnormally high temperatures can lead to premature cable, connector, or coil failures.

3. During refueling outages, it is important to monitor the amount of wear or degradation which has occurred in the compo- nents located in harsh environments. A visual inspection of CRDMs should include:

- Condition of cables and integrity of water tight seals on operating coil stack connectors

- Signs of primary coolant (boric acid) leakage from vent valves, instrument sensing lines or CRD housings

\section{MAINTENANCE RECOMMENDATIONS}

1. Measuring the resistance of cables, connectors, and coils following refueling outages is recommended. Measurements of loop inductance and dissipation factor may also be used to detect degradation.

2. A current signature analysis technique being used by some plants should be evaluated by others. This technique permits the observation of electrical and mechanical parameters during normal power operation.

3. Because of the inaccessibility during operation of the mechanical and structural portions of the CRD system, it is important to conduct and document a thorough inspection during refueling outages. Using underwater TV cameras, areas of wear should be noted and their cause determined. Particular parameters of interest based on aging concerns are:

- guide tube wear

- drive rod and latch wear

- rodlet fretting, cracking, or bulging

- cable, connector, coil appearance

\section{OPERATIONS RECOMMENDATIONS}

1. The ventilation systems in the upper head region and in the area where the power and logic cabinets are located should maintain low ambient temperatures. It is important that operating personnel be aware of unsatisfactory conditions so that prompt corrective action may be taken.
2. A positive aspect of the Westinghouse CRD system design is that it contains sensors which detect component failures. An urgent alarm, which results in a rod block, or a nonurgent alarm, indicating a loss of redundancy, provide an important input to the control room operators.

\section{DESIGN/TEST RECOMMENDATIONS}

1. The rod drop timing test is required to be performed once per cycle in accordance with the technical specifications. Pulling the fuse to perform this test reduces the force between the fuse clip and the fuse. The design should include a more permanent means for satisfying this required testing.

2. Modifications to the cooling of the power and logic cabinets have been necessary at several plants. Temperatures as high as $125^{\circ} \mathrm{F}$ have been recorded in the cabinets, which are typically designed for $90^{\circ} \mathrm{F}$.

3. The number of connector problems in the upper head region due to moisture ingress or contamination from borated water leakage indicates the need for a more substantial connector design.

4. The integrity of the control rod drive system cables located in containment can be improved by using higher temperature rated assemblies. 


\section{IE POWERS SYSTEM}

FUNCTIONAL DESCRIPTIONBAAKGROUND The IE power system provides electrical power for the safety systems in the plant. The IE power system includes an emergency power source (usually diesel generators) and three subsystems, the alternating current (ac) power system, the direct current (dc) power system, and the vital ac power system. Failure data were reviewed to identify failure modes experienced during operation and their cause. About 33\% of the failures are aging related. Because the $1 \mathrm{E}$ power system is a highly redundant system, complete loss of essential electrical power has not been common.

\section{BASED ON NPAR REPORTS:}

1. NUREG/CR-5181, Nuclear Plant Aging Research: The 1E Power System, 5/90.
2. NUREG/CR-4747 Volume 1, An Aging Failure Survey of Light Water Reactor Safety Systems and Components, 7/87. 1

AGING RELATED ISSUES Aging is a concern for the $1 \mathrm{E}$ power system since the NPRDS data base shows that about $33 \%$ of the failures are aging related. The components failing most often are breakers, diesel engines/generators, chargers, and inverters. These are followed by batteries and transformers. Each of the above are discussed in more detail in corresponding aging assessment sections.
OPERATING EXPERIENCE The effect of $1 \mathrm{E}$ power system failures was determined from the NPRDS data. The three most frequent effects were loss of redundancy, loss of subsystem/channel, and system function unaffected; and were nearly identical. While only about $48 \%$ of $1 \mathrm{E}$ power system failures were detected with routine IS\&MM, about $52 \%$ of the failures were detected during normal operation or incidently (nonroutinely). Non-routinely detected failure rates for the most significant components are inverters $(77 \%)$, breakers $(48 \%)$, batteries $(44 \%)$, and relays $(30 \%)$. Transformers, chargers, ac generators, conductors, power supplies, and motors also had a very large percentage of their failures (60\% or greater) detected non-routinely. However each of these account for $2 \%$ or less of the total failures of the $1 \mathrm{E}$ power system. For nonroutinely detected failures the primary causes were: defective circuit, corroded contacts, short/ground, wear, burned component, and defective connection. This failure pattern and the research results indicate trending parameters normally measured during maintenance, such as megger testing results, and the use of advanced monitoring methods such as infrared thermography and electrical circuit characterization and diagnostics, could be useful in improving the reliability of the $1 \mathrm{E}$ power system.

Aging related causes accounted for about $33 \%$ of the failures reported in NPRDS. Aging failures included (among others) wearout, set point drift, insulation breakdown, short/ grounded circuit, open circuit, contacts 
corroded, defective connections, circuit defective, electrical overload, and mechanical damage. The failure cause classified as other

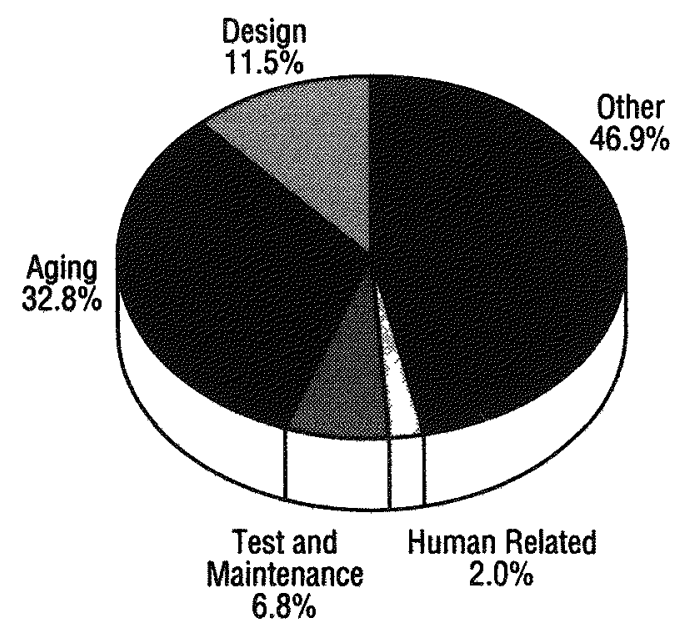

includes fouling/blockage/foreign material, overload/pressure, normal wearout, corrosion, miscellaneous.

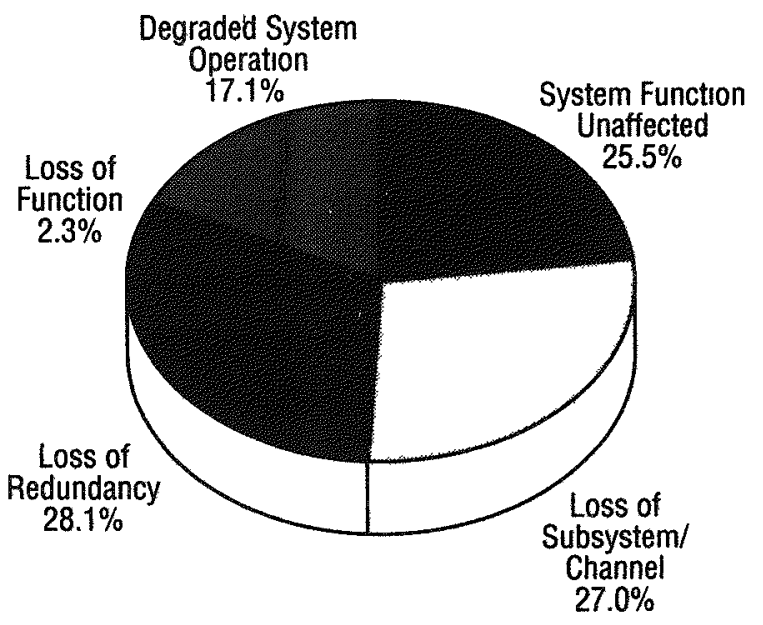

RESEARCH RECOMMENDATIONS A preventive maintenance (PM) program should exist for the $1 \mathrm{E}$ power system. The PM program should include periodic testing, monitoring, and inspections. Because the $1 \mathrm{E}$ power system is composed of four subsystems (emergency power, alternating current (ac) power system, direct current (dc) power system, and the vital ac power system), the system can not be tested with a single set of tests. Each of the major components (breakers, relays, transformers, cabling, batteries, chargers, inverters, and diesel generators) can be the subject of a maintenance and surveillance program. General guidance is provided in IEEE Std. 338, and Regulatory Guide 1.118. These documents recommend instrument checks, functional tests, calibration verification tests, and response time verification tests. Factors that should be considered are system failure modes, component failure modes, applicable reliability modeling, reliability allocation and availability, failure report analyses and other historical data, and logic configuration.

Periodic tests are in situ tests performed in plant on the equipment at scheduled intervals to detect degradation and verify operability. Technical Specifications require verification of offsite and ESF power, diesel generator testing, undervoltage tests, voltage and frequency verification, tests of batteries, and response time tests to be performed on a periodic basis ranging from weekly to once each refueling outage (18 months). Emergency diesel teardowns may be required every 5 years. The results from these tests and surveillance tests can be analyzed to provide an early indication of aging degradation. Also, advanced monitoring methods such as the use of infrared thermography could be useful in detecting impending component failure and thereby improve the reliability of the $1 \mathrm{E}$ power system.
REFERENCES There is a large amount of reference material available for the $1 \mathrm{E}$ Electrical Power System. The following reflect those which may be readily accessible to the inspector.

1. IEEE Std. 338, Criteria for Periodic Testing of Nuclear Power Generating Station Safety Systems.
2. Regulatory Guide 1.118, Periodic Testing for Electric Power and Protection Systems.

3. EPRI NP-3416, A Guide for Developing Preventative Maintenance Programs in Electric Power Plants. 


\section{AGING ASSESSMENT GUIDE 1E POWER SYSTEM}

\section{Observations on the aging of $1 \mathrm{E}$ power system}

- Aging effects account for about $33 \%$ of the component failures.

- Inverters, breakers, batteries, and relays have experienced the most failures that were not detected with routine monitoring and surveillance methods.

- Approximately 52\% of the failures were discovered during normal operations rather than during routine maintenance, testing and inspection.

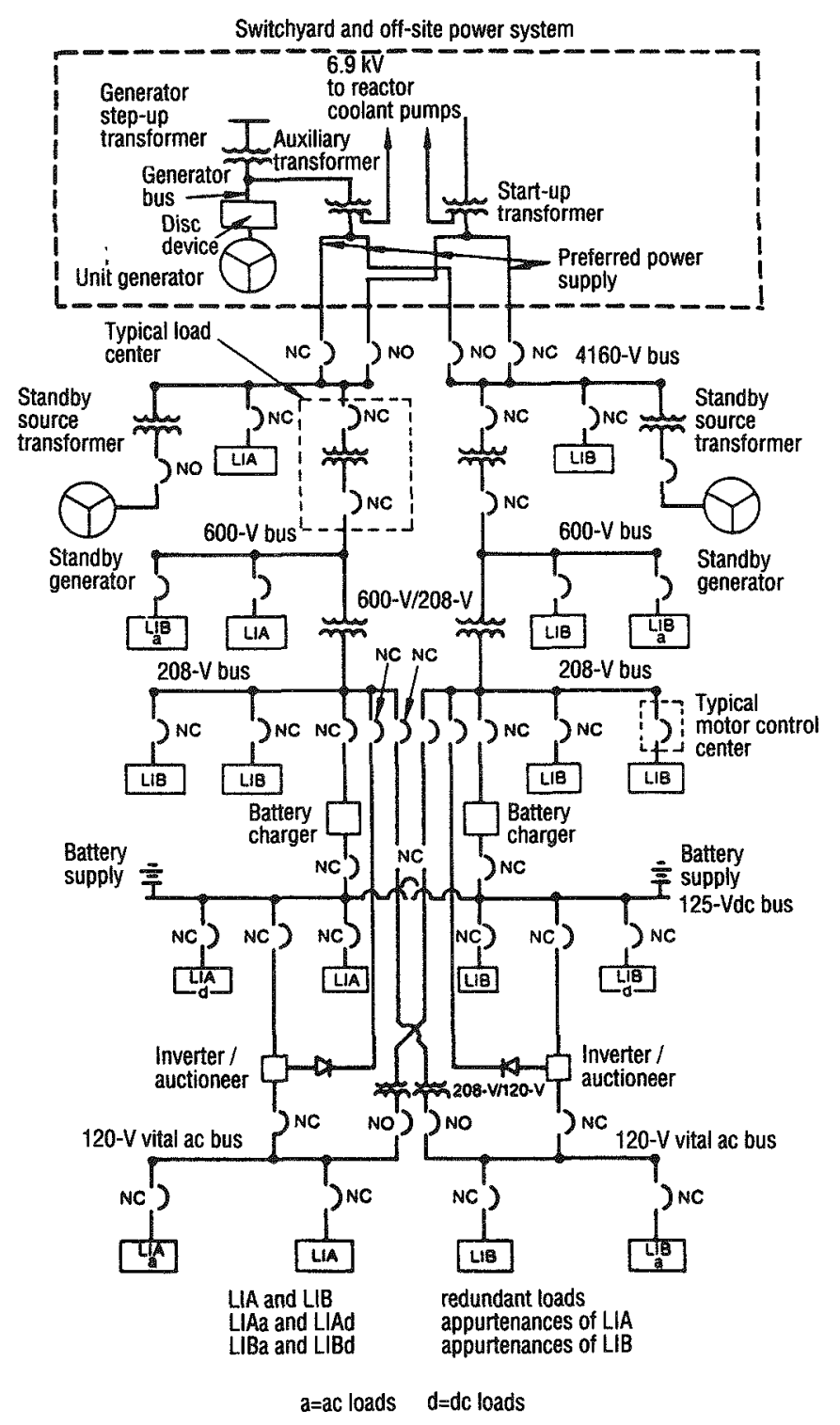

CLASS IE POWER SYSTEM WITH TWO DIVISIONS
RECOMMENDATIONS FOR INSPECTION

1. Verification of offsite and ESF power, diesel generator testing, undervoltage tests, voltage and frequency verification, tests of batteries, and response time tests during all phases of operation.
2. Cables and wiring in harsh environments should be visually inspected during outages for evidence of degradation from temperature, moisture, or radiation. 


\section{MAINTENANCE RECOMMENDATIONS}

1. Trend results of surveillance tests.

2. Trend failure rates of components.

3. Clean connections if corrosion is noted.

4. Clean components to remove dirt and other foreign material.

5. Changeout air filters in chargers, inverters, and other electrical equipment with forced air ventilation.
6. Perform PM on breakers to prevent faulty operation from dirt, contamination, hardened grease, and wear.

7. Meggering and Doble testing to verify electrical insulation properties. Considering use of advanced monitoring methods, such as infrared thermography. 


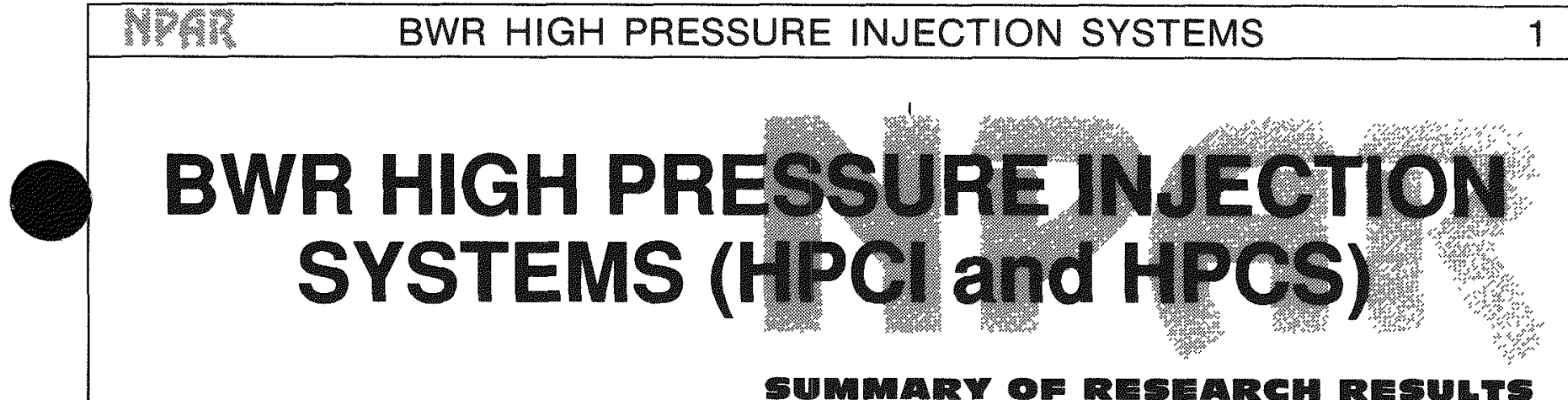

FUNCTIONAL DESCRIPTIONBACKGROUND The two main BWR high pressure injection systems (HPISs) are high pressure coolant injection ( $\mathrm{HPCl}$ ) and high pressure core spray (HPCS). The main purpose of the HPIS is to permit injection of coolant into the reactor vessel al reactor pressures up to 1120 psia for a wide variety of transients and accidents. Data analysis from three failure information data bases and one plant specific study showed aging degradation has occurred in BWR HPISs.

\section{BASED ON NPAR REPORT:}

1. NUREG/CR-5462, Aging Study of Boiling Water Reactor High Pressure Injection Systems, (Draft) 2/91.

AGING RELATED ISSUES The system stressors which contribute to age-related degradation include testing, operation, environment (pressure, temperature, humidity, radiation, etc.); vibration, dirt, foreign material, water hammer, improper lubrication, and improper maintenance. Dominantfailure mechanisms include wear, fatigue, setpoint drift, or out-of-calibration instrumentation.
OPERATING EXPERIENCE The most commonly failed BWR HPIS components included valves, valve operators, instrumentation and control (I\&C), pumps, turbines, pipe, and pipe supports. The most common failure modes for the components identified above include degraded operation (valves, valve operators, and turbines), loss of function (I\&C), low injection flow (pumps); leakage (pipe), and failure to operate (pipe supports). The failure data bases indicate 46 to $68 \%$ of the failures were not detected by surveillance testing. This information is summarized in the accompanying figure and Table 1.

Approximately $11.4 \%$ of the failures in the LER database resulted in a failure of the system to operate, and $8.4 \%$ of the failures in the NPRDS database resulted in a complete
COMPONENT FAILURES

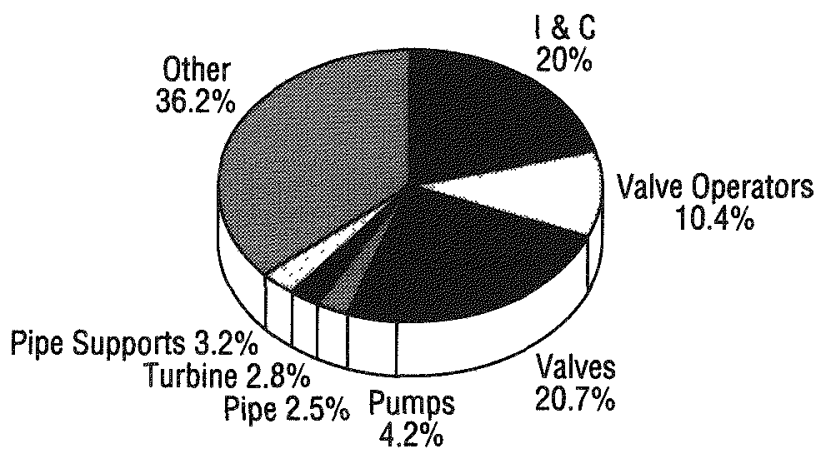

loss of system function. The components that most often caused a complete loss of function were valve operators, valves, circuit breakers, mechanical controllers, bistable switches, and the turbine. 


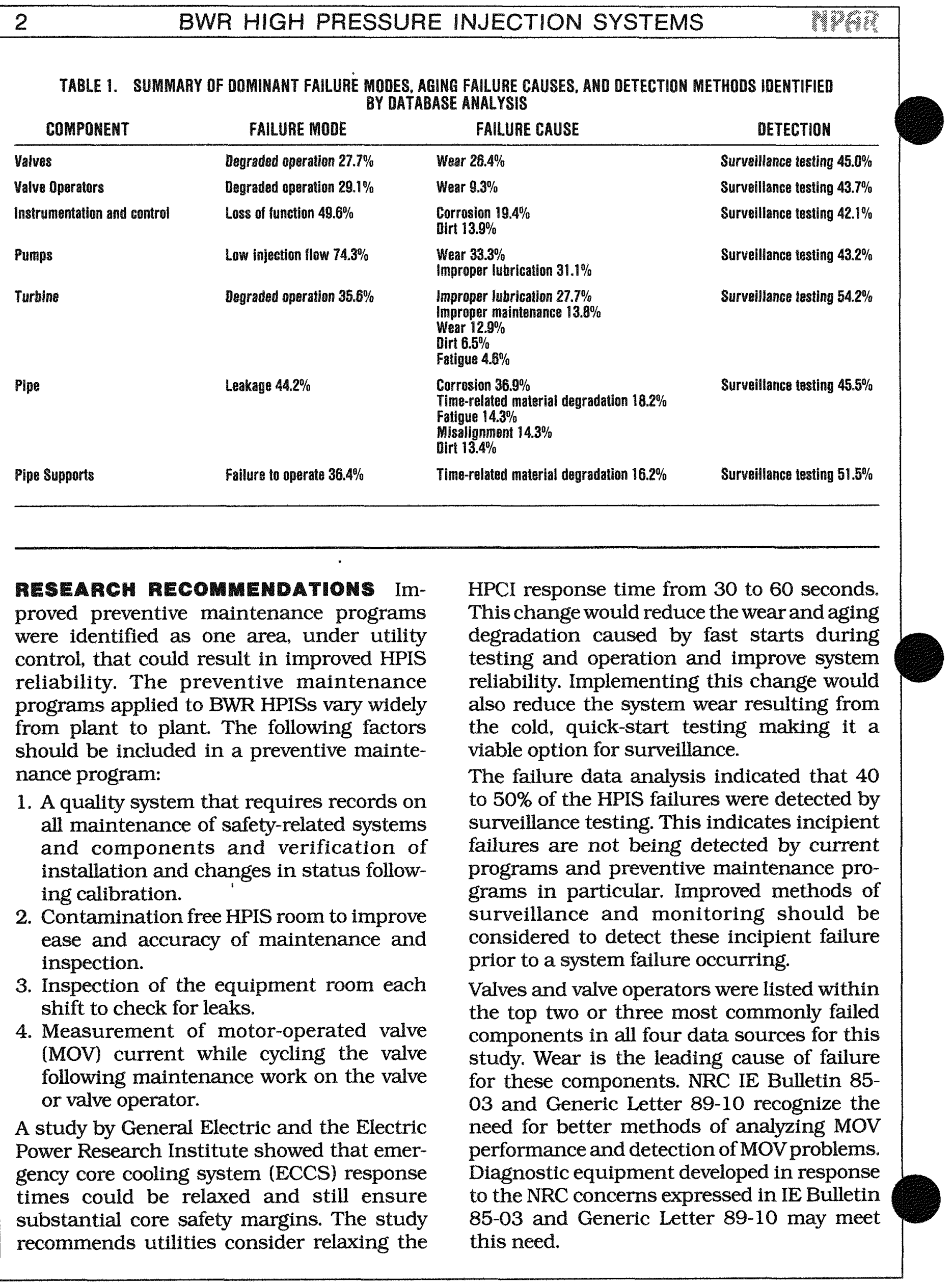


The HPCI systems should switch to a recirculation mode after water level recovery is verified. This leaves the system running and available if needed without requiring another startup challenge with the associated system startup stresses. Another change that would result in a fewer number of startup challenges is including a time delay on the isolation logic for high steam flow in the turbine inlet line. This will reduce spurious isolations caused by the startup transient or setpoint drift after an automatic initiation.

Motor-operated valves should not be electrically backseated. This overstresses the valve stem and seats and may lead to failures such as valve stem breaking or elongation, backseat damage, or stem nut cracking.

Also, the valve operator should be sized properly. Many MOV failures are the result of valve and operator incompatibility. The operators are oversized during the design process, and the resulting torque loads can be up to ten times the torque required for valve operation. This may lead to failures such as bent valve stems, cracked seats or disks, and deformed valve bodies or yokes.

\section{REFERENCES}

1. F.J. Mollerus, Reliability of BWR High Pressure Core Cooling, NSAC-53, August 1982.

2. K.F. Cornwell, G.L. Sozzi, and B. Chexal, Basis For Relaxing ECCS Pefformance Requirements for $B W R / 4 s$, NSAC-131, September 1988.
3. NRC Bulletin 85-03, Motor-Operated Valve Common Mode Failures During Plant Transients Due to Improper Switch Settings.

4. NRC Generic Letter 89-10, SafetyRelated Motor-Operated Valve Testing and Surveillance. 

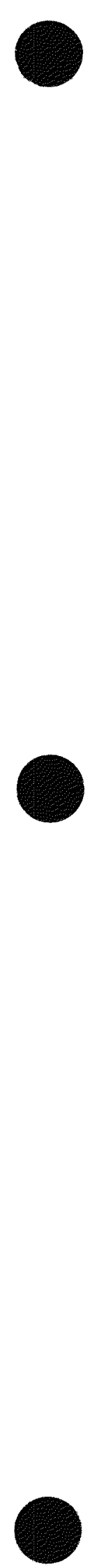


\section{AGING ASSESSMENT GUIDE BWR HIGH PRESSURE INJECTION SYSTEMS (HPCI and HPCS)}

\section{Observations on the aging of BWR Migh Pressure Injection Systems}

- Valves, valve operators, instrumentation and control (I\&C), pumps, turbines, pipe, and pipe supports experienced the most failures.

- A wide variety of stressors and failure mechanisms are causing aging degradation in BWR high pressure injection systems (HPISs).

- Only $10 \%$ of failures cause a complete loss of system function; most failures result in degraded operation.

TYPICAL HIGH PRESSURE CORE INJECTION SYSTEM FLOW DIAGRAM

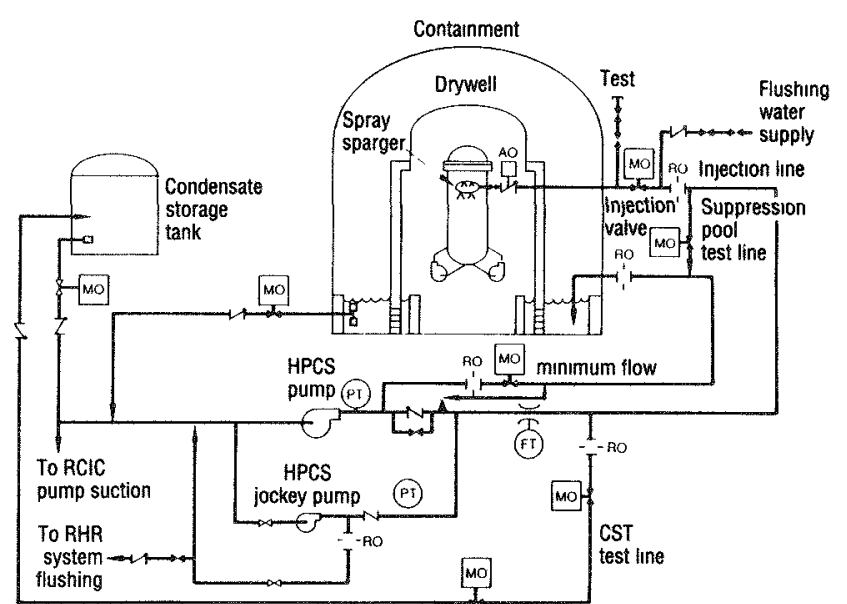

TYPICAL HIGH PRESSURE CORE SPRAY SYSTEM FLOW DIAGRAM

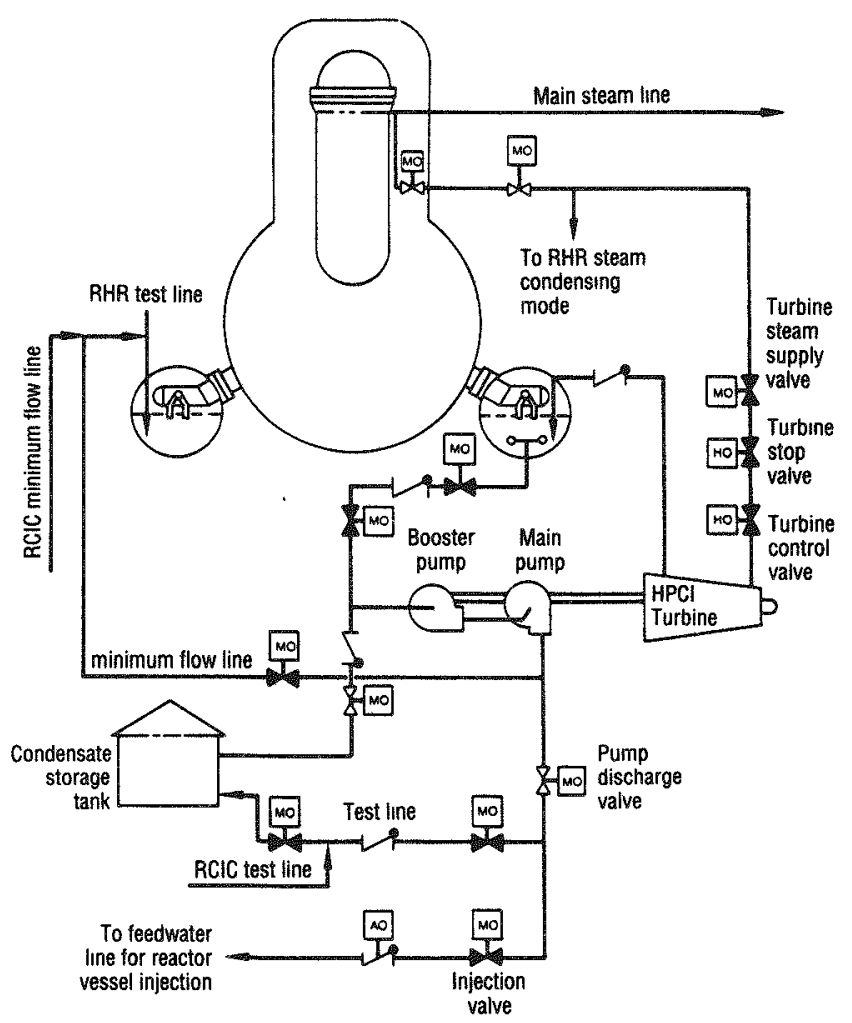




\section{RECOMMENDATIONS FOR IMSPECTION}

1. High pressure injection system testing should include visual inspection in the HPIS room to verify proper equipment operation.
2. The HPIS room should be checked each shift for leaks or problems.

\section{MAINTENANCE RECOMMENDATIONS}

1. Better methods should be considered for use in analyzing MOV performance and detection of MOV problems. Diagnostic equipment developed in response to NRC concerns expressed in Generic Letter 8910 may meet this need.

2. Plants that have a lot of HPIS failures would benefit from reviewing their preven- tative maintenance programs and determining where the weak points in their programs could be strengthened. Comparing their program to one at a BWR with low HPIS failure rates could be beneficial.

3. The HPIS room should be kept contamination free to improve ease and accuracy of inspection and maintenance activities.

\section{OPERATIONS RECOMMENDATIONS}

1. Motor-operated valves should not be electrically backseated. This overstresses the valve stem and seats and may lead to failures such as valve stem breaking or elongation, backseat damage, or stem nut cracking.

2. The HPCI systems should switch to a recirculation mode after water level recovery is verified. This leaves the system running and available if needed without requiring another startup challenge with the associated system startup stresses. Another change that would result in a fewer number of startup challenges is including a time delay on the isolation logic for high steam flow in the turbine inlet line. This will reduce spurious isolations caused by the startup transient or setpoint drift after an automatic initiation.

\section{DESIGN/TEST RECOMMENDATIONS}

1. The valve operator should be sized properly. Many MOV failures are the result of valve and operator incompatibility. The operators are oversized during the design process, and the resulting torque loads can be up to ten times the torque required for valve operation. This may lead to failures such as bent valve stems, cracked seats or disks, and deformed valve bodies or yokes.
2. A study by General Electric and the Electric Power Research Institute showed that emergency core cooling system (ECCS) response times could be relaxed and still ensure substantial core safety margins. The study recommends utilities consider relaxing the $\mathrm{HPCl}$ response time from 30 to 60 seconds. This change would reduce the wear and aging degradation caused by fast starts during testing and operation, and improve system reliability. 


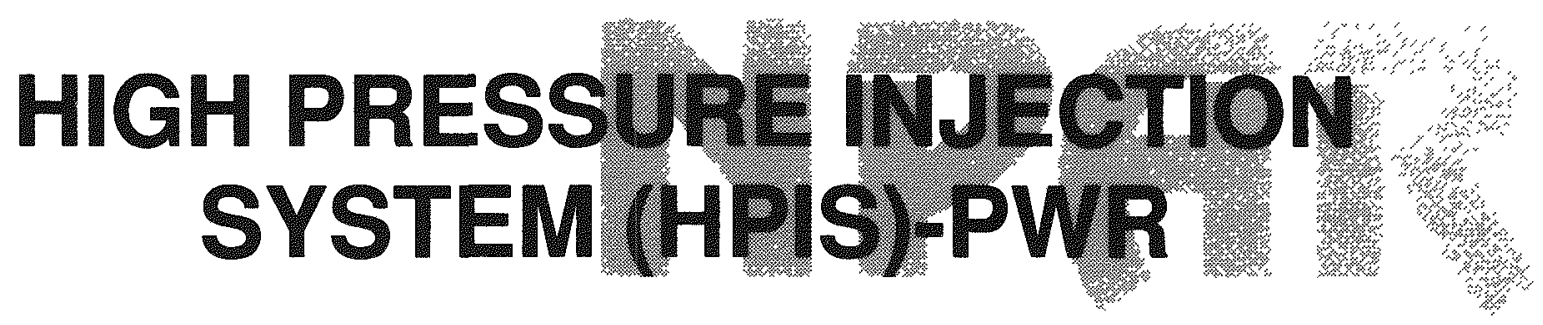

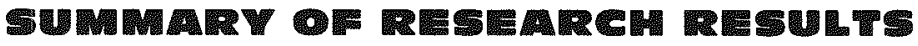

FUNCTIONAL DESCRIPTION/BACKGROUND The HPIS provides high pressure injection of borated water to prevent uncovering of the core for small LOCAs and to delay uncovering the core for intermediate sized LOCAs. The HPIS can also be used to cool the core following a reactor shutdown when heat removal by the steam generator cannot be achieved. For some plants, the HPIS provides normal primary coolant system charging and provides seal injection water for the reactor coolant pumps. Review of the HPIS failures found that at least $21 \%$ are aging related; but because the HPIS is a redundant system only $0.7 \%$ of the failures caused loss of system function.

\section{BASED ON MPAR REPORT:}

1. NUREG/CR-4967, Nuclear Plant Aging Research on High Pressure Injection System, 8/89.

AGING RELATED ISSUES Aging is a concern for the HPIS. The NPRDS and NPE data bases show that about $21 \%$ to $28 \%$ of the failures are aging related. The most frequent failures that may be age related are electrical and mechanical control malfunctions for pumps and valves. Boron crystallization from leaking packing and seals or faulty heat tracing have caused valve and pump malfunction. Leaking of borated water on to carbon steel parts of HPIS components and on adjacent systems has caused corrosion. Of special concern, is a potential for fatigue failure of the stainless steel pipe and nozzles resulting from loose thermal sleeves or valve seat leakage.
OPERATING EXPERIENCE The effect of component failure on system performance was determined from the NPRDS data. Approximately $57 \%$ of the failures caused either degraded operation, loss of redundancy or loss of channel, which implies reduced reliability if the system were called on to perform its safety function. Because of componet redundancy, only $0.7 \%$ of the failures actually caused a loss of system function.

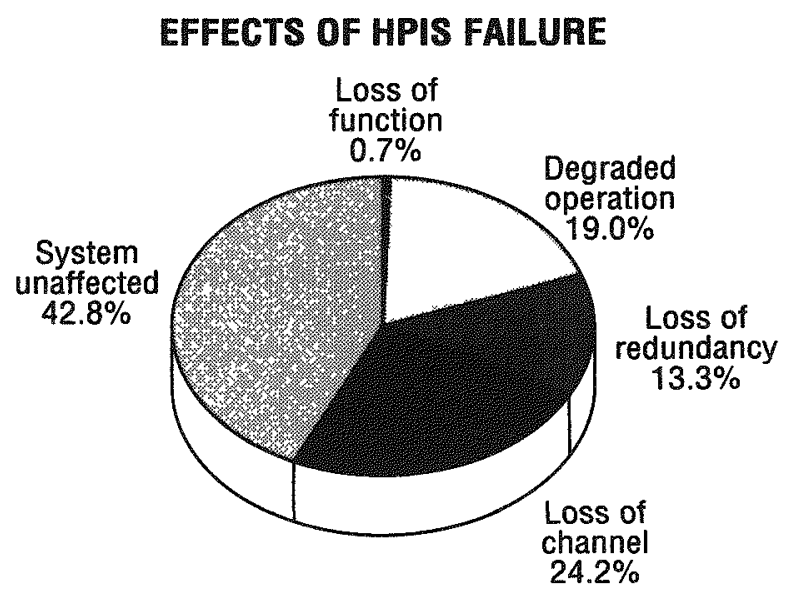


The relative frequencies of HPIS components failures were determined from the NPE data. Valve failures were the dominant failure. Also, a probabilistic risk analysis of the system showed that the failure of valves to open contributed the most to system unavailability.

\section{COMPONENT FAILURES}

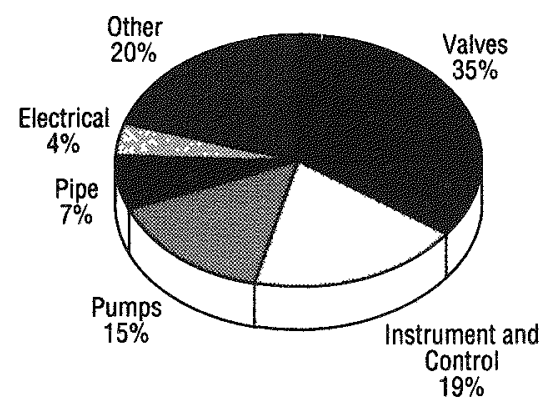

Mechanical disability was the most frequent potentially aging related failure cause listed in the NPE data. Other potentially aging related failure causes listed were local I\&C failures, setpoint drift, subcomponent sticking, short/ground, and weld failures.

Loose thermal sleeves have lead to a through wall fatigue crack in one plant and cracks with up to $25 \%$ penetration in five other plants. The cracks occurred in the weld at the safe end and were caused by thermal fatigue resulting from makeup flow cycling on and off and initiation of high pressure injection flow. Thermal sleeves have been redesigned to prevent loosening and a continuous make up flow is maintained to prevent thermal cycling and thereby prevent

\section{CAUSE OF SYSTEM FAILURES}

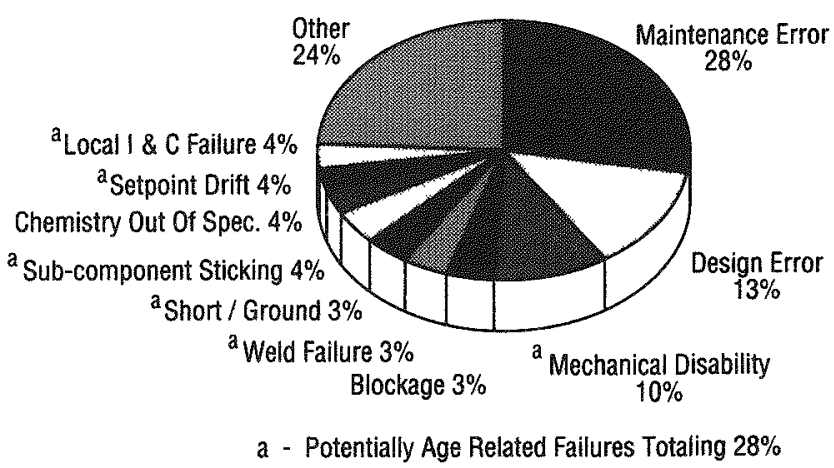

cracking. Leaking valves have lead to thermal fatigue and cracks in the base metal, welds and the heat effected zone of the elbow between the hot leg and the first check valve at two plants. The leaking valves allowed cold water to flow into the hot section of the injection line causing stratified flow that lead to the fatigue failure. Enhanced ultrasonic testing was required to detect the cracks after leaking was observed.
RESEARCH RECOMMENDATIONS A preventive maintenance program should be in place for the HPIS. The PM program should include periodic testing, monitoring and inspections to provide for detection of degradation and replacement or repair prior to failure. Technical specifications require quarterly inservice testing of pumps and valves in accordance with Section XI of the ASME Boiler and Pressure Vessel Code. Pump testing should be supplemented with electrical characteristic measurement of the motor to detect degradation of electrical insulation and other electrical components.

Valves are the most troublesome component of the HPIS. The stroke time tests required for Section XI are not completely effective in monitoring aging. The diagnostic testing required by Generic Letter 89-10 will help insure the operational readiness of the motor-operated valves.

Pump and Valve control circuit malfunctions and failures have been the leading problems with HPIS operation. These circuits should be tested periodically to demonstrate they are functioning properly.

Frequent visual inspections to detect and repair leaks will avoid the problems of boron crystal build-up in pumps and valves and boric acid corrosion of carbon steel parts.

Careful monitoring of thermal sleeve integrity and valve leakage and implementation of operating practices that reduce thermal cycles will prevent cracking of the pipes and 
nozzles from thermal fatigue. This should be supplemented by enhanced ultrasonic test- ing of the welds and high stressed areas of the base metal.

\section{REFERENCES}

1. Section XI of ASME Pressure Vessel Code, Rules for Inservice Inspection of Nuclear Power Plant Components.

2. ASME OM Code, Code for Operation and Maintenance of Nuclear Power Plants.

3. Information Notice 88-01, Safety Injection Pipe Failure.

4. Bulletin 88-08 and Supplements 1 and 2, Thermal Stresses in Piping Connected to Reactor Coolant Systems.
5. Information Notice 82-09, Cracking in Piping of Makeup Coolant Lines at B\&W Plants.

6. Information Notice 88-30, Loss of Thermal Sleeves in Reactor Coolant System Piping and Certain Westinghouse PWR Power Plants.

7. NUREG/CR-4234 Vol. 2, Aging and Service Wear of Electric Motor Operated Valves Used in Engineered SafetyFeature Systems of Nuclear Power Plants. 




\section{AGING ASSESSMENT GUIDE \\ HIGH PRESSURE INJECTION SYSTEM \\ (HPIS) - PWR}

\section{Observations on the aging of high pressure injections systems (HPIS) in PWRs}

- Valves, I\&C equipment and pumps have experienced the most failures.

- Motor-operated valves are the most troublesome and risk significant active components.
- Through wall cracks in the injection line and nozzles have developed from thermal fatique.

- Design and operational changes and improved inspection and testing will effectively manage aging.

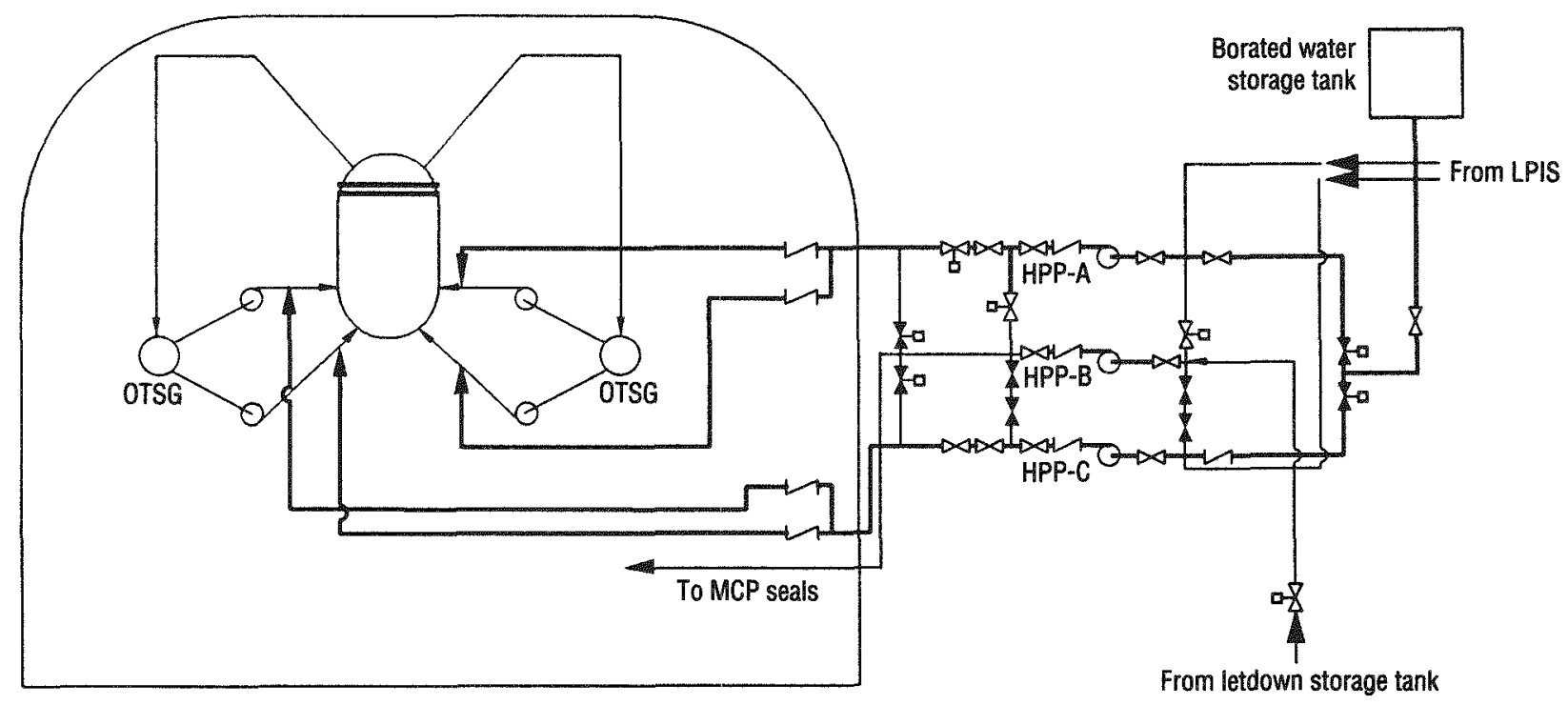

HIGH PRESSURE INJECTION SYSTEM

\section{RECOMMENDATIONS FOR INSPECTION}

1. Valve packing, valve bonnet connections, pump seals, piping and nozzles should be periodically inspected for leaks and boron crystal deposits. Adjacent pipes and equipment should be inspected for boron crystal deposits.

2. The major valves should be monitored for leakage with special attention to the normally closed valves and check valves at the interface of primary coolant and HPIS borated water.

3. Cables and wiring of pump and motoroperated valve power and control circuits in harsh environments should be visually inspected during outages for evidence of degradation from temperature, moisture or radiation. 


\section{MAINTENANCE RECOMMENDATIONS}

1. The vender recommendations for preventive maintenance of the HPIS electrical and mechanical equipment should be followed. For example, Limitorque valve motor-operators should have periodic 18month routine maintenance for inspection, cleaning and lubrication.
2. Guidance for maintenance of pump motors, motor-operated valves, check valves and the various electrical equipment components are given in the corresponding Recommendations for Assessing Aging.

\section{OPERATIONS RECOMMENDATIONS}

1. Plants that use HPIS for normal charging should maintain a continuous small makeup flow to avoid thermal shock of the injection nozzles caused by the makeup flow cycling on and off.

\section{TEST AND IMSPECTION}

\section{RECOMMENDATIONS}

1. The ASME Code Section XI inservice testing of pumps should be supplemented with measurements of the electrical characteristics of the pump motors.

2. The ASME Code Section XI stroke time tests may not be effective in monitoring aging of motor-operated valves. Trending of the parameters measured for Generic Letter 89-10 tests should be considered.

3. The nozzles safe ends and elbows between the cold leg and the first check valve of the injection lines should be periodically inspected using enhanced ultrasonic testing.

4. Pump and valve control circuits should be tested periodically to insure they are functioning properly.

Note: Section XI will refer to the ASME OM Code, "Code for Operation and Maintenance of Nuclear Plants", for pump and valve inservice testing. 


\section{INSTRUMENT
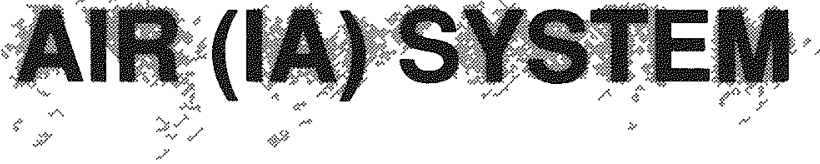

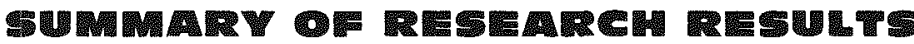

FUNCTIONAL DESCRIPTION/BACKGROUND Air systems are used in nuclear power plants to actuate or control equipment that is vital to normal plant operation as well as to shutdown the plant safely during an abnormal or emergency condition. Aging degradation occurs in the compressed air system and becomes an increasing factor as the system ages. The external systems most often affected by IA degradation are containment isolation, main feedwater/main steam, auxiliary feedwater and the BWR scram system. Since aging processes affect the compressed air system and its components, an aggressive preventive maintenance program should be followed to mitigate these effects. For this study, the air system includes the compressed air supply, the filter/dryers, and the distribution piping.

\section{BASED ON NPAR REPORT:}

1. NUREG/CR-5419, Aging Assessment of Instrument Air Systems in Nuclear Power Plants, 1/90.

AGING RELATED ISSUES The components experiencing the most failures due to aging degradation were compressors, air system valves, dryers and filters.

1. COMPRESSORS: Failures were largely attributed to wear from normal service. Degraded operation was due to failure to load/unload properly, and leakage.

2. AIR DRYERS: The dominant failure mechanisms are blocking or clogging, corrosion, deterioration, and contamination. This resulted in the delivery of compressed air with a higher dewpoint than specified.
3. FILTERS: Blocking and clogging were the major failure mechanisms on the prefilters and after-filters. This severely diminished the air flow in several cases.

4. VALVES: Wear and corrosion accounted for more than half of the failures associated with air system valves. This resulted in an inability to open or close manual and power operated valves. Seat leakage was also a common failure mode.
OPERATING EXPERIENCE Few events occurred in which a total loss of air took place. Partial loss or degraded system operation were most common. Several cases led to reactor scrams, and some introducted transients into the safety systems they serve. Moisture and particles in the air system, and hydrocarbon contamination caused numer- ous failures of components in the air system. Data were obtained from six nuclear plants and sorted to determine the distribution of air system failures among the major components. The ranges of the failure percentages are illustrated in the adjacent figure. This data may be used for consideration in the allocation of resources. 
Reciprocating compressors comprise $90 \%$ of the IA compressors used. The adjacent figure represents failures that occurred in the 14 th to 18 th years of operation.

\section{DOMINANT FAILURE MECHANISMS AND MODES}

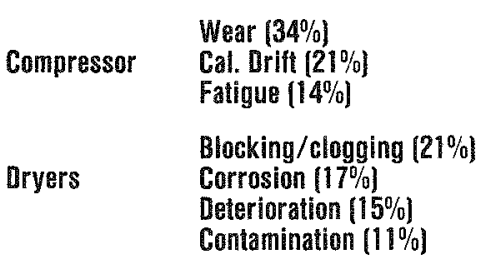

Failure to load/unload Leaks (air and oill

Dessicant and moisture Carry-Over

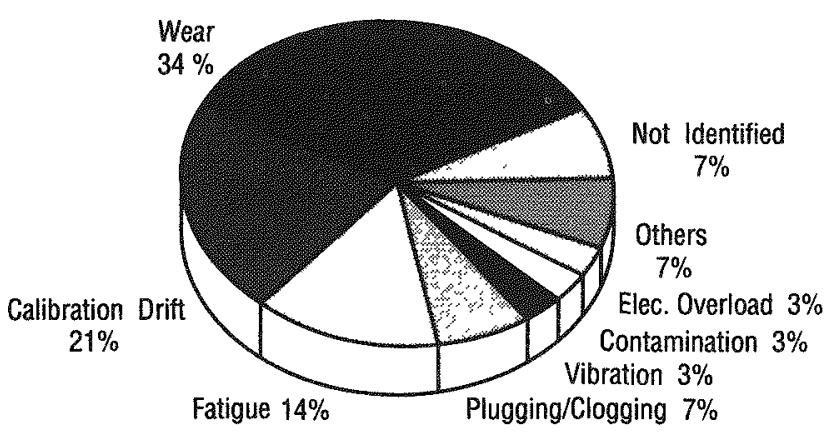

FAILURES OF RECIPROCATING COMPRESSORS

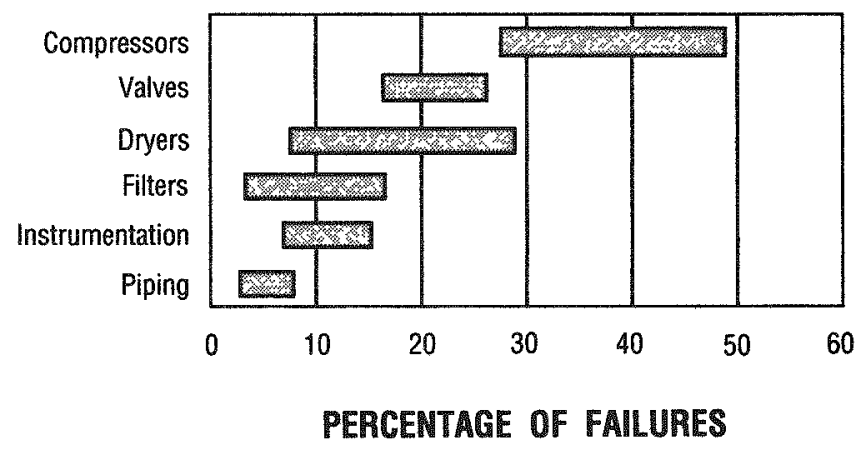

PERCENTAGE OF FAILURES

\section{RESEARCM RECOMMENDATIONS}

1. Frequent monitoring, including system walkdowns and visual inspection of key equipment, should be a routine part of the maintenance program for the IA system. The frequency of inspections and walkdowns on air receivers, piping, aftercoolers, and valves should be increased as the system ages.

2. Degraded pressure operation is the most common failure mode seen in the air system. Emergency procedures for response to and recovery from degraded air system events should be developed, along with procedures for the response/ recovery to the complete loss of air.

3. Periodic testing for gradual loss of pressure should be performed to test the performance of safety grade accumulators, check valves, and isolation valves under these conditions.

4. Air system valves should receive more maintenance, particularly LA/SA cross connection valves, or low pressure isolation valves.

\section{Specific Maintenance Recommendations}

AIR INTAKE \& FILTER: Interior surfaces should be free of rust and dirt. Filters should be changed periodically to preclude high differential pressures(dp). This pressure and its associated instruments should be monitored; an unusually low dp could indicate a broken filter screen.

AIR COMPRESSORS: Oil samples should be taken to determine if water intrusion or particulate buildup has occurred. This will effectively supplement bearing vibration and temperature monitoring.

INTERCOOLERS AND AFTERCOOLERS: Periodic inspection and cleaning of the heat exchanger tubes will insure that heat transfer capability due to corrosion buildup has not been affected.

DRYERS: The outlet dewpoint should be checked, preferrably by on-line instrumentation. Internal to the dryer skid are several important valves used for switching towers or blowing down excess moisture. Proper operation and alignment of these valves is 


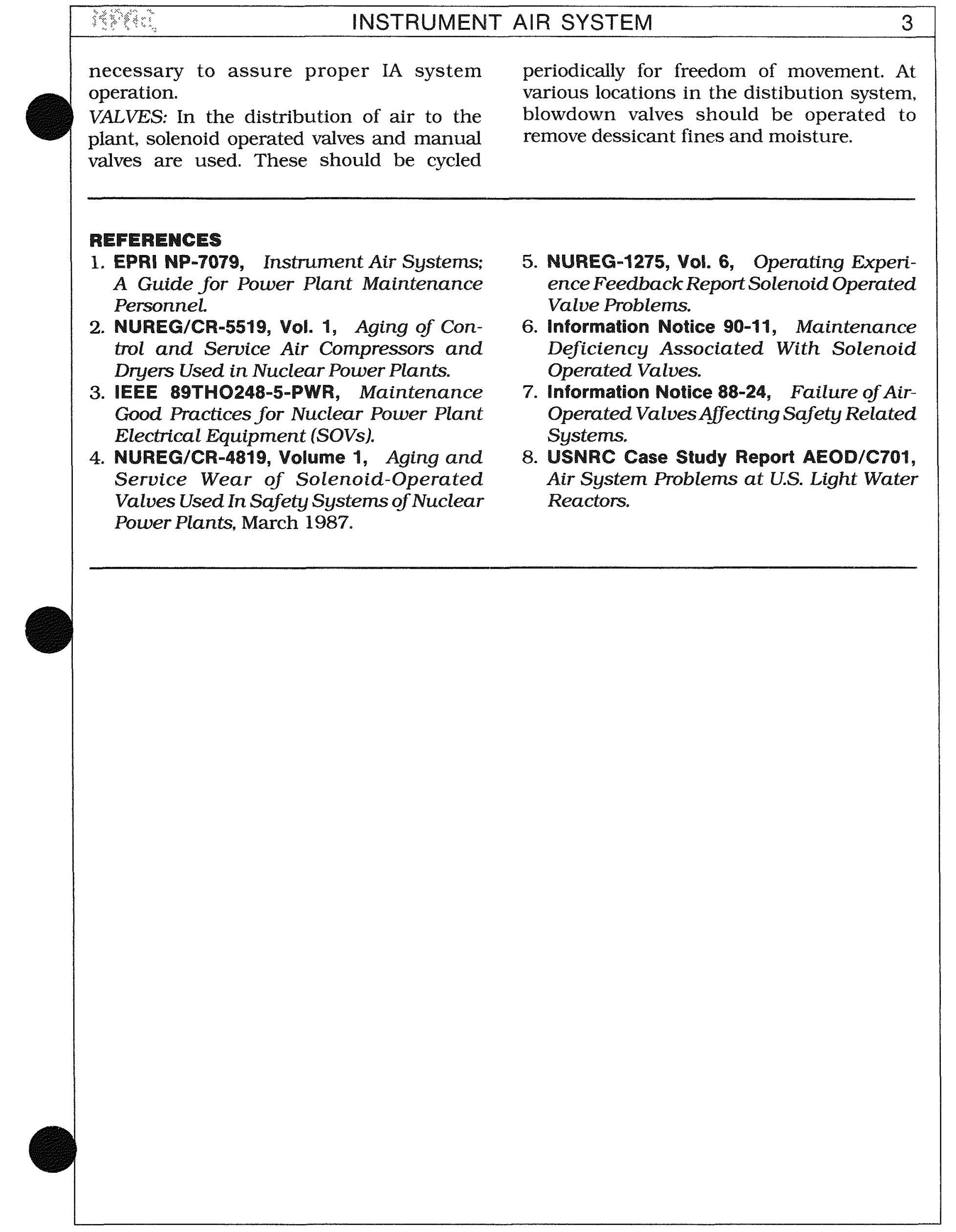


-

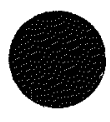

1

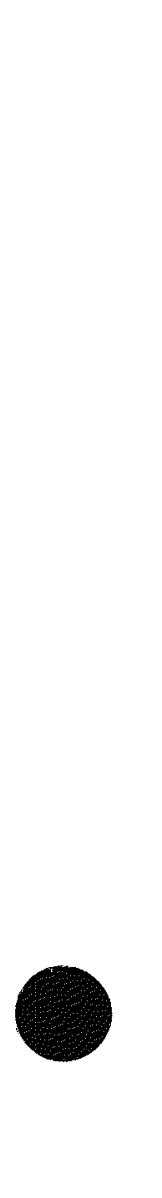




\section{AGING ASSESSMENT GUIDE INSTRUMENT AIR (IA) SYSTEM}

\section{Observations on the Aging of Instrument Air Systems}

- Normal wear of the system and contamination of the air dominate the problems of the IA system.

- Compressors, air system valves, and air dryers comprise the majority of failures.

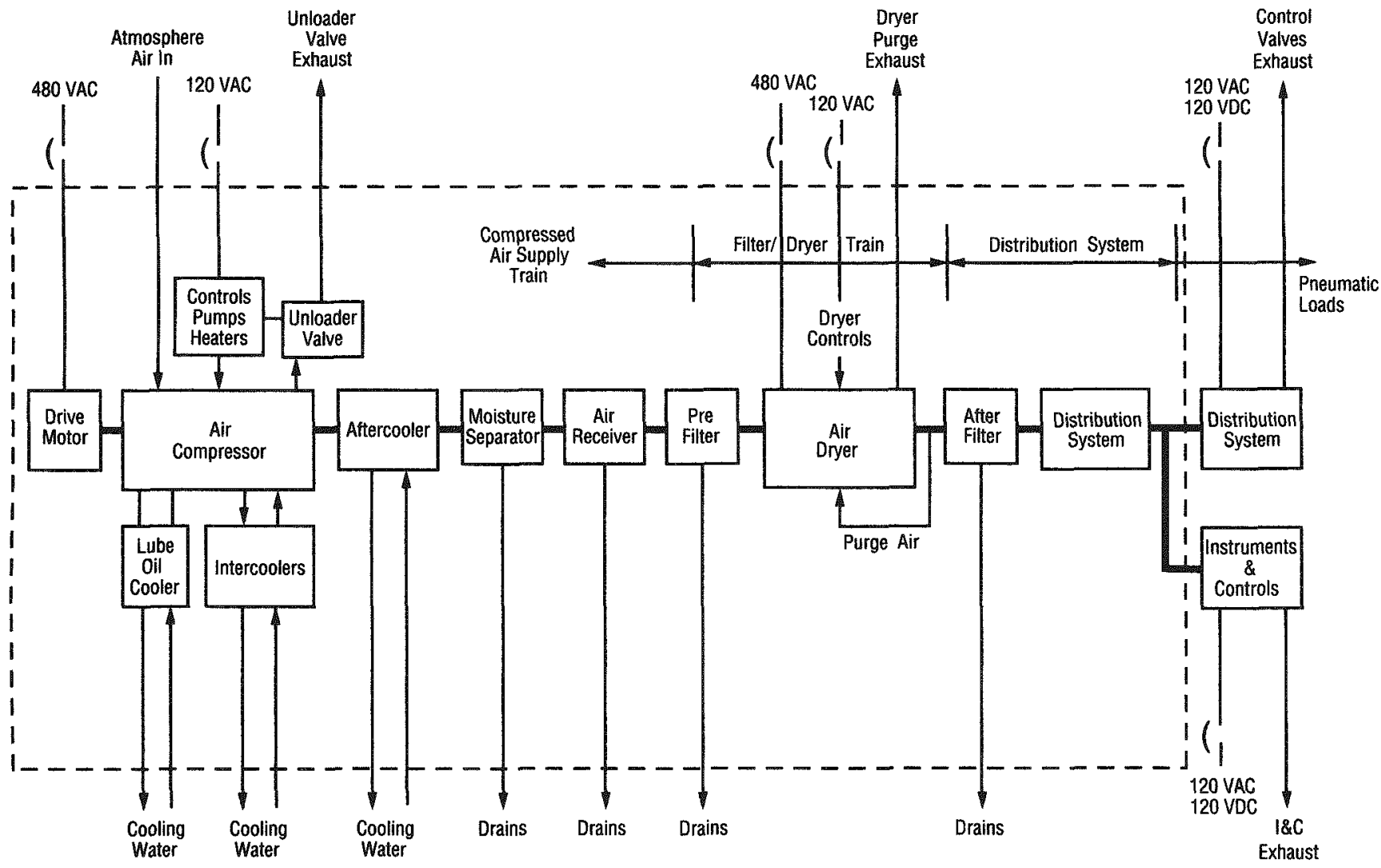

BOUNDARIES OF THE INSTRUMENT AIR SYSTEM FOR AGING STUDIES

\section{RECOMMENDATIONS FOR INSPECTION}

Observe local conditions at the air compressors for proper operation of the system and its key components. This includes:

1. Inlet filter differential pressure readings are normal

2. No major air leaks exist
- Most system problems are detected by local monitoring, walkdowns and inspections, and preventative maintenance. 


\section{MAINTENANCE RECOMMENDATIONS}

In general, predictive maintenance and trending techniques should be used to establish preventive maintenance schedules for routine tasks such as dessicant changeout, filter replacement, and system blowdowns. Because the IA system is continually operating, maintenance to account for expected wear should be scheduled, such as:
- overhaul of compressor internals; examination of bearings, piston clearances, cyclinder condition, etc.

- inspection and cleaning of heat exchangers

- calibration of instrumentation and controls

- air receiver internal inspection and pressure test

\section{OPERATIONS RECOMMENDATIONS}

A great deal of information regarding the overall health of the IA system can be gained through routine operator duties. Logs of filter differential pressures, cooling water temperatures and pressures, and dryer outlet dewpoint are important data for monitoring system performance.

Other activities which should be performed by operating personnel to assure continued satisfactory performance of the IA system are:

- periodic blowdown of air receiver tanks, low points in the distribution system, and line filters

- actively pursue sources of air leakage

- verify dessicant levels are satisfactory

- inspect operation of automatic condensate drain valves and traps

\section{DESIGN/TEST RECOMMENDATIONS}

1. Periodic testing for gradual loss of pressure should be performed to test the performance of safety grade accumulators, check valves, and isolation valves. Degraded pressure operation was the most common failure mode observed for the IA system.
2. The crossconnect valve between the Instrument Air and Service Air systems is a critical component. Status indication should be considered, as well as manual bypass or override capability.

3. Air quality should be monitored periodically for adherence to design specifications or ANSI/ISA S7.3-1975. 


\section{REACTOR PROTECTION}
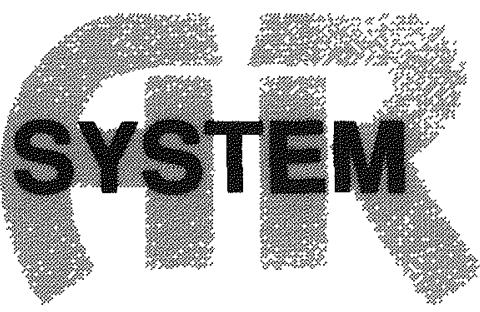

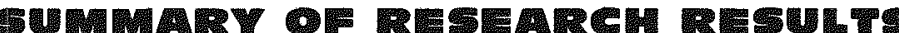

FUNCTIONAL DESCRIPTION/BACKGROUND The reactor protection system (RPS) measures critical parameters that describe whether the reactor system is operating within a safe envelope, initiates alarms if an unsafe condition is being approached, and initiates engineered safety systems when necessary to prevent further development of potentially unsafe conditions. Failure data were reviewed to identify failure modes experienced during operation and their causes. At least $23 \%$ of the failures are aging related but because the RPS is a highly redundant system only about $0.2 \%$ of the component failures caused a system failure.

BASED ON MPAR REPORT:

1. NUREG/CR-4740, Nuclear Plant Aging Research on Reactor Protection Systems, $1 / 88$.

AGIM RELATED ISSUES Aging is a concern for the RPS since the NPRDS and NPE data bases show that about $23 \%$ to $49 \%$ of the failures are aging related. The aging related failure causes are $\mathrm{I} \& \mathrm{C}$ component failure, mechanical wear, drift, short circuits, environmental conditions, normal wear, and corrosion. Too frequent testing intervals can also be an aging effect resulting in degradation of components. Obsolescence of electronic components is also a problem for older plants.
OPERATING EXPERIENCE The effect of RPS failures was determined from the NPRDS data. The largest effect was loss of subsystem/channel followed by system function unaffected, loss of redundancy, and degraded system performance. Only $0.2 \%$ of the failures resulted in loss of system function.

I\&C component failure is the most dominant failure cause that is not human related, followed by wear/broken/damaged, drift, and short/grounding/arcing. The failure cause classified as other includes fouling/blockage/ foreign material, overload/pressure, normal wearout, and corrosion. Aging related causes accounted for about $23 \%$ of the failures reported in NPRDS.

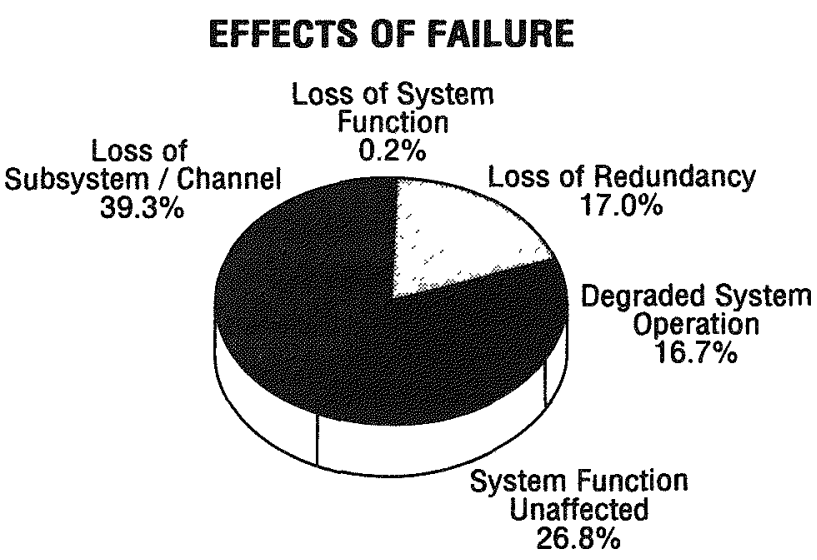

Failure of no one component stands out as being significantly more prevalent than others. However, the components failing most often are sensors/transmitters (13\%), 


\begin{abstract}
electronic parts $(13 \%)$, bistables $(10 \%)$, breakers $(8 \%)$, power supply/fuses $(8 \%)$, and wire/cable/conectors (7\%). Also, approximately $34 \%$ of the failures occurred during normal operations rather than during maintenance, testing, or inspection. This failure pattern and the research results indicate trending parameters normally measured during maintenance, such as response time and calibrations, and the use of advanced monitoring methods such as on line monitoring with comparison of redundant channels, and electrical circuit characterization and diagnostics, could be useful in improving the reliability of the RPS.
\end{abstract}

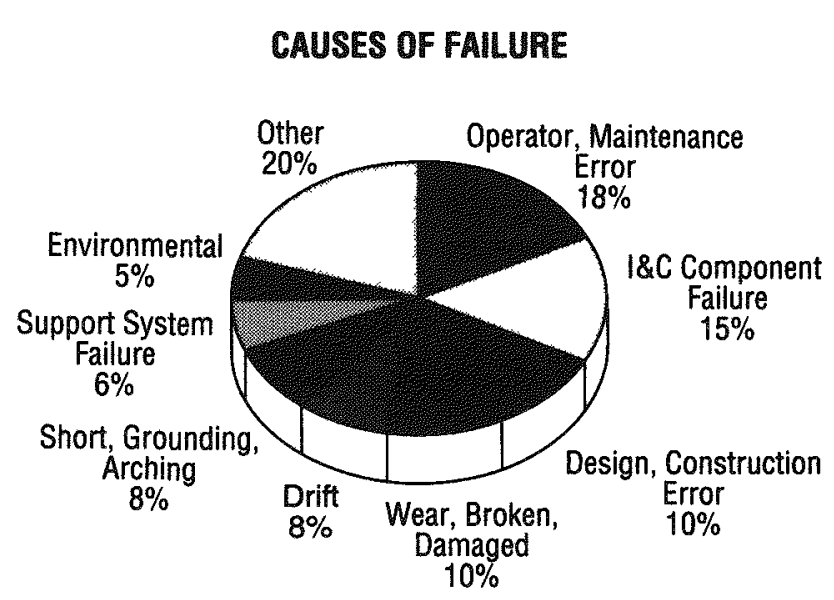

RESEARCH RECOMMENDATIONS A preventive maintenance program should exist for the RPS. The PM program should include periodic testing, monitoring, and inspections. Periodic tests are in situ tests performed in plant on the equipment at scheduled intervals to detect degradation and verify operability. Technical Specifications require response time testing, functional checks, channel calibrations, and operational tests to be performed on a periodic basis ranging from twice per day to once each refueling outage (18 months). The results from these surveillance tests provide much information that can be analyzed to provide an early indication of aging degradation. Trending of the measured values, as well as failure rates, not only provides an indication of when components should be replaced but also provides a method of anticipating component failure. Also, advanced monitoring methods should be useful in detecting impending component failure and thereby improve the reliability of the RPS.
REFERENCES There is a large amount of reference material available for RPS systems. However the following reflect those which may be readily accessible.

1. IEEE Std. 338, Criteria for Periodic Testing of Nuclear Power Generating Station Safety Systems.
2. Regulatory Guide 1.22, Periodic Testing of Protection System Actuation Systems.

3. Regulatory Guide 1.118, Periodic Testing for Electric Power and Protection Systems.

4. EPRI NP-3416, A Guide for Developing Preventative Maintenance Programs in Electric Power Plants. 


\section{AGING ASSESSMENT GUIDE REACTOR PROTECTION SYSTEM}

\section{Observations on the aging of the Reactor Protection System}

- Sensors/transmitters, electronic parts, bistables, breakers, power supply/fuses, and wire/cable/connectors have experienced the most failures.

- Aging accounts for about 23\% of the component failures.

- Approximately $34 \%$ of the failures were discovered during normal operations.

RPS TRIP STRING FOR ONE CHANNEL

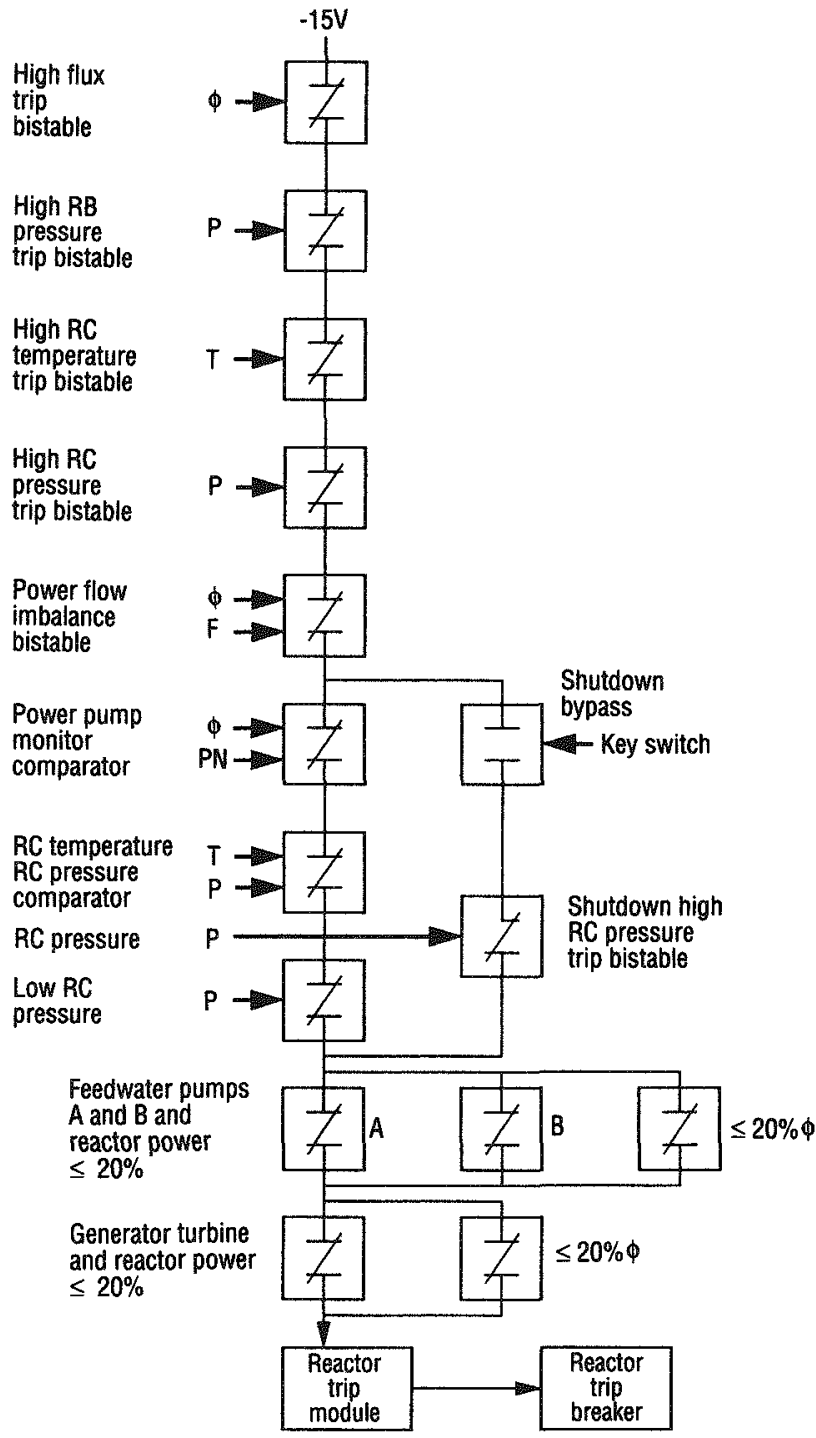

RPS REACTOR COOLANT PRESSURE CHANNEL

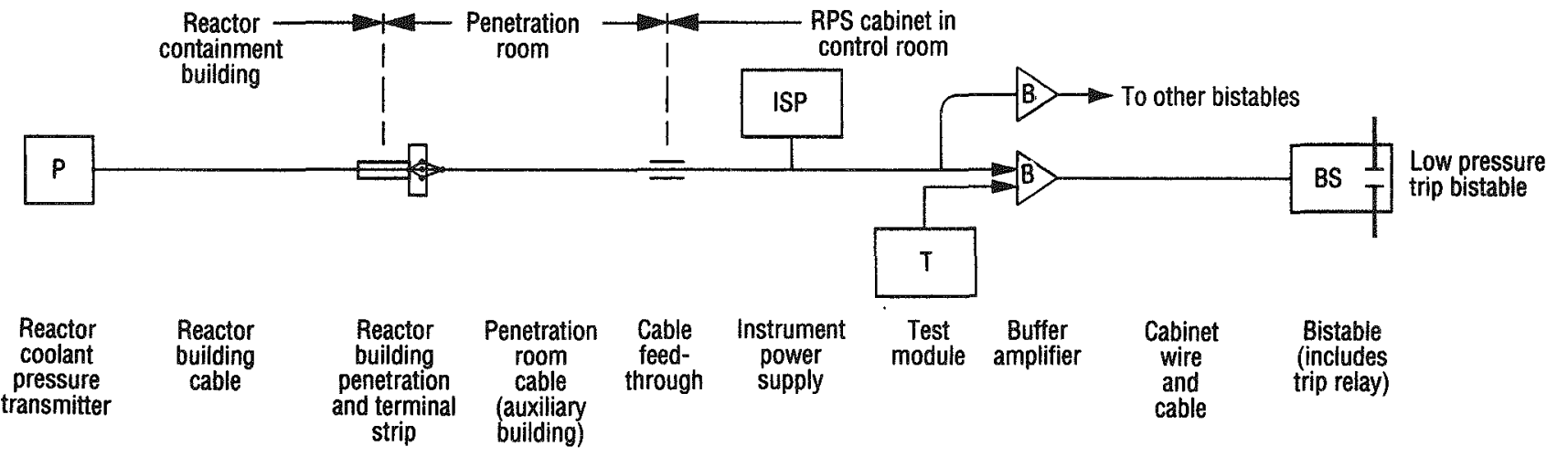




\section{RECOMMENDATIONS FOR INSPECTION}

1. Response time testing, functional checks, channel calibrations, and operational tests during all phases of operation.
2. Cables and wiring in harsh environments should be visually inspected during outages for evidence of degradation from temperature, moisture, or radiation.

\section{MAINTEMANCE RECOMMENDATIONS}

1. Trend results of response time tests and channel calibrations.

2. Trend failure rates of components.

3. Clean connections if corrosion is noted.

4. Perform PM on breakers to prevent faulty operation from dirt, contamination, hardened grease, and wear.

5. Monitor failures that occur during normal operation and consider use of advanced monitoring methods where these failures are a concern. 


\section{RESIDUAL HEA SYSTEM-B WR
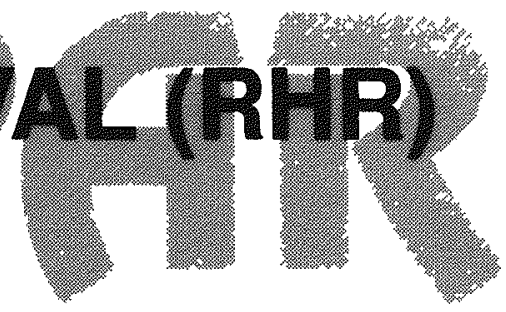

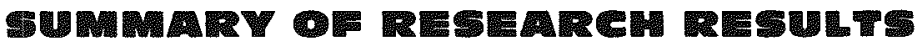

FUMCTIONAL DESCRIPTION/BACKGROUMD The RHR System in a BWR serves a variety of purposes for operation during routine, abnormal, and emergency conditions. While the failure data reviewed covered all phases of operation, the emphasis of evaluating system effects and operating stresses was on the Low Pressure Coolant Injection (LPCI) and Shutdown Cooling (SDC) operating modes. Aging has a moderate impact on RHR component failure rates ( 0 to $17 \%$ per year increase). Standby systems such as RHR may be less affected by aging than continuously operating systems.

\section{BASED ON NPAR REPORT:}

1. NUREG/CR-5268, Aging Study of Boiling Water Reactor Residual Heat Removal System, 6/89.

AGING RELATED ISSUES Aging is a concern for RHR systems. The evaluation of multiple data bases showed that more than $50 \%$ of the failures were attributed to aging. Different aging mechanisms are present, related to the operating status of the system. While in standby, the aging mechanisms are:

- corrosion

- set point drift

- embrittlement

Aging degradation due to wear takes place while the system is in the shutdown cooling or testing mode. Operational stresses are enhanced by the synergistic effects of various standby stresses. One important source of stress is testing. Plants with a common minimum flow line for 2 RHR pumps, for instance, should closely monitor pump performance since aging can degrade performance, and lead to dead-headed pump operation on one of the pumps. This can result in overheating and premature failure.
OPERATING EXPERIENCE The effect of each RHR failure on system performance was determined from the NPRDS data. Over half of the failures resulted in degraded operation of the system. This implies that the system can still perform its function; however if left uncorrected, the failure could cause a loss of system function.

No failures were reported in which the complete loss of LPCI resulted. However, the complete loss of the shutdown cooling mode of RHR resulted from some of the component failures. These typically involved a failure of the instruments controlling the inboard or outboard isolation valves, or a failure of the valves themselves.

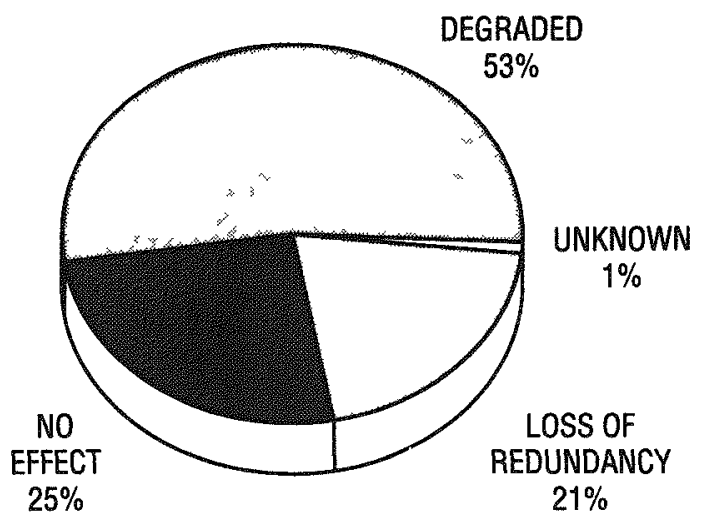


Failure Mechanisms A failure mechanism is the physical, chemical, or other process by which a component or system degrades or fails. Since the RHR system has standby modes as well as operational modes, there are several different failure mechanisms.

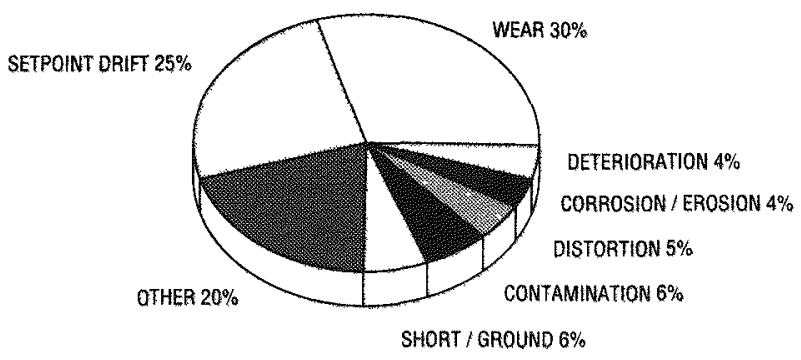

Wear represents an exposure to stresses encountered during operation, which results in some portion of the component being worn away. The failure mechanism classified as Other includes embrittlement, fatigue, vibration, and fracture. Deterioration includes failures where a material of construction is broken down physically by the environment to a point where it can no longer perform its function; i.e. insulation or gaskets.
Failure Modes A failure mode is the manner in which a component fails. The failure modes for the RHR system are diverse. The

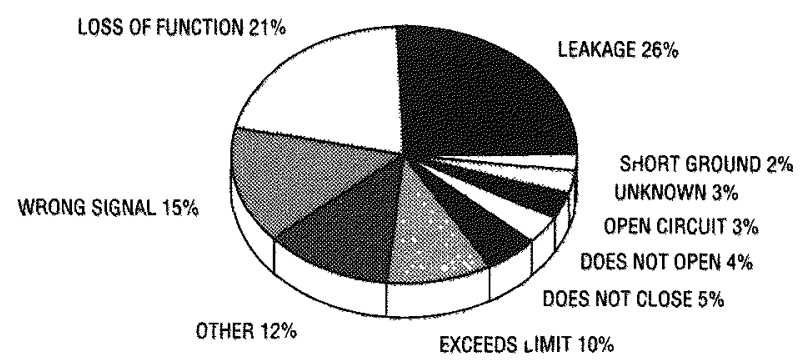

predominant modes include Leakage, Loss of Function, and Wrong Signal. Leakage includes internal and external leakage of valves, along with leakage of pump seals, piping and pipe fittings. The Loss of Function mode includes failure of an instrument to operate or failure of a pump to run. The Wrong Signal mode includes a position switch indicating a valve is closed when it is actually open, or a pressure transmitter indicating the incorrect pressure.
RESEARCH RECOMMENDATIONS The operational readiness of the RHR system can best be assured from three tests:

1. Valve stroke tests

2. Control logic response tests

3. In-service inspection pump tests

This choice is supported by the data which showed valves and instrumentation/controls to be the two predominant types of components in the RHR system which fail.

The type and amount of periodic testing, preventive maintenance, and corrective maintenance performed on the major system components are described in the following summary:

\section{RHR Pumps}

TESTING: During the quarterly testing required by technical specifications for RHR pumps, it is recommended that other information is recorded such as bearing vibration and temperature, motor amps and voltage, and motor winding temperature.
Bearing degradation can be detected by increasing vibration and temperatures. Likewise, motor and pump degradation may be apparent from increasing motor current or winding temperatures.

PREVENTIVE MAINTENANCE: Due to environmental qualification requirements, bearings, seals, and gaskets are replaced at prescribed intervals. Activities such as cleaning and lubrication should be periodically conducted regardless of whether the pump is in standby or is continuously operating.

The frequencies at which PM activities are performed are normally based on the equipment's operating experience, plant configuration, and the impact of pump failure on plant risk. The limited PM activities described may be justified based on the extent of periodic testing that is performed.

\section{RHR Valves}

TESTING: In accordance with technical specifications, periodic testing is required for 
key RHR valves, including measurements of valve stroke time and valve seat leakage. Technical specifications also requires that each valve in the flow path be periodically checked to verify its correct position. Other periodic testing that utilities have successfully employed to monitor valve degradation are:

1. Relief valve setpoint verification (5 years)

2. MOV signature analysis (18 months)

3. Position indicator functional test (18 months)

As a result of numerous problems with MOVs, further research is being conducted. Stroke time testing may be of only limited value, and the frequent operation required by testing may result in accumulated wear to the valve seats. NRC Generic Letter 89-10 addresses this concern.

PREVENTIVE MAINTENANCE: Utility practices for RHR valve PM consist primarily of inspection and lubrication. The frequency of this activity ranges from annually to every four years. Some utilities also periodically megger the motors on the MOV. Inspection and lubrication of manual and check valves

\section{REFERENCES}

1. Bulletin 88-04, Potential RHR Pump Loss.

2. Generic Letter 89-10, Safety-Related Motor Operated Valve Testing and Surveillance. are also performed. PM on AOVs and SOVs is largely based on EQ requirements.

It should be noted that post maintenance testing is performed for valves, especially MOVs. Following packing adjustments or torque/limit switch corrections, stroking the valve is useful to verify proper operation.

\section{RHR Heat Exchangers}

TESTING: In-service testing, such as a heat balance, is a standard non-intrusive test for determining heat exchanger capacity. Design calculations assume a certain amount of fouling; the heat balance determines the continued validity of the assumption. Other periodic tests such as a hydrostatic or leak test verify the integrity of the pressure boundary interfaces. Research is continuing to determine the effectiveness of other methods such as eddy current and acoustic testing.

PREVENTIVE MAINTENANCE: The preventive maintenance activities specified for the RHR heat exchanger includes inspection, tube cleaning, and a periodic replacement of gaskets.
3. Bulletin 86-01, Minimum Flow Logic Problems That Could Disable RHR Pumps.

4. Information Notice 86-36, Failure of RHR Pump Motors and Pump Internals. 

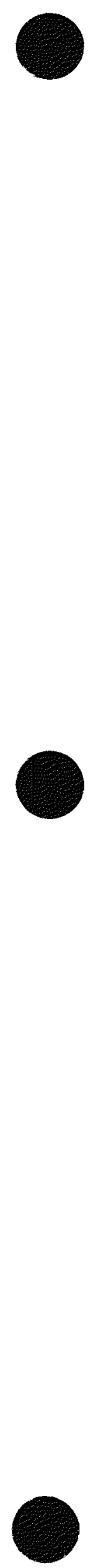


\section{AGING ASSESSMENT GUIDE RESIDUAL HEAT REMOVAL (RHR) SYSTEM - BWR}

Observations on the aging of the Residual Heat Removal (RHR) System in BWRs.

- Valves and I\&C equipment have experienced the most failures

- To date, the effects of aging have not increased with time

- Testing has been effective in detecting aging related degradation
LOW PRESSURE COOLANT INJECTION (LPCI) MODE

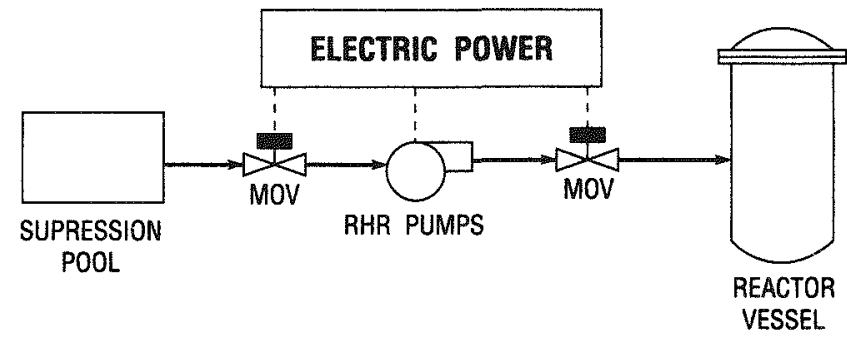

SHUTDOWN COOLING (SDC) MODE

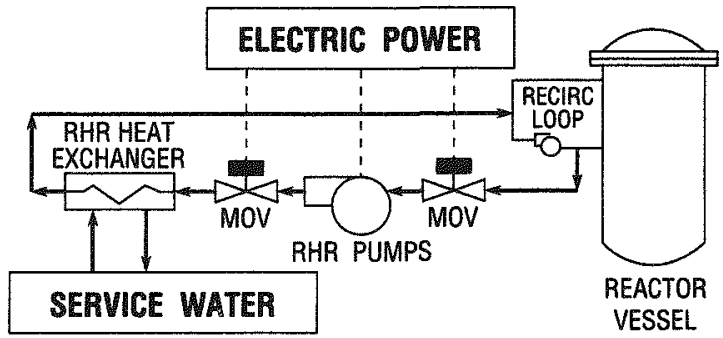

RECOMMENDATIONS FOR INSPECTION

1. When in the standby mode, the pump areas should be checked for environmental conditions; temperature, cleanliness.

2. When a pump is operating, vibration levels, motor amps, and motor winding temperatures should be observed.
3. The major valves should be monitored for leakage and appearance.

4. The heat exchangers should be inspected for leakage, temperature.

\section{MAINTENANCE RECOMMENDATIONS} RHR Pumps:

1. Trend pump performance (flow, pressure).

2. Monitor bearing temperature \& vibration (periodic testing).

3. Perform an analysis of lube oil quality.

4. Monitor and trend motor performance (amps, windings).

\section{RHR Heat Exchangers:}

1. Trend the inlet and outlet temperatures.

2. Perform eddy current or acoustic testing (or equivalent) to determine tube sheet condition.

\section{RHR Valves:}

1. Monitor the operator current/voltage.

2. Check the relief valve setpoints.

3. Perform post maintenance testing following corrective maintenance activities.

4. Trend the results of the technical specification tests.

\section{RHR Instrumentation:}

1. Routinely calibrate the instrumentation channels, especially those associated with system actuation, isolation and permissives.

2. Properly fill and vent the instruments following testing or maintenance. 

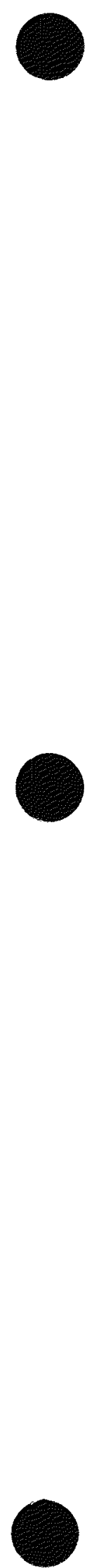


\section{SERVICE WATER SYSTEM IR}

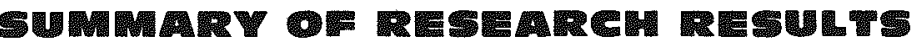

FUNCTIONAL DESCRIPTION/BACKGROUND The Service Water System (SWS) in nuclear reactors performs vital safety functions, as the final link between the reactor and the ultimate heat sink (river, lake, cooling pond, etc.). The system also provides essential cooling to safety-related equipment such as emergency diesel generators and emergency core cooling systems. Depending on the design, all or part of the system will be exposed to raw water. Therefore, the SWS components (pumps, valves, pipes, heat exchangers, etc.) are subject to a wide range of corrosion mechanisms.

\section{BASED ON NPAR REPORT:}

1. NUREG/CR-5379, Nuclear Plant Service Water System Aging Degradation Assessment. Volumes 1 and 2,6/89.

AGING RELATED ISSUES The SWS is subject to age-related degradation. A 1988 analysis indicated that the SWS at U.S. nuclear plants has a degraded performance rate of 0.4 per reactor year and a complete system failure rate of $1.5 \times 10^{-2}$ per reactor year. Mechanisms related to age-related degradation caused $\sim 60 \%$ of the SWS degradation events. The principal degradation mechanisms were corrosion, biofouling, and wear.
OPERATING EXPERIENCE In open (oncethrough) SWS types, corrosion was the largest contributor to failure. Biofouling has been a major concern at some plants, due to infestation of species such as asiatic clams and Zebra mussels. In closed (intermediate heat exchanger) SWS types the largest cause of functional failure was biofouling of heat exchangers, followed by corrosion of valves. In recirculating (spray pond or cooling tower) SWS types, corrosion was the largest failure cause, predominantly affecting valves and sensors.
FAILURE MECMANISMS Corrosion, fouling (biological and inorganic accumulation) and wear are the dominant failure mechanisms in the open portions of the SWS. Additional mechanisms that result in signif- icant SWS failures include: erosion, cavitation, structural impact (water hammer), and foreign debris. To a lessor extent vibration, fatigue and thermal cycling have also resulted in component functional failures. 
FAILURE MODES Failure of valve operators has been a major SWS phenomenon, but the cause is generally corrosion related. Heat exchanger failures occur predominantly by plugging due to biofouling, but corrosion is also a significant mechanism. Large pipe degradation is due to corrosion; small pipes are also susceptible to plugging from biota or sedimentation. Sensors fail by corrosion and by buildup of deposits.

RESEARCM RECOMMENDATIONS Root cause analysis should be performed to understand the causative factors before aging mitigation strategies are implemented. For the aggressive and varied degradation factors found in SWS, it is important to differentiate degradation caused by corrosive chemistries from degradation due to biological species [e.g., microbiologically-influenced corrosion (MIC)].

A necessary element to minimize degradation in any type of SWS is control of water purity
BASED ON LER DATA FROM 1980 TO 1987

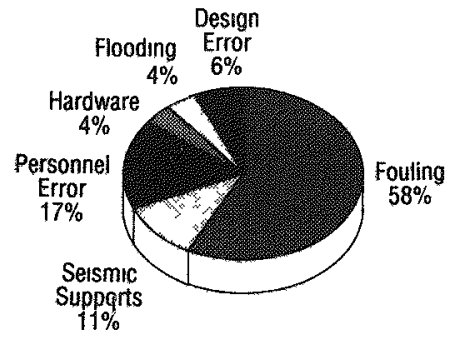

FALLURE CATEGORY

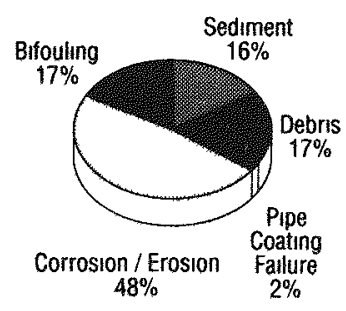

FAILURE MECHANISM and chemistry. Where confirmed biologicalagents are active, a biocontrol program (chemical, thermal, etc.) is an obvious requirement. Environmental regulations can limit the extent to which some of these recommendations can be pursued, and a careful consideration of alternatives is necessary to select the most cost-effective solution. Any changes to the control program should be accompanied by monitoring for induced stressors (e.g., denickelfication of $\mathrm{Cu} / \mathrm{Ni}$ heat exchangers by a chlorination biocide).

\section{REFERENCES}

1. Generic Safety Issue No. 51, Improved Reliability of Open Service Water System.

2. Generic Letter 89-13, Service Water Problems Affecting Safety-Related Equipment.
3. NUREG-1275, Vol. 3, Operating Experience Feedback Report-Service Water System Failures and Degradations, $11 / 88$. 


\section{AGING ASSESSMENT GUIDE SERVICE WATER SYSTEM}

\section{Observations on the aging} of the Service Water System

- Corrosion, biofouling, and wear are the leading causes of SWS agerelated degradation.

- All aspects of the system need to be considered, including wetted, non-wetted, and underground components; the effectiveness of cathodic protection needs periodic assessment.

- Components exposed to raw (chemically uncontrolled) water require frequent monitoring for aging degradation.

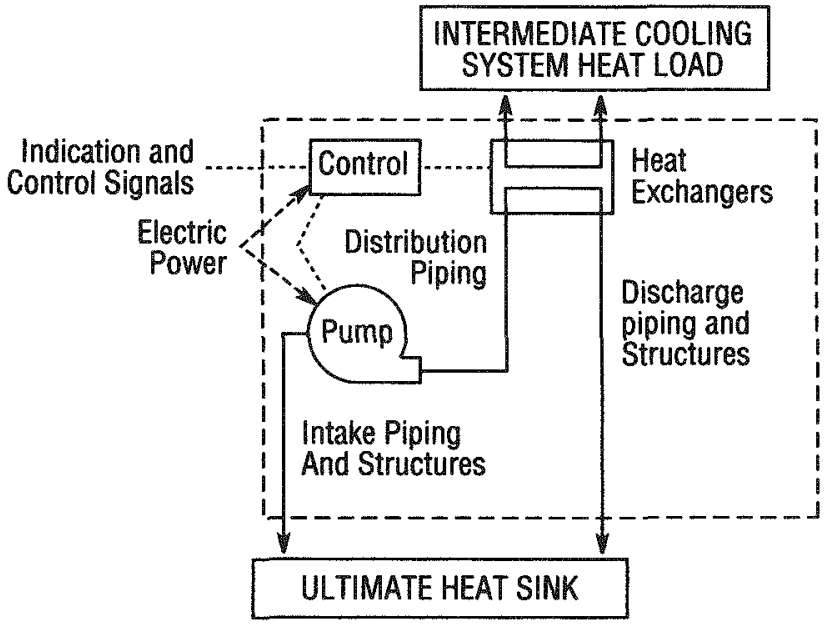

\section{RECOMMENDATIONS FOR INSPECTION}

1. Observe timely painting of exposed structures.

2. Verify operability of cathodic protection circuits.

3. Flanges, joints, and pump and valve packing glands periodically inspected for visible leakage.
4. Look for local discoloration below system components and piping for evidence of leakage (may also indicate excessive condensation on cold SWS surfaces).

5. Observe vibration and temperature readings on operating SWS pumps.

\section{MAINTENANCE RECOMMENDATIONS}

\section{Heat Exchangers:}

1. Need periodic visual inspections and flow monitoring.

2. Appearance of biological deposits may require mechanical and chemical cleaning if interference with heat transfer is indicated.

\section{Pumps:}

1. Perform trending of pump performance (flow, pressure).

2. Periodically monitor bearing temperature and vibration.
3. Test lube oil quality.

4. Monitor and trend motor performance (amps, windings, temperature).

\section{Valves:}

1. Monitor motor operator current/voltage; inspect valve surfaces for corrosion or biofouling if excessive.

2. Trend results of technical specification tests.

3. Operationally test system valves on regular frequency (18 month cycle). 

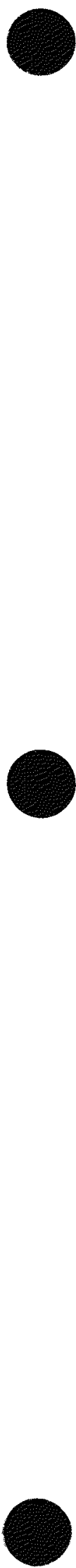


\begin{tabular}{|c|c|}
\hline $\begin{array}{l}\text { NRC FORM } 335 \\
\text { (289) } \\
\text { NRCM 1102. } \\
32013202 \\
\text { BIBLIOGRAPHLC DATA SHEET } \\
\text { (See instructions on the reverse) }\end{array}$ & \multirow{2}{*}{ 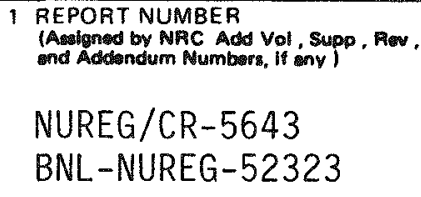 } \\
\hline \multirow{4}{*}{ Insights Gained From Aging Research } & \\
\hline & DATE REPORT PUBLISHED \\
\hline & \begin{tabular}{|l|r|} 
MONTH & YEAR \\
March & 1992 \\
\end{tabular} \\
\hline & $\begin{array}{l}4 \text { FIN OR GRANT NUMBER } \\
\text { A3270 }\end{array}$ \\
\hline $\begin{array}{l}5 \text { AuThor(s) } \\
\text { D.E. Blahnik, D.A. Casada, J.L. Edson, D.L. Fineman, } \\
\text { W.E. Gunther, H.D. Haynes, K.R. Hoopingarner, M.J. Jacobus, }\end{array}$ & 6 TYPE OF REPORT \\
\hline $\begin{array}{l}\text { D.B. Jarrel1, R.C. Kryter, H.L. Magelby, G.A. Murphy, } \\
\text { M. Subudhi }\end{array}$ & 7 PERIOD COVERED (Inclustve Dates) \\
\hline
\end{tabular}
name and malling address.)

Brookhaven National Laboratory

Upton, NY 11973

9 SPONSORING ORGANIZATION - NAME AND ADDRESS IIf NRC type 'Same as above ' if contractor provide NRC Division Office or Region, U S Nuclear Regulatory Commission and mauling address.)

Division of Engineering

Office of Nuclear Regulatory Research

U.S. Nuclear Regulatory Commission

Washington, DC 20555

10 SUPPLEMENTARY NOTES

11 ABSTRACT (200 words or less)

The USNRC Office of Nuclear Regulatory Research has implemented hardware-oriented engineering research programs to identify and resolve technical issues related to the aging of systems, structure, and components (SSCS) in operating nuclear power plants. This report provides a summary of those research results which have been compiled and published in NUREGs and related technical reports. The systems, components and structures that have been studied are organized by alphabetical order. The research results summary on the SSCs is followed by an assessment guide to emphasize inspection techniques which may be useful for detecting aging degradation in nuclear power plants. This report will be updated periodically to reflect new research results on these or other SSCs.

12 KEY WORDS/DESCR'PTORS IList words ot phrases that will assist researciters in locating the report

Nuclear Power Plants - Aging, BWR Type Reactors, PWR Type Reactors, Reactor Components - Aging, System Failure Analysis, Inspection, Reactor Safety - Research Programs, Performance Testing, Reactor Maintenance, Reactor Operation, Recommendations, Technology Assessment, Reliability.

\begin{tabular}{|c|}
\hline $\begin{array}{l}13 \text { AVAILABILITY STATEMENT } \\
\text { Unlimited }\end{array}$ \\
\hline 14 SECURITY CLASSIFICATION \\
\hline This Pagel \\
\hline Unclassified \\
\hline (Thus Repont) \\
\hline Unclassified \\
\hline 15 NUMBER OF PAGES \\
\hline 16 PRICF \\
\hline
\end{tabular}


